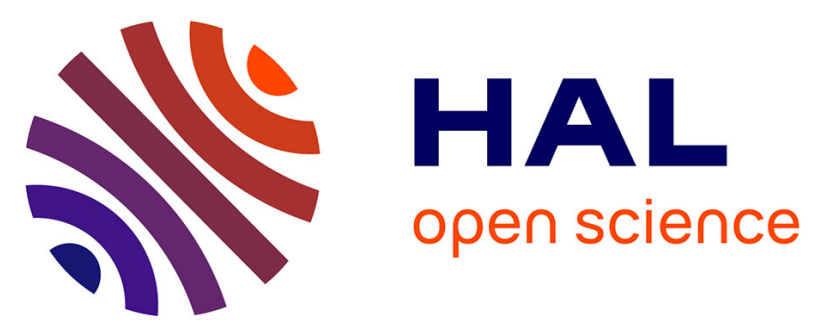

\title{
Origin, distribution, and behaviour of rare earth elements in river bed sediments from a carbonate semi-arid basin (Tafna River, Algeria)
}

\author{
A. Benabdelkader, Ahmed Taleb, J.L. Probst, N. Belaidi, A. Probst
}

\section{To cite this version:}

A. Benabdelkader, Ahmed Taleb, J.L. Probst, N. Belaidi, A. Probst. Origin, distribution, and behaviour of rare earth elements in river bed sediments from a carbonate semi-arid basin (Tafna River, Algeria). Applied Geochemistry, 2019, 106, pp.96-111. 10.1016/j.apgeochem.2019.05.005 . hal02357625

\section{HAL Id: hal-02357625 \\ https://hal.science/hal-02357625}

Submitted on 25 Oct 2021

HAL is a multi-disciplinary open access archive for the deposit and dissemination of scientific research documents, whether they are published or not. The documents may come from teaching and research institutions in France or abroad, or from public or private research centers.
L'archive ouverte pluridisciplinaire HAL, est destinée au dépôt et à la diffusion de documents scientifiques de niveau recherche, publiés ou non, émanant des établissements d'enseignement et de recherche français ou étrangers, des laboratoires publics ou privés.

\section{(ㅇ)(1) $\$$}

Distributed under a Creative Commons Attribution - NonCommerciall 4.0 International 
1 Origin, distribution, and behaviour of rare earth elements in river bed sediments from a 2 carbonate semi-arid basin (Tafna River, Algeria)

3

A. Benabdelkader ${ }^{1,2}$, A. Taleb ${ }^{2}$, J.L. Probst ${ }^{1}$, N. Belaidi ${ }^{2}$, A. Probst ${ }^{1 *}$

${ }^{1}$ EcoLab, Université de Toulouse, CNRS, Toulouse, France

${ }^{2}$ LEcGEN, Université de Tlemcen, Tlemcen, Algeria

\section{Abstract}

The behaviour and sources of rare earth elements (REE) in river sediments were investigated at ten stations and two dams of the Tafna basin (Northern Algeria) during contrasting hydrological conditions and using a combination of normalisation procedures, REE anomalies, various REE ratios, and multivariate statistical analysis. The ranking and REE concentrations were in the range of other carbonated areas. The classical fractionation of the heavy REE(HREE) erosion pattern, evidenced from upstream to downstream by the $\mathrm{La} / \mathrm{Yb}$ or $\mathrm{Sm} / \mathrm{Yb}$ ratios, was disturbed by the presence of dams, which retained the light REE (LREE) in particular. The hydrological conditions, particle size, and geochemical characteristics controlled the REE patterns. The LREE were associated with clay minerals and HREE with coarse silts, whereas carbonate and particulate organic carbon (POC) did not influence the transport downstream. The total concentration of REE in sediments was not strongly affected by anthropogenic inputs from various sources (industrial activities, and domestic or medical wastes). Indeed, some LREE enrichment and anomalies were detected at a few stations and locally for $\mathrm{Gd}, \mathrm{Tb}$, and $\mathrm{Yb}$. However, the anthropogenic contribution can partially be hidden by dilution due to particle erosion. High flow increased the LREE and MREE enrichment and LREE/HREE fractionation in some places due to erosion processes and anthropic influences (dam releases and local wastes inputs). Middle REE (MREE) and HREE were the most extractable elements unlike LREE (which are the most concentrated), particularly during high water conditions. Finally, the REE demonstrated the impact of natural processes (hydrological, geochemical, and physical) and some anthropogenic disturbances (waste inputs, fertilisers, and dams). This might inspire to develop such investigations in other similar semi-arid basins undergoing various pressures. The use of local bedrock as a reference and a set of geochemical and statistical tools, is recommended.

\footnotetext{
*Corresponding author
} 
anne.probst@ensat.fr

Keywords: Rare earth elements, bottom sediments, hydrological conditions, dams, erosion, contamination

\section{Introduction}

Rare earth elements (REE), from the lightest lanthanum (La) to the heaviest lutetium (Lu) and Ytterbium (Yb), are characterised by similar chemical properties. They have been commonly used as input provenance markers, to investigate weathering and meteorisation processes in drainage basins, as tracers of changes in environmental conditions in water and sediments (Sholkovitz, 1995; Borrego et al., 2004), or to reconstruct REE dispersal patterns (Depetris et al., 2003; Lee et al., 2008; Xu et al, 2009). Indeed, they are known for their high affinity for fine grain size fractions in soils or sediments (Cullers et al., 1975; Ramesh et al., 2000; Caetano et al., 2013; Bayon et al., 2015), and also for their association with several chemical fractions (Zhang et al., 1998; Gu et al., 2001; Aubert et al., 2004; Davranche et al., 2008). Carbonates, iron oxides, and organic matter are thought to be among the more important controlling factors of REE (Leybourne and Johannesson, 2008; Zhang et al., 2014). The grain size, mineralogy, and carbonate content of sediments could thus contribute to the significant differences in the distribution and fractionation of REE (Yang et al., 2002; Feng, 2010; Suja et al., 2017). However, such investigations are still poorly documented for sediments under carbonated conditions and according to Leybourne and Johannesson, (2008), there is a need for more data from eroded material from around the rivers of the world.

Parameters such as $\mathrm{pH}$, redox conditions, aqueous and complex surface reactions (Song and Li, 1998; Zhang et al., 1998), as well as other environmental conditions, can strongly control or influence the processes of adsorption, desorption, complexation, and co-precipitation of the REE in the various sediment chemical fractions o (Song and Li, 1998; Aubert et al., 2004), i.e., the fractionation of REE in the leachable fraction (Zhang et al., 1998; Yang et al., 2002; Leleyter et al., 2012).

River bottom sediments constitute storage material for contaminants that can be removed and transported downstream with successive storm flow events (Probst et al., 1999; N'Guessan et al., 2009; Leleyter et al., 2012; Roussiez et al., 2013). Recognised worldwide as emerging micro pollutants in aquatic systems (Gonzalez et al., 2014; Hissler et al., 2014), the high REE concentration in sediments can be attributed to higher inputs from sources such as terrestrial weathering and anthropogenic activities (Ramesh et al., 1999). Indeed, REE have been 
frequently used to evaluate anthropogenic influences and sources for river waters or sediments (Bau and Dulski, 1996; Fuganti et al., 1996; Xu et al., 2012; Gallello et al., 2013). The natural distribution of REE in water, soil, and sediment from densely industrialised and populated regions can be altered by anthropogenic influences (Nozaki et al., 2000; ElbazPoulichet et al., 2002; Oliveira et al., 2003; Kulaksiz and Bau, 2007; Di Leornardo et al., 2009; Rabiet et al., 2009). The widespread and growing relevance of REE in a number of industrial, agricultural, and medical technologies and procedures (Bau and Dulski, 1996) has become evident in the last decades (USEPA, 2012) since they are used in various applications, such as permanent magnets ( $\mathrm{Pr}, \mathrm{Nd}, \mathrm{Sm})$, catalysts for petroleum refining (La, $\mathrm{Ce})$, polishing powders (Ce), and LCD screens (Eu) among other high technological products; they can be also incorporated to fertilisers (Baba et al., 2011; Xie et al., 2014; Diehl et al., 2018). Gd and some other REE are heavily used. The growing medical use of REE over the last decades (Lerat-Hardy et al., 2019) together with their high-tech applications, should demonstrate the urgent need for investigations into these elements (Gwenzi et al., 2018). Even if $\mathrm{Gd}$ is mainly transported as a dissolved fraction (Kulaksiz and Bau, 2013), according to Migaszewski and Gałuszka (2015) the origin and mechanisms of controlling the LREE, MREE, or HREE enrichment in soluble and solid fractions are still unknown. It is particularly unclear whether the REE patterns are linked to the aqueous processes or are related to the source of these elements (Ebrahimi and Barbieri, 2019). In recent reviews, Rogowska et al. (2018) reported the scarcity of information on the level of $\mathrm{Gd}$ in aquatic sediments and the lack of any speciation analysis (China, Australia, Europe) and Migaszewski and Galuska et al. (2015) highlighted the need to improve our knowledge about behaviour and origin of REE in the environment.

REE thus have a great potential as geochemical tracers in soils or river sediments due to their strong binding capacity, low natural background, low mobility, chemical stability, and the availability of a range of these elements with similar properties (Zhu et al., 2011). REE have been characterised neither as essential elements for life nor as strongly toxic elements in the environment (Hu et al., 2006). Although the environmental toxicity of REE is largely unknown, environmental contamination has already been found in some mineralised areas, as well as in soils that are affected by the long-term application of sludge. Several negative effects of REE on organisms have been reported (Wang and Liang, 2015). Gonzalez et al. (2014) reviewed the scarce knowledge about the ecotoxicity of these emerging micro contaminants for a proper risk assessment of the REE in aquatic and terrestrial systems. 
Indeed, as a first step in adding to the total concentration data, it is necessary to investigate the distribution of REE in non-residual fractions of sediments from rivers receiving anthropogenic inputs. This step is of importance since it enables us to appreciate the potential of REE that could end up in river water if physico-chemical conditions change, and therefore could become potentially available and a risk to living organisms (Gwenzi et al., 2018).

The alternance of river flow conditions is responsible for the transport, storage, and remobilisation of river sediments, and thus of REE linked to solid material. The behaviour of most metals in sediments according to river flow conditions has been quite frequently investigated in the literature (e.g. Roussiez et al., 2013; Martinez et al., 2015). However, REE patterns have been less investigated in southern countries where dams are constructed with an increasing frequency and flood events are more severe. Dams are known to retain sediments and the associated metals transported during high flow (Audry et al., 2004). However, few data exist for the REE patterns in dam sediments (Franklin et al., 2016) and for the role of dams in the transfer of these elements downstream (Yang et al., 2002).

In North Africa, the high degree of climatic fluctuations, intense flood events, low vegetation cover, and excessive soil exploitation have a big impact on erosion, yield sediment, fluvial transport, and dam sedimentation issues, and consequently, on the socio-economic parameters of the countries in this region (Lahlou, 1994). Some studies have investigated the behaviour of REE in river sediments around the world (Sholkovitz, 1995; Leleyter et al., 1999; Yang et al., 2002; Ma et al., 2011) and especially in the estuaries of Mediterranean Rivers (Borrego et al., 2004; Roussiez et al., 2013), however, there are very few along river channels (Bounouira et al., 2013) in Northern Africa. In addition, the potential anthropogenic sources, the role of anthropogenic influences such as the presence of dams along the river channels, and the role of hydrological conditions on the REE extractability, were not investigated considering those hydroclimatic conditions. The Tafna basin was investigated in this study as one of the major contributing rivers to the Mediterranean Sea. The contamination of bed sediments by trace metals from various sources has been evidenced (Taleb, 2004; Benabdelkader, 2018). However, the REE distribution and their origin, as well as the influence of hydrological conditions, anthropogenic inputs, and management structures on REE transport dowstream the river channel have not yet been studied.

In this study we hypothesise that: (i) the composition of REE in sediment evolved along the river channel as a consequence of various natural or anthropogenic inputs, the presence of 
dams, and erosion processes; and (ii) hydrological conditions influence the patterns and extractability of REE in sediment.

To verify these assumptions, the objectives of this study were to: 1) quantify REE and evaluate their patterns in river bed sediments from upstream to downstream in the Tafna basin in contrasting hydrological conditions; 2) identify REE anomalies, fractionation ratios, and controlling parameters such as texture, carbonate, organic matter, and oxides contents; 3) evaluate the influence of constructed dams on REE transfer downstream; and 4) determine the main extractable fraction of REE in sediments.

\section{Material and method}

\subsection{Description of the study area}

The Tafna watershed is located in the Northwest of the Algerian territory, extending into Morocco (27\% of the total area of the basin i.e. $7245 \mathrm{~km}^{2}$ ). The basin is delimited to the north by the mountains of Traras, to the south by the mountains of Tlemcen, to the west by the Beni-Snassen Mountains in Morocco (BS Mountains), and to the east by the Sebaa-Chioukh Mountains (SC Mountains) (Fig. 1). The main stream is the Tafna wadi, whose source is at an altitude of $1100 \mathrm{~m}$ on the southern slope of the Tlemcen Mountains at the level of Ghar Boumaaza (GB Source). It flows $170 \mathrm{~km}$ along an average slope of $6.5 \%$ and empties into the Mediterranean Sea. The Isser wadi is the main right-end tributary of the Tafna wadi, originating at an altitude of $900 \mathrm{~m}$. With a slope of $6.9 \%$, it flows into the Tafna with a confluence at $80 \mathrm{~m}$ of altitude in the plain close to the Tafna outlet (Fig. 1).

For the whole Tafna basin, the slope ranges from $<5 \%$ to $>30 \%$. In the Mouillah subcatchment, the slope is estimated to be $<5 \%$, with an erosion rate of $400 \mathrm{t} \mathrm{km}^{-2} \mathrm{yr}^{-1}$. In the upstream Tafna basin, the slope is $>25 \%$ and it exceeds $30 \%$ in the Isser sub-catchment with an erosion rate of $1000 \mathrm{t} \mathrm{km}^{-2} \mathrm{yr}^{-1}$ (Tidjani et al., 2006; Zettam et al., 2018).

The climate of the Tafna basin is of Mediterranean type with a sub-arid tendency; the average precipitation ranges between 183 and $474 \mathrm{~mm}$ and the mean annual temperature is $18{ }^{\circ} \mathrm{C}$ (period 2000-2015). The daily temperature can reach up to $47^{\circ}$ (2009), which increases the rate of evapotranspiration. The hydrological regime is Mediterranean, alternating heavy storm events and severe drought periods; the mean annual flow over the last fifteen years varies 
between $0.11 \mathrm{~m}^{3} \mathrm{~s}^{-1}$ (2008) and $10.95 \mathrm{~m}^{3} \mathrm{~s}^{-1}$ (2014) at the downstream station (National Agency of Hydrologic Resources (ANRH), 2016).

The agricultural land is mainly used for cereals, which cover $1699 \mathrm{~km}^{2}(23.6 \%$ of the total area), $342 \mathrm{~km}^{2}$ for horticulture (4.75\% of the total area), and $263 \mathrm{~km}^{2}$ for arboriculture $(3.65 \%$ of the total area) (Algerian Ministry of Agriculture, 2011). Some forests, sparse vegetation, and pasture occupy mainly the upper basin, whereas irrigated crops cover the rest (Benabadji et Bouazza, 2001).

The Tafna basin is divided into two zones of bedrock types: the upstream part where the river runs in a canyon through Jurassic rocks rich in limestone and dolomite, and the downstream part where it drains a tertiary basin characterised by Miocene marls covered by recent alluvium belonging to the quaternary (Guardia, 1975; Taleb, 2004).

Calcareous soils dominate the upper part of the basin, whereas salt soils are encountered in the middle course of the Tafna Wadi (Khaldi, 2005). Approximately 50 quarries that exploit clays or limestone to make aggregates are distributed in the Tafna basin.

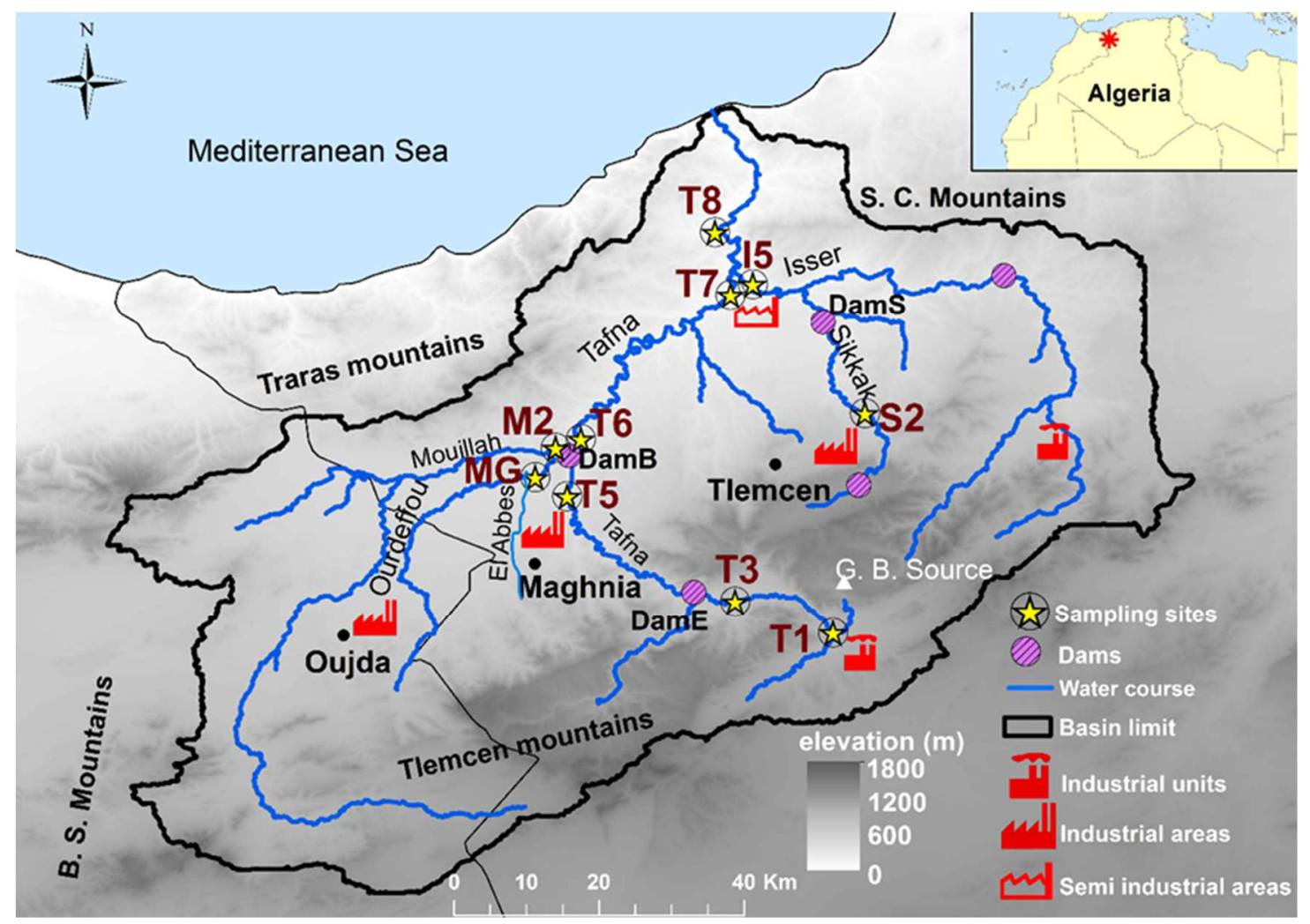

Fig. 1: Study area, elevation, and sediment sampling sites in the Tafna river basin (northwestern Algeria) (treated map of digital elevation data source, de Ferranti, 2014 (http://www.viewfinderpanoramas.org). 
The Tafna watershed is thus characterised by a semi-arid climate, limestone dominant lithology, strong erosion due to erratic storm events, and a degraded vegetation cover, in addition to the presence of dams. These characteristics are similar to those of large river basins in the Maghreb region and consequently, the Tafna can be considered a representative of other basins in Morocco (Moulouya Basin, Tekken and Kropp, 2012; Tovar-Sanchez et al., 2016); Algeria (Chelif Riber Basin, Saint Martin et al., 1992; Taibi et al., 2015; Wadi Rhumel-Boumerzoug, Bentellis-Mosbah et al., 2003); and Tunisia (Medjerda Basin, Bouraoui et al., 2005).

\subsection{Sampling strategy and anthropic activities}

In this study, ten river stations (T1, T3, T5, MG, M2, T6, T7, S2, I5, and T8) and two dams (DamS and DamB) were sampled (Fig. 1). These stations were chosen on the basis of preliminary survey results and as described in Benabdelkader et al. (2018), due to the presence of several anthropic activity sources (industrial and agricultural) and also to the hydrology of the basin from upstream to downstream to the Mediterranean Sea (Fig. 1). The stations are located as follows: downstream industrial units and villages, with a textile industry (T1); ENOF (bentonite business: $600 \mathrm{~m}^{3}$ day $^{-1}$ ), ENCG (fats business: $528 \mathrm{~m}^{3}$ day $^{-1}$ ), ERIAD (corn mill $1600 \mathrm{~m}^{3}$ day $^{-1}$ ), and effluents from Maghnia town including hospital waste (MG); downstream from the industrial unit CERTAF (ceramics: $130 \mathrm{~m}^{3}$ day) (T5) (Tidjani, 2006); at the outlet of the Mouillah tributary (M2), T5 and M2 being located at the DamB entrance; at DamB outlet (T6), and downstream of a large flat agricultural area with a lot of river meanders between (T7); downstream of a public dump, urban effluents including hospital waste from the eastern part of Tlemcen city, and industrial effluents (S2); at the outlet of the main downstream tributary Isser wadi, immediately downstream of the ceramic industry (CERAMIR) (I5) (Ministry of Energy and Mining of Algeria, 2007); and at the outlet of the whole Tafna basin for (T8) outside of any seawater influence.

In this basin, several main dams were constructed, including DamB-Boughrara Dam-the largest one in the basin with a capacity of 177 million $\mathrm{m}^{3}$, DamE-Beni Bahdel—with a capacity of 66 million $\mathrm{m}^{3}$, and DamS with a capacity of 27 million $\mathrm{m}^{3}$ (National Agency for Dams and Transfers (ANBT)). In the upstream part of the Tafna basin there is a textile industry and 5 main dams (among which are DamB and DamS), ensuring water supplies 
along the river course. These dams, after filling, are sparsely emptied during high water flow periods, leading to the transfer of accumulated sediments downstream.

\subsection{Physical and chemical sample treatment}

River bed surface sediments (the top $3 \mathrm{~cm}$ ) were manually collected in polyethylene containers at each sampling site from the river bank where they had accumulated, under running water conditions. The samples were stored in a box and transported the same day to the laboratory. The sampling was performed during four sampling campaigns in recession periods: June 2014 (low water flow), October 2014 (high water flow, corresponding to the first rainfalls after the dry season), February 2015 (high water flow), and August 2015 (low water flow). At each station, bedrock was also sampled from outcroppings of the dominant drainage bedrock in the location. Bottom sediments from two dams (DamB and DamS) were taken during the low water period (August 2015) from the centre area using an Ekman grab (Ekman, 1911; Blomqvist, 1990). The grab was lowered to the sediment surface at $35 \mathrm{~m}$ depth and approximately a $10 \mathrm{~cm}$ depth of sediment was sampled over a surface of $0.1 \mathrm{~m}^{2}$.

\subsubsection{Physical treatment}

In the laboratory, the samples were air dried, carefully homogenised with an agate mortar and quartered, then sieved (with nylon sieve) to obtain three fractions (a fine fraction $<63 \mu \mathrm{m}$ ), a coarse fraction $(63 \mu \mathrm{m}-2 \mathrm{~mm})$, and the fraction $>2 \mathrm{~mm}$ and each fraction was weighed.

To determine precisely the texture of the sediment (percentage of clay $(<2 \mu \mathrm{m})$, silt $(2-63$ $\mu \mathrm{m}$ ), and sand (63-2000 $\mu \mathrm{m}$ ), a microgranulometric analysis was carried out (from $0.01 \mu \mathrm{m}$ to $3000 \mu \mathrm{m}$ ) using a Horiba LA 950 microgranulometry laser at the EcoLab laboratory. Each sample was treated with a solution of sodium hexa-meta-phosphate to increase the particle dispersion of the solution. The accuracy and precision were $0.6 \%$ and $0.1 \%$, respectively.

\subsubsection{Chemical treatments and analysis}


Mineralisation was performed on the $<63 \mu \mathrm{m}$ fraction due to its dominance and affinity for metals (Probst et al., 1999).

Each sediment sample was dissolved in a chemical mixture of $\mathrm{HF} / \mathrm{HNO}_{3} / \mathrm{H}_{2} \mathrm{O}_{2}$ following a well calibrated procedure of several steps (Marin, 1998; N'Guessan et al., 2009). In the EcoLab clean room, firstly $100 \mathrm{mg}$ of sediment was digested in a teflon cup with $0.6 \mathrm{~mL}$ $\mathrm{HNO}_{3}$ (suprapure) and $0.5 \mathrm{~mL} \mathrm{HF}$ at $90{ }^{\circ} \mathrm{C}$ for $17 \mathrm{~h}$, then another $0.6 \mathrm{~mL} \mathrm{HNO}_{3}$ was added and incubated overnight at $85{ }^{\circ} \mathrm{C}$, and finally the solution was evaporated. In a second step, to remove the organic matter, $\mathrm{H}_{2} \mathrm{O}_{2}(0.5 \mathrm{~mL})$ was added at three times in an ultrasonic bath (Branson 1510) at $15 \mathrm{~min}$ intervals of until the effervescence has disappeared when the solution was stirred. Finally, after a complete evaporation, the residue was recovered with 2 mL $\mathrm{HNO}_{3} 2 \%$. Blanks and the standard sediments SUD-1, WQB-1, and STSD-3 were prepared following the same dissolution procedure.

After the dilution process, the concentration of the major elements $\mathrm{Ca}, \mathrm{Al}, \mathrm{Fe}, \mathrm{S}, \mathrm{P}$, and $\mathrm{Mn}$ were first analysed on an optical emission spectrometer (ICP-OES Thermo IRIS Intrepid II XDL) at EcoLab (Toulouse, France). Secondly, the concentration of trace elements, REE, Th, $\mathrm{Y}, \mathrm{Sc}$, and U were analysed using an inductively coupled plasma-mass spectrometry (ICP-MS Quad AGILENT 7500ce) at OMP (Observatoire Midi-Pyrénées analytical platform, Toulouse, France). The trace elements and major elements are presented in the paper by Benabdelkader et al. (2018) and detailed data can be found in SM Table 1. For the trace metals, the yielded recovery rates for the standards SUD-1, WQB-1, and STSD-3 were between 85\% and 110\%, and the blank samples used to test for solvent contamination were below the detection limit. The detection limit varies around $0.5 \mathrm{mg} \mathrm{L}^{-1}$ for ICP-OES, and for ICP-MS, the detection limits (DL) was $10^{-2} \mu \mathrm{g} \mathrm{L^{-1 }}$.

The major and rare earth elements in the bedrock samples were analysed using an ICP-MS in Center for Petrographic and Geochemical Research (CRPG, Nancy, France) (http://www.crpg.cnrs-nancy.fr/index.php) after alkaline fusion with lithium metaborate (Govindaraju and Mevelle, 1987; Garzanti, 2010), using a well calibrated dissolution procedure (Carignan et al., 2001), as for sediment.

Many metal extraction protocols have been used in the literature, however, since in sediments the majority of anthropogenic metals (including REE) are linked to organic matter and oxide compounds, EDTA extraction was frequently used due to its greater ability to extract such element fractions (Beckett, 1989; Leleyter et al., 2012). Such a simple chemical extraction 
was thus used to determine the available fraction of REE in the sediments: $1 \mathrm{~g}$ of sediment was leached with $10 \mathrm{~mL}$ of $0.05 \mathrm{~mol} \mathrm{~L}^{-1}$ EDTA at ambient temperature $\left(20^{\circ}\right)$ and filtered using a $0.22 \mu \mathrm{m}$ porosity filter (Ghestem and Bermond, 1998). After dilution, the solution obtained was analysed in the same way as the total dissolution of sediment. The extraction process was only performed for sediments from the two campaigns in 2014. Note that Sm was not detected during the analytical process since at $\mathrm{pH} 7.5$, it is the most retained REE during an EDTA extraction (Fernandez and Alonso, 2008).

The particulate organic carbon (POC) was analysed with an NA 2100 Protein (Thermo Fisher) at EcoLab laboratory. Every sediment sample was decarbonated with $\mathrm{HCl}(2 \mathrm{~N})$. Usually the addition of $\mathrm{HCl}$ lasts $48 \mathrm{~h}$ by drips, however, for the Tafna sediment which is much enriched in carbonates, the $48 \mathrm{~h}$ period was exceeded until the disappearance of effervescence was observed. Subsequently, $5 \mathrm{mg}$ of each sample was analysed.

\subsection{Data treatment}

To investigate REE patterns along the Tafna river, for some results, the basin was divided into two groups of stations: the stations from the upper basin (T1, T3, T5, MG, M2, DamB, T6, and T7) and those from the main right-hand tributaries joining the Tafna river in its lower part upstream of the estuary of the basin (stations S2, I5, T7, and T8).

As usually performed in the literature (Sholkovitz, 1995; Romero-Freire et al., 2018), the REE were divided into three sub-groups: LREE (from La to Nd), MREE (from Sm to Gd), and HREE (from $\mathrm{Tb}$ to $\mathrm{Lu}$ ).

\subsubsection{Normalisation and element ratio}

The relative abundance of REE was normalised to the local bedrock to assess the enrichment or depletion of sediments from their bedrock origin, which is more representative than a distant or global reference (Inguaggiato et al., 2017), as has been observed for other metals (N'Guessan et al., 2009; Benabdelkader et al., 2018). Nevertheless, we used also the normalisation to Post Archean Australian Shale (PAAS, Taylor and McLennan, 1985), since this composition has been most frequently used in normalisation procedures, facilitating the comparison with data in the literature (McLennan et al., 1980; Moller et al., 2002; Tranchida et al., 2011).

Variations and the behaviour across the REE series were indicated by the proportion of enriched light rare earth elements (LREE) with respect to medium rare element (MREE) and 
to heavy rare earth elements (HREE). This was illustrated by the (La/Yb)n ratio (representative of LREE/HREE), (La/Sm)n ratio (representative of LREE/MREE), and $(\mathrm{Sm} / \mathrm{Yb}) \mathrm{n}$ ratio (representative of MREE/HREE), respectively (Condie, 1993; Mao et al., 2014; Inguaggiato et al., 2017), where $\mathrm{n}=$ every element concentration in sediment normalised to its concentration in bedrock.

\subsubsection{REE anomalies calculations}

Anomalies in the normalised REE trends have been frequently used to identify sources of some elements and particular processes such as fractionation (Sholkovitz, 1995; Moller et al., 2002) In this study, the anomalies were calculated for Eu and Gd using three equations.

The calculation of the $\mathrm{Eu}$ positive or negative anomaly $\left(\mathrm{Eu}_{\mathrm{n}} / \mathrm{Eu}_{\mathrm{n}}{ }^{*}\right)$ according to its neighbouring pairs of elements was proposed (Eq. 1) and has been used by several authors (Elderfield and Greaves, 1982; Taylor and McLennan, 1985; Bau and Dulski, 1996).

The Ce, $\mathrm{Yb}$, and $\mathrm{Tb}$ anomalies were calculated respectively, as follows (De Baar et al., 1985; Sholkovitz, 1995):

The gadolinium anomaly $\left(\mathrm{Gd}_{\mathrm{n}} / \mathrm{Gd}_{\mathrm{n}} *\right.$ ) was estimated according to (Eq. 2) (Bau and Dulski, 1996).

$\mathrm{Gd}_{\mathrm{n}} / \mathrm{Gd}_{\mathrm{n}} *=(\mathrm{Gd})_{\mathrm{n}} /\left(0.33(\mathrm{Sm})_{\mathrm{n}}+0.67(\mathrm{~Tb})\right)$

327 The subscript (n) denotes normalisation to the bedrock, and the superscript $(*)$ denotes the geogenic background (extrapolated/ interpolated) (Kulaksız and Bau, 2013). 
$333 \operatorname{Gd}_{\text {anth }}(\%)=\frac{\text { Gd anth }}{\text { Gd measured }} \times 100$.

Where $\mathrm{Gd}_{\text {measured }}$ was the $\mathrm{Gd}$ concentration in sediment and $\mathrm{Gd}_{\text {bedrock }}$ was the concentration of

Gd in the local bedrock (Lawrence et al., 2009).

A value of 1 means that the element was not fractionated relative to the crustal composition, whereas a depletion relative to its neighbouring REE yields values $>1$ (positive anomalies) or $<1$ (negative anomalies) (Sholkovitz, 1995).

\subsection{Statistical analysis}

341

The statistical investigation was carried out using Excel (2010, Microsoft $®$ ) and STATISTICA (StatSoft, Inc., Dell Software, France) software version 8.0.306.0 (2007). R software (R Foundation for Statistical Computing, Vienne) version 3.3.1 was used for the Principal Component Analysis (PCA), which was performed on raw data transformed with log-ratio data using the rgr package. The exception was for grain size, which was not measured in the same units as the elements.

\section{Results}

\subsection{Particle size distribution of the sediment samples}

The grain size distribution was assessed in the bulk fraction $(<2000 \mu \mathrm{m})$ and the fine fraction $(<63 \mu \mathrm{m})$ of sediment from the different stations during two contrasting hydrological conditions (high water and low water). The fine fraction was used in the REE investigations (Table 1).

Table 1: Mean relative texture composition (in \%) of the bulk sediment $(<2000 \mu \mathrm{m})$ and of the fine fraction ( $<63 \mu \mathrm{m}$, used to determine REE concentrations), during two contrasting hydrological conditions (LW: low water and HW: high water) in the 2014 and 2015 campaigns (except for the dams which were only sampled in LW in 2015) at the sampled stations (see Fig. 1). Clay: <2 $\mu$ m; fine silt:

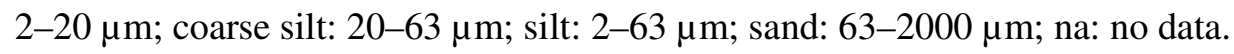




\begin{tabular}{|c|c|c|c|c|c|c|c|c|c|c|c|c|}
\hline \multirow[b]{2}{*}{ Station } & \multicolumn{6}{|c|}{ Bulk sediment $(<2000 \mu \mathrm{m})$} & \multicolumn{6}{|c|}{ Fine fraction $(<63 \mu \mathrm{m})$} \\
\hline & \multicolumn{2}{|c|}{ Clay (\%) } & \multicolumn{2}{|c|}{ Silt (\%) } & \multicolumn{2}{|c|}{ Sand (\%) } & \multicolumn{2}{|c|}{ Clay (\%) } & \multicolumn{2}{|c|}{ Fine Silt (\%) } & \multicolumn{2}{|c|}{ Coarse Silt (\%) } \\
\hline & $\mathrm{HW}$ & LW & HW & LW & HW & LW & HW & LW & $\mathrm{HW}$ & LW & $\mathrm{HW}$ & LW \\
\hline T1 & 2 & 10 & 12 & 64 & 86 & 26 & 13 & 14 & 59 & 57 & 28 & 29 \\
\hline T3 & 1 & 6 & 20 & 52 & 79 & 42 & 6 & 11 & 51 & 59 & 43 & 30 \\
\hline T5 & 15 & 21 & 51 & 47 & 34 & 32 & 22 & 29 & 50 & 49 & 28 & 22 \\
\hline MG & 1 & 1 & 13 & 34 & 86 & 65 & 4 & 5 & 40 & 51 & 56 & 44 \\
\hline M2 & 17 & 27 & 43 & 62 & 40 & 11 & 27 & 25 & 58 & 64 & 15 & 11 \\
\hline T6 & 0 & 12 & 11 & 59 & 89 & 29 & 8 & 17 & 65 & 55 & 27 & 28 \\
\hline T7 & 5 & 23 & 39 & 74 & 56 & 3 & 15 & 27 & 48 & 51 & 37 & 22 \\
\hline S2 & 2 & 4 & 15 & 60 & 83 & 36 & 7 & 6 & 43 & 58 & 50 & 36 \\
\hline 15 & 23 & 9 & 67 & 51 & 10 & 40 & 22 & 17 & 57 & 50 & 21 & 33 \\
\hline T8 & 10 & 19 & 38 & 69 & 52 & 12 & 20 & 22 & 45 & 50 & 35 & 28 \\
\hline DamB & na & 25 & na & 75 & na & 0 & na & 25 & na & 73 & na & 2 \\
\hline Dams & na & 25 & na & 65 & na & 10 & na & 31 & na & 52 & na & 17 \\
\hline
\end{tabular}

\subsubsection{Bulk fraction}

In the bulk fraction, the clay and silt relative content was higher (silt dominant) in low water conditions than high water conditions for every station, except I5 (for clay and silt) and T5 (for silt). In contrast, the sand content was higher during high water conditions, except at the I5 station. During low and high water conditions, the highest percentages of clay were observed in M2, T7, and T5 with (27 to $21 \%$ ) and in I5, M2, and T5 (23 to $15 \%$ ), respectively, and of silt in T7, T8, and T1 (74 to $64 \%$ ) and in I5, T5, and M2 (67 to $43 \%$ ), respectively.

372 The sediments from the two dams, which were only collected during low water conditions in 3732015 , have roughly the same texture, dominated by silts, with a $10 \%$ sand composition for DamS.

\subsubsection{Fine fraction}

376 In the fine fraction, the percentage of clay was between 4 and $29 \%$; the clay content was 377 higher in the low water condition than the high water condition for all stations, except I5, and 378 to a lesser extent in M2 and S2, where it was approximately equivalent. The fine silt was the 379 main fraction in LW conditions and in most of the stations during high flow conditions, except at MG and S2. This fraction was also higher in LW than HW, except at T6 and I5, and 
to a lesser extent T1 and T5. The coarse silt fraction ranged between 11 and $56 \%$ and was found to be higher in HW, except at I5, and to a lesser extent at T1 and T6.

In the dams, fine silt was also the dominant fraction. Clay and coarse silts were found to be higher in DamS (31\% and $17 \%$, respectively) than in DamB (25\% and $2 \%$, respectively). In contrast, fine silt was higher in DamB (73 \%) than DamS.

\subsection{REE concentrations and other reference elements in sediment}

Table 2 presents the average concentration of REE and trace elements (Th, Y, Sc, and U) in the Tafna River bed sediments collected during four campaigns at ten sites and two dams (DamB and DamS), as well as in local bedrock (BR) and bedrocks taken as a reference (PAAS, McLennan, 2001; and carbonates, Turekian and Wedepohl, 1961).

The average ranking of concentrations was as follows: $\mathrm{Ce}>\mathrm{La}>\mathrm{Nd}>\mathrm{Pr}>\mathrm{Sm}>\mathrm{Gd}>\mathrm{Dy}>\mathrm{Yb}>\mathrm{Er}>\mathrm{Eu}>\mathrm{Ho}>\mathrm{Tb}>\mathrm{Tm}=\mathrm{Lu}$, from 42.22 to $0.21 \mu \mathrm{g} \mathrm{g}^{-1}$ for $\mathrm{Ce}$ and $\mathrm{Tm}=\mathrm{Lu}$, respectively. These concentrations are in the vicinity of the concentrations found in other carbonate rivers, such as the Sebou River (NW Morocco; Leleyter, 1998) and the Gascogne Rivers (N'Guessan, 2008), although they are higher in the Sebou (except Pr and Ce). The REE concentrations followed the same order of classification as in the Tafna, however, the HREE are less concentrated in the sediments from the Gascogne area, whereas the opposite is true for LREE and MREE (except Gd). A reverse pattern was observed for the Sebou River. Moreover, the $\mathrm{CaO}$ concentration in the Tafna sediments (8.13 to $34.50 \%$, Benabdelkader et al., 2018) was higher than in the Sebou River (9.14 and $19.10 \%$, Leleyter, 1998 ) and in the Gascogne Rivers (0.28 and $14.62 \%$, N'Guessan et al., 2009).

The concentrations of REE from the Tafna sediments are much lower than the values (104 and $0.58 \mu \mathrm{g} \mathrm{g}^{1}$ ) observed in sediments from the Bouregreg silicate basin (Morocco, Bounouira et al., 2008), but in the range of two basins draining mining waste from southern Spain (45.79 for Ce and $0.17 \mu \mathrm{g} \mathrm{g}^{-1}$ for Lu for the Odiel and Tinto Rivers in Spain (Borrego et al., 2004)). Only the concentrations of La and Yb slightly exceeded those of the Tafna.

The average $\Sigma$ REE in the Tafna sediments was $102 \mu \mathrm{g} \mathrm{g}^{-1}$ and varied between $153.39 \mu \mathrm{g}$ $\mathrm{g}^{-1}$ and $90.27 \mu \mathrm{g} \mathrm{g}^{-1}$ in DamB and T3, respectively. Based on $\sum \mathrm{REE}$, the stations ranked as follows: DamB $>$ I5 $>$ DamS $>$ T5 $>$ T7 $>M 2>$ T8 $>$ MG $>$ T6 $>$ T1 $>$ S2 $>$ T3. The I5 station, at the outlet of the Isser tributary, had the highest concentrations of LREE, MREE, and HREE. The most 
concentrated element was Ce $\left(54.36 \mu \mathrm{g} \mathrm{g}^{-1}\right)$ for LREE, Sm $\left(4.69 \mu \mathrm{g} \mathrm{g}^{-1}\right)$ for MREE and Dy

$413\left(1.15 \mu \mathrm{g} \mathrm{g}^{-1}\right)$ for HREE. The REE in sediment from the I5 station were even more

414

415

416

417

418

419

420

421

422

423

424

425

426

427

428

429

430

431

432 concentrated than in DamS. Among all the stations from the Tafna River course, the highest REE concentrations were found in sediments from the T5 station, whereas the lowest ones were found in the upstream part of the Tafna (T1 and T3 stations). Indeed, REE in the sediments from DamB and I5 were 1.6 and 1.3 times higher than in those from the other sites, respectively (Table 2 ).

The REE in the bedrocks collected from the Tafna basin ranged from $15.26 \mu \mathrm{g} \mathrm{g}^{-1}$ to $0.15 \mu \mathrm{g}$ $\mathrm{g}^{-1}$ with $\Sigma$ REE $=41.21 \mu \mathrm{g} \mathrm{g}^{-1}$ (Table 2). These concentrations were low compared to the Tafna river sediments and to the PAAS reference bedrock (184.77 $\mu \mathrm{g} \mathrm{g}{ }^{-1}$, McLennan, 2001), however, they were in the range of or even higher than other carbonate bedrocks (ranging from 11.50 to $0.04 \mu \mathrm{g} \mathrm{g}^{-1}$, for Ce and Tm, respectively (Turekian and Wedepohl, 1961).

The analysed trace element concentrations (Th, $\mathrm{Y}, \mathrm{Sc}$, and $\mathrm{U}$ ) ranked as follows: $\mathrm{Y}>\mathrm{Sc}>\mathrm{Th}>\mathrm{U}$ on average for the Tafna sediments. The highest concentrations of Th, Y, and $\mathrm{U}$ were found for the I5 station, which is consistent with the levels of REE and DamB, and contrary to Scandium, which was found at the lowest concentration in I5 $\left(9.84 \mu \mathrm{g} \mathrm{g}^{-1}\right)$ and the highest in the upstream station T1 $\left(17.18 \mu \mathrm{g} \mathrm{g}^{-1}\right)$. The trace elements (Th, Y, Sc, and U) in Tafna bedrock followed the same ranking as in the Tafna sediments, and varied between 10.40 and $2.20 \mu \mathrm{g} \mathrm{g}^{-1}$ for $\mathrm{Y}$ and $\mathrm{U}$, respectively. The concentration of Th and Sc in the local bedrock was higher than in other carbonate bedrocks, and the opposite was observed for Y (Turekian and

Wedepohl,

1961;

Olivarez

et

al.,

1991). 
Table 2: Rare earth element and trace element (Th, Y, Sc, and U) concentrations in sediments from each sampling sites $($ mean $(\overline{\mathrm{x}})$, standard deviation $(\sigma))$ collected during the four sampling periods, except for the dams (DamB and DamS), which were only sampled once in LW in 2015. The mean value for the Tafna sediment (this study, mean Tafna sed, $\mathrm{n}=40$ ) was the average of the river stations, except the dams. The REE composition of other carbonate rivers is indicated: the Sebou River ${ }^{1}$ from the Maghreb area (Morocco, Leleyter, 1998) and the Gascogne Rivers ${ }^{2}$ (SW France, N'Guessan, 2008). The REE concentration in the local Tafna bedrock (mean value, $\mathrm{n}=10$ ), the PAAS (McLennan, 2001) and the carbonate bedrocks ${ }^{4}$ (Turekian and Wedepohl, 1961) are shown. (-): not determined. $\mathrm{R}=$ river, $\mathrm{BR}=$ bedrock.

\begin{tabular}{|c|c|c|c|c|c|c|c|c|c|c|c|c|c|c|c|c|c|c|c|c|c|}
\hline$\mu \mathrm{g} \cdot \mathrm{g}^{-1}$ & Station & & La & $\mathrm{Ce}$ & Pr & Nd & Sm & Eu & Gd & $\mathbf{T b}$ & Dy & Ho & Er & Tm & $\mathbf{Y b}$ & $\mathbf{L u}$ & $\sum$ REE & Th & $\mathbf{Y}$ & Sc & $\mathbf{U}$ \\
\hline \multirow[t]{24}{*}{ Sediment } & \multirow[t]{2}{*}{$\mathrm{T1}$} & $\bar{x}$ & 18.76 & 37.64 & 4.71 & 17.71 & 3.54 & 0.76 & 3.30 & 0.46 & 2.56 & 0.50 & 1.46 & 0.22 & 1.48 & 0.22 & 93.32 & 5.56 & 13.73 & 17.18 & 1.44 \\
\hline & & $\sigma$ & 2.65 & 5.31 & 0.72 & 2.75 & 0.62 & 0.13 & 0.63 & 0.09 & 0.57 & 0.11 & 0.33 & 0.05 & 0.39 & 0.04 & 10.81 & 0.99 & 3.21 & 4.44 & 0.27 \\
\hline & \multirow[t]{2}{*}{ T3 } & $\bar{x}$ & 18.28 & 36.72 & 4.53 & 16.99 & 3.37 & 0.78 & 3.18 & 0.44 & 2.40 & 0.47 & 1.36 & 0.2 & 1.35 & 0.20 & 90.27 & 5.01 & 12.69 & 15.75 & 1.40 \\
\hline & & $\sigma$ & 2.24 & 4.64 & 0.50 & 1.83 & 0.35 & 0.08 & 0.38 & 0.04 & 0.18 & 0.03 & 0.05 & 0.02 & 0.11 & 0.01 & 10.53 & 0.58 & 0.74 & 1.46 & 0.09 \\
\hline & \multirow[t]{2}{*}{ T5 } & $\bar{x}$ & 22.24 & 44.46 & 5.38 & 20.09 & 3.94 & 0.78 & 3.57 & 0.48 & 2.75 & 0.49 & 1.45 & 0.21 & 1.46 & 0.21 & 107.51 & 6.22 & 14.13 & 12.81 & 1.49 \\
\hline & & $\sigma$ & 4.77 & 9.13 & 1.14 & 3.99 & 0.87 & 0.21 & 0.91 & 0.14 & 0.83 & 0.16 & 0.50 & 0.08 & 0.62 & 0.07 & 12.77 & 1.64 & 4.97 & 3.13 & 0.52 \\
\hline & MG & $\bar{x}$ & 20.34 & 40.67 & 4.92 & 18.56 & 3.66 & 0.78 & 3.36 & 0.47 & 2.60 & 0.48 & 1.44 & 0.21 & 1.49 & 0.22 & 99.20 & 6.23 & 13.67 & 12.65 & 1.55 \\
\hline & \multirow[t]{2}{*}{ M2 } & $\bar{x}$ & 20.73 & 45.00 & 4.96 & 18.19 & 3.56 & 0.75 & 3.24 & 0.45 & 2.42 & 0.46 & 1.35 & 0.21 & 1.45 & 0.21 & 102.98 & 6.69 & 12.25 & 14.17 & 1.47 \\
\hline & & $\sigma$ & 4.57 & 10.44 & 1.14 & 4.26 & 0.94 & 0.20 & 0.79 & 0.11 & 0.68 & 0.12 & 0.40 & 0.06 & 0.46 & 0.05 & 12.67 & 2.47 & 4.10 & 4.45 & 0.45 \\
\hline & \multirow[t]{2}{*}{ T6 } & $\bar{x}$ & 19.88 & 39.98 & 4.80 & 18.15 & 3.54 & 0.76 & 3.25 & 0.48 & 2.51 & 0.48 & 1.47 & 0.20 & 1.43 & 0.21 & 97.14 & 5.40 & 13.66 & 11.18 & 1.50 \\
\hline & & $\sigma$ & 1.02 & 1.71 & 0.29 & 1.21 & 0.24 & 0.11 & 0.39 & 0.09 & 0.45 & 0.10 & 0.30 & 0.05 & 0.32 & 0.05 & 11.46 & 0.62 & 2.66 & 1.80 & 0.33 \\
\hline & \multirow[t]{2}{*}{ T7 } & $\bar{x}$ & 21.84 & 44.02 & 5.31 & 20.16 & 3.95 & 0.84 & 3.65 & 0.50 & 2.86 & 0.52 & 1.53 & 0.22 & 1.75 & 0.21 & 107.36 & 6.07 & 15.28 & 11.88 & 1.59 \\
\hline & & $\sigma$ & 4.48 & 9.72 & 0.96 & 3.48 & 0.45 & 0.07 & 0.35 & 0.04 & 0.27 & 0.05 & 0.15 & 0.03 & 0.35 & 0.03 & 12.62 & 1.13 & 1.96 & 1.66 & 0.31 \\
\hline & $\mathbf{S 2}$ & $\bar{x}$ & 18.56 & 37.96 & 4.59 & 17.28 & 3.41 & 0.71 & 3.18 & 0.45 & 2.55 & 0.46 & 1.32 & 0.20 & 1.35 & 0.20 & 92.22 & 5.07 & 13.08 & 16.18 & 1.38 \\
\hline & \multirow[t]{2}{*}{15} & $\bar{x}$ & 26.17 & 54.36 & 6.52 & 24.06 & 4.69 & 0.95 & 4.27 & 0.58 & 3.15 & 0.58 & 1.70 & 0.24 & 1.64 & 0.24 & 129.15 & 7.45 & 16.39 & 9.84 & 1.70 \\
\hline & & $\sigma$ & 5.49 & 11.71 & 1.25 & 4.68 & 0.84 & 0.14 & 0.73 & 0.10 & 0.52 & 0.09 & 0.29 & 0.03 & 0.31 & 0.03 & 15.51 & 1.37 & 2.94 & 1.14 & 0.30 \\
\hline & \multirow[t]{2}{*}{ T8 } & $\bar{x}$ & 20.23 & 41.44 & 5.10 & 19.17 & 3.86 & 0.83 & 3.61 & 0.49 & 2.71 & 0.50 & 1.43 & 0.20 & 1.30 & 0.20 & 101.07 & 5.63 & 13.95 & 10.06 & 1.32 \\
\hline & & $\sigma$ & 1.39 & 2.71 & 0.32 & 1.50 & 0.31 & 0.09 & 0.29 & 0.04 & 0.27 & 0.05 & 0.14 & 0.01 & 0.10 & 0.01 & 11.87 & 0.18 & 1.19 & 1.62 & 0.08 \\
\hline & \multirow[t]{2}{*}{ Mean Tafna R } & $\bar{x}$ & 20.70 & 42.22 & 5.08 & 19.05 & 3.75 & 0.79 & 3.46 & 0.48 & 2.65 & 0.49 & 1.45 & 0.21 & 1.47 & 0.21 & 102.01 & 5.93 & 13.88 & 13.17 & 1.48 \\
\hline & & $\sigma$ & 2.33 & 5.17 & 0.58 & 2.07 & 0.39 & 0.07 & 0.34 & 0.04 & 0.22 & 0.04 & 0.11 & 0.01 & 0.14 & 0.01 & 12.07 & 0.78 & 1.21 & 2.57 & 0.11 \\
\hline & Sebou $^{1} R$ & $\bar{x}$ & 21.29 & 41.84 & 5.03 & 19.44 & 3.98 & 0.89 & 3.62 & 0.59 & 3.16 & 0.67 & 1.70 & 0.28 & 1.72 & 0.27 & 104.47 & - & - & - & - \\
\hline & Gascogne $^{2}$ R & $\bar{x}$ & 25.34 & 55.58 & 6.09 & 23.46 & 4.57 & 0.89 & 3.15 & 0.44 & 2.44 & 0.47 & 1.30 & 0.19 & 1.25 & 0.18 & 125.35 & - & - & - & - \\
\hline & DamS & & 22.65 & 45.60 & 5.63 & 21.05 & 4.23 & 0.91 & 4.02 & 0.55 & 3.03 & 0.60 & 1.62 & 0.23 & 1.56 & 0.22 & 111.90 & 5.89 & 15.81 & 12.13 & 1.72 \\
\hline & DamB & & 31.72 & 64.73 & 7.61 & 28.27 & 5.47 & 1.22 & 5.08 & 0.67 & 3.64 & 0.68 & 2.00 & 0.27 & 1.76 & 0.27 & 153.39 & 8.21 & 18.21 & 15.81 & 1.79 \\
\hline \multirow[t]{3}{*}{ Bedrock } & BR Tafna & $\bar{x}$ & 7.53 & 15.26 & 1.89 & 7.24 & 1.65 & 0.30 & 1.53 & 0.27 & 1.75 & 0.37 & 1.05 & 0.16 & 1.05 & 0.16 & 40.21 & 3.30 & 10.40 & 5.90 & 2.20 \\
\hline & PAAS $^{3}$ & $\bar{x}$ & 38.20 & 79.60 & 8.83 & 33.90 & 5.55 & 1.08 & 4.66 & 0.77 & 4.68 & 0.99 & 2.85 & 0.41 & 2.82 & 0.43 & 184.77 & - & - & - & - \\
\hline & Carbonate $\mathrm{BR}^{4}$ & $\bar{x}$ & - & 11.50 & 1.10 & 4.70 & 1.30 & 0.20 & 1.30 & 0.20 & 0.90 & 0.30 & 0.50 & 0.04 & 0.50 & 0.20 & 24.54 & 1.70 & 30.00 & 1.00 & 2.20 \\
\hline
\end{tabular}


442

443

444

445

446

447

448

449

450

451

452

453

454

455

456

457

458

459

460

461

462

\subsection{Rare earth element normalisation}

\subsubsection{General patterns and elemental fractionation}

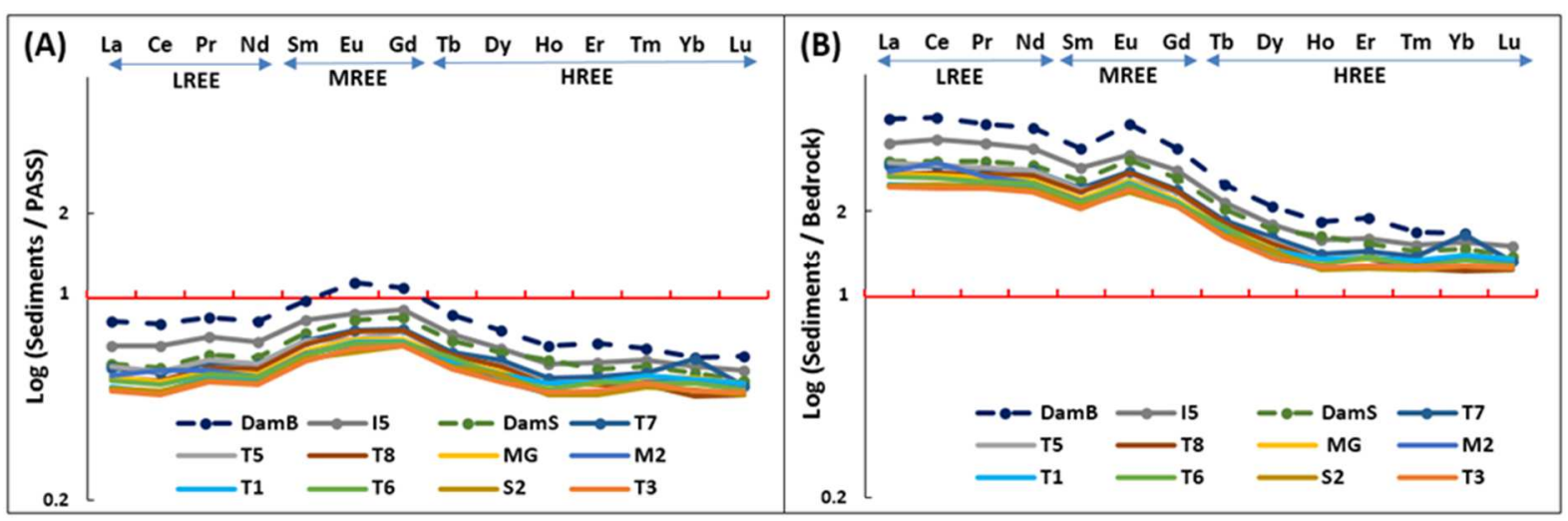

Fig. 2: Normalised REE patterns for each Tafna site (mean for the four sampling periods) using PAAS (A) and the mean local bedrock (B) as normalisers.

The average of REE concentrations in sediments from the different studied stations for the four sampling campaigns were normalised using two bedrock references, the PAAS (McLennan., 2001) (Fig. 2 A) and the mean local bedrock (Fig. 2 B). For the two normalisations, a different general pattern and enrichment was observed, however, the ranking of the stations was similar. The highest patterns were in the order DamB $>$ I5 $>$ DamS $>$ T7 $>$ T8 and the lowest one was for T3 station irrespective of the normalisation method.

REE in the Tafna sediments were impoverished relative to PAAS, particularly LREE and HREE (Fig. 2 A), however, there was a relative enrichment of MREE. When using the mean Tafna bedrock (Fig. 2 B), a general enrichment was observed, which was more obvious for LREE and MREE, with a relative impoverishment of HREE for some stations.

The fractionation ratio was calculated as the mean for high water and for low water conditions (Table 3). The $(\mathrm{La} / \mathrm{Yb})_{\mathrm{n}}$ ratio varied in between 1.14 and 2.95 in $\mathrm{T} 7$ and $\mathrm{T} 6$, respectively, for high water conditions. This ratio was higher in high water flow conditions than in low water conditions, except at the T3, S2, T5, T6, and T7 stations in 2015. Moreover, during high water conditions, the ratio was higher in $2014(X=2.47$, ranging from 2.19 to 2.95) than in 2015 ( $\overline{\mathrm{X}}=1.96$, ranging from 1.14 to 2.43 ), and it was generally the reverse for low water flow conditions $(\bar{X}=1.68$, ranging from 1.42 to 2.06 in 2014 and $\bar{X}=2.01$, ranging from 1.72 to 
2.56 , in 2015). In the dams only sampled in 2015, the ratio exceeded 2 and was the highest in $\operatorname{DamB}(2.52)$.

Irrespective of the year of sampling, in HW, stations I5, T8, and T5 always had the highest $(\mathrm{La} / \mathrm{Yb})_{\mathrm{n}}(>2)$ and T6 and T7 the biggest difference between the two years of sampling. T5 and S2 exhibited the highest ratio in LW in 2015, whereas T5, T7, T6, and I5 exceeded 2.5 in HW in 2014. The $(\mathrm{La} / \mathrm{Yb}) n$ ratio increased from upstream to downstream in the upper Tafna (T1<T3<T5), except in high water conditions in 2015. At the outlet of the Mouillah and Ourdeffou Rivers (stations M2 and MG, respectively), which contributed to DamB inputs, the ratio was lower than at the Tafna station (T5). Indeed, the ( $\mathrm{La} / \mathrm{Yb}) \mathrm{n}$ ratio in DamB during LW conditions was similar to T5 and was higher than in DamS.

The $(\mathrm{La} / \mathrm{Sm}) \mathrm{n}$ and $(\mathrm{Sm} / \mathrm{Yb}) \mathrm{n}$ ratios were lower than the $(\mathrm{La} / \mathrm{Yb}) \mathrm{n}$ ratio for all the stations (1.08-1.56 in $\mathrm{T} 1$ and $\mathrm{M} 2,1.03-2.22$ in $\mathrm{T} 5$ and $\mathrm{T} 7$, respectively). The (La/Sm)n was quite similar (even slightly higher during $\mathrm{HW}$ ) for the two hydrological conditions $(\overline{\mathrm{X}}=1.23$, ranging from 1.11 to 1.56 in $\mathrm{HW}$ and $\overline{\mathrm{X}}=1.18$ ranging from 1.08 to $1.23 \mathrm{in} \mathrm{LW}$, respectively). The exception was a higher value during high water flow in T1, I5, and T6, T7 in 2014 as well as T1 and M2 in 2015. In low water conditions, the (Sm/Yb)n was higher in 2015 than in 2014 and was higher for high water conditions in 2014 than for low water conditions, and the reverse was found for 2015 (except for T1, MG and I5). This pattern was similar to the (La/Yb)n ratio, except for the M2 station in 2015, as well as for the dams. The $(\mathrm{La} / \mathrm{Sm}) n$ was similar in T5, MG, and M2, and was higher in DamB than in DamS. Similarly to (La/Yb)n, the $(\mathrm{La} / \mathrm{Sm}) \mathrm{n}$ ratio tends to be higher in the upper Tafna basin, except in high water conditions.

\subsubsection{Individual REE patterns and main pattern anomalies}

The sediment REE patterns normalised to the local bedrock are shown for each station during each sampling condition (HW and LW in 2014 and 2015), except DamB and DamS, which were only sampled in LW in 2015 (Fig. 3). The data were separated in two sets of stations: (i) those of the upper Tafna river course (Tafna +Mouillah) down to the T7 station (T1 T3, T5, M2, MG, DamB, T6, and T7) (Fig. 3 A, B, i.e. 2015 low and high water campaigns, respectively, and Fig. 3 C, D, i.e. 2014 low and high water campaigns, respectively, and Fig. 1); (ii) the stations from the main right hand tributary of the Tafna (Isser) to the basin outlet (S2, DamS, I5, and T8, with T7 for the Tafna upstream reference) (Fig. 3 A', B', i.e. 2015 
low and high water campaigns, respectively, and Fig. 3 C', D', i.e. 2014 low and high water campaigns, respectively, and Fig. 1) for the two hydrological conditions.

The general mean pattern of fractionation for each station was evaluated using the $\mathrm{La} / \mathrm{Yb}$ ratio. Similarly to the mean value, on the whole, the REE patterns were consistent, irrespective of the hydrological condition, with the LREE being more enriched than HREE, however, this relative enrichment depended on the station and on the discharge condition (Table 3; Fig. 3). HREE were also generally slightly enriched relatively to bedrock, but some impoverishment was observed for some stations, such as M2, T6, and T5 (HW 2014), S2 (LW 2015), T1 (HW 2015) (Fig. 3 D). Generally, the ranking of stations driven by LREE was as a whole conservative for MREE and to a less extent for HREE.

During high water flow conditions in 2015 (Fig. 3 B, B'), a higher enrichment (particularly obvious for LREE) was observed for some stations such as MG, M2 (Mouillah river), I5, and S2 (Isser tributary). The highest fractionation between LREE and HREE was for I5 (from 1.7 $\mathrm{Tm}$ to $4.5 \mathrm{Ce}$ ). In contrast, other stations such as T3 and T8 showed rather stable patterns regardless of the conditions. Compared to low water conditions, this fractionation was decreased for the upstream station T1 and most obviously for T5 (Fig. 3 A, B; A', B'); this was also observed in HW in 2014 (Fig. 3 C, D; C', D'). During LW conditions in 2015 (Fig. A'), the pattern of REE enrichment for the outlet station T8 remained similar to that of Dam S, T7, and I5. For HREE, in high flow conditions, except at I5, the patterns were more or less the same. For some stations (MG, M2, I5, and S2), the enrichment increased in 2015 (Fig. 3 A, A', B, B'). In 2014 this was observed for I5, T3, T7, and T8, whereas for the other stations such as T5, M2, MG, T6, and S2, the enrichment decreased (Fig. 3 C, C'; D, D').

Sampling of the dams during low water conditions in 2015 indicated, as a whole, the highest REE enrichment in DamB, particularly for LREE and MREE.

For almost all the stations, MREE exhibited an enrichment for Eu (Fig. 3; Table 3). Based on the mean hydrological conditions (high water and low water; Eq. 1), $E u_{n} / E_{n} *$ exceeded 1 for all stations, with the highest values for MG, T6, M2, and T8 (1.28 to 1.32) in low water and the lowest values for T5 and S2 (HW 2014 and HW 2015, respectively). The Eu anomaly was higher during LW than HW for all stations, except for T1, T5, T6, and T7 during the 2015 campaign. For HW conditions, this anomaly was lower in 2014 than in 2015 (except for MG, S2, I5, and T8), whereas similar values were observed for the two years during LW 
526 conditions, except for T5, T7, and T8. The $\mathrm{Eu}_{\mathrm{n}} / \mathrm{Eu}_{\mathrm{n}}$ * in DamB was similar to T8 (LW 2015)

527 and higher than the DamS value.

528 Positive anomalies were also observed but to a lesser extent for some other REE: Tb at T6 $529\left(\mathrm{~Tb}_{\text {sed }} / \mathrm{Tb}_{\text {bedrock }}=2.10\right.$; Fig. $\left.3 \mathrm{~B}\right)$; Dy* at S2 in high water in 2015 (Dysed/Dybedrock=1.80; Fig. 3 530 B'); Ce* at M2 with a value between 1.03 and 1.15 (Fig. 3 A, B, C; Eq. 2), except in HW 5312014 , to a lesser extent at I5 with a value between 1.02 and 1.06 (Fig. 3 B', D'), and at the T7 532 station, it was only detected in the high water condition in 2014 (Ce*=1.04; Fig. 3 D'); Yb* at 533 T7 in HW in 2015 (Yb*=1.61; Fig. 3 B'; Eq. 3), M2 in LW in 2015 (Yb*=1.11; Fig. 3A), and 534 for most stations in LW in 2014 (Fig. 3 B, B', C, C'); and Tb* at T6 in HW in 2015 (Fig. 3 535 B'). The positive Gd anomaly (Eq.4) detected at stations MG and S2 ranged between 1.11 and $5361.19\left(\mathrm{Gd}_{\text {anth }} 10 \%\right.$ and $16 \%$; Eq.7) and 1.13 and $1.19\left(\mathrm{Gd}_{\mathrm{anth}} 12 \%\right.$ and $\left.16 \%\right)$, respectively. 
Table 3: REE ratios $(\mathrm{La} / \mathrm{Yb}, \mathrm{La} / \mathrm{Sm}, \mathrm{Sm} / \mathrm{Yb})$ and REE anomaly $(\mathrm{Eu} / \mathrm{Eu} *)$ during four campaigns (in 2014 and 2015) associated with two contrasting

538 hydrological conditions (HW: high water; LW: low water), normalised to mean local bedrock.

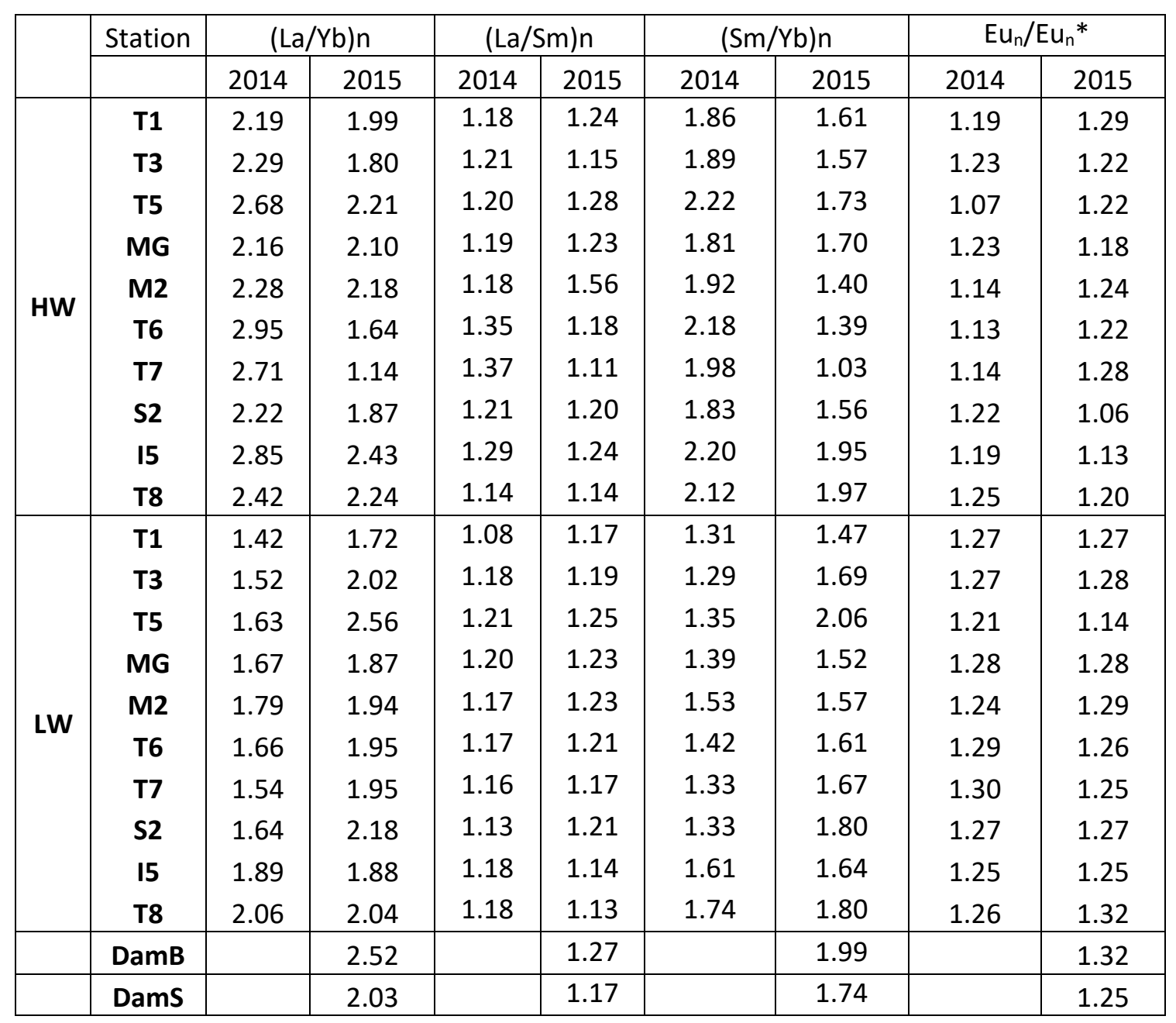



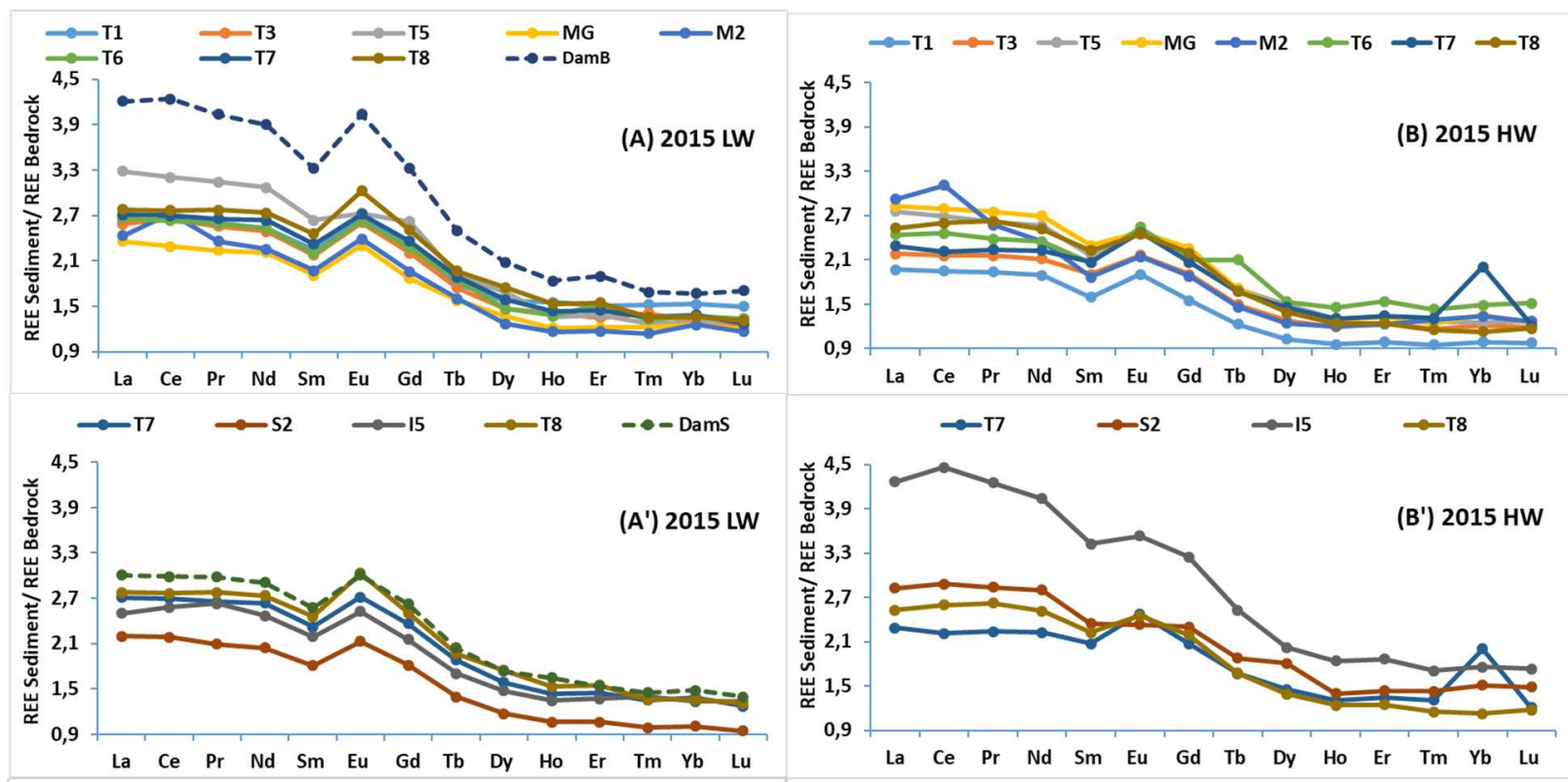

$\rightarrow \mathrm{T} 1 \rightarrow \mathrm{T} 3 \rightarrow \mathrm{T} 5 \rightarrow \mathrm{MG} \rightarrow \mathrm{M} 2 \rightarrow \mathrm{T6} \rightarrow \mathrm{T} \rightarrow \mathrm{T} 8$
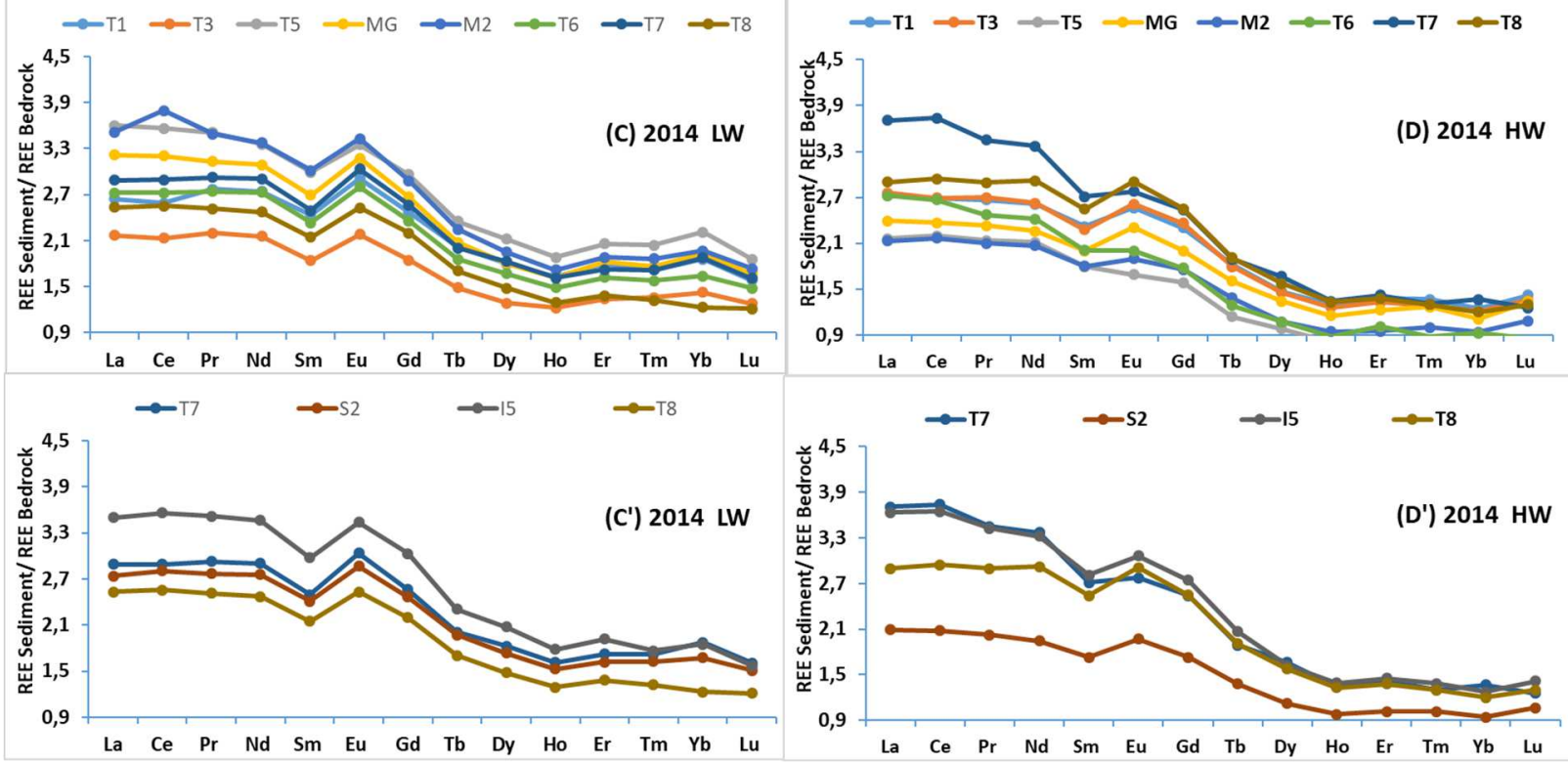

543 Fig. 3: Normalised REE patterns for each Tafna site and for the four sampling periods using the mean

544 local bedrock as a normaliser (A, A': low water (LW) in February 2015; B, B': high water (HW) in

545 February 2015; C, C': low water (LW) in June 2014; D, D': high water (HW) in October 2014),

546 calculated by dividing the basin into two parts: A, B, C, D the Tafna river with T1, T3, T5, MG, M2,

547 T6, and T7 stations; A', B', C', D' the right hand tributary including the Isser River with S2, DamS,

548 and $\mathrm{I} 5$ and the Tafna downstream part T8 and T7 (the T7 station was included also in this group to

549 evaluate its influence on the outlet station). 
552 Table 4: Concentrations of EDTA extractable REE (except Sm and La, Ce, and Nd in MG, which were 553 below the detection limit) in Tafna River bed sediments (\% of total content) from the sampling 554 stations during two contrasting hydrological conditions (high water, HW, October 2014) and (low 555 water, LW, June 2014).

\begin{tabular}{|c|c|c|c|c|c|c|c|c|c|c|c|c|c|c|c|}
\hline \multirow{2}{*}{$\begin{array}{l}201 \\
4 \\
\end{array}$} & \multirow{2}{*}{$\begin{array}{l}\text { Statio } \\
\mathrm{n}\end{array}$} & \multicolumn{14}{|c|}{ Extractable REE $\left(\mu \mathrm{g} \cdot \mathrm{g}^{-1}\right)$} \\
\hline & & La & $\mathrm{Ce}$ & $\mathrm{Pr}$ & $\mathrm{Nd}$ & $\begin{array}{l}\mathrm{S} \\
\mathrm{m}\end{array}$ & $\mathrm{Eu}$ & $\mathrm{Gd}$ & $\mathrm{Tb}$ & Dy & Ho & $\mathrm{Er}$ & $\mathrm{Tm}$ & $\mathrm{Yb}$ & $\mathrm{Lu}$ \\
\hline \multirow[t]{20}{*}{ HW } & \multirow[t]{2}{*}{$\mathrm{T} 1$} & 1.4 & 3.7 & 0.4 & 1.9 & - & 0.1 & 0.4 & 0.0 & 0.3 & 0.0 & 0.1 & 0.0 & 0.1 & 0.02 \\
\hline & & 0 & 0 & 6 & 5 & & 0 & 6 & 7 & 3 & 6 & 5 & 2 & 1 & \\
\hline & \multirow[t]{2}{*}{ T3 } & 1.7 & 4.5 & 0.5 & 2.4 & - & 0.1 & 0.5 & 0.0 & 0.4 & 0.0 & 0.1 & 0.0 & 0.1 & 0.02 \\
\hline & & 3 & 0 & 8 & 2 & & 3 & 8 & 8 & 0 & 7 & 8 & 2 & 3 & \\
\hline & \multirow[t]{2}{*}{ T5 } & 0.8 & 1.8 & 0.2 & 1.0 & - & 0.0 & 0.2 & 0.0 & 0.1 & 0.0 & 0.0 & 0.0 & 0.0 & 0.01 \\
\hline & & 0 & 0 & 5 & 4 & & 6 & 4 & 4 & 7 & 3 & 8 & 1 & 5 & \\
\hline & \multirow[t]{2}{*}{ MG } & 0.9 & 2.2 & 0.3 & 1.2 & - & 0.0 & 0.3 & 0.0 & 0.2 & 0.0 & 0.1 & 0.0 & 0.0 & 0.01 \\
\hline & & 3 & 0 & 1 & 9 & & 7 & 1 & 5 & 2 & 4 & 0 & 1 & 8 & \\
\hline & \multirow[t]{2}{*}{$\mathrm{M} 2$} & 0.7 & 1.7 & 0.2 & 0.9 & - & 0.0 & 0.2 & 0.0 & 0.1 & 0.0 & 0.0 & 0.0 & 0.0 & 0.01 \\
\hline & & 1 & 7 & 2 & 2 & & 5 & 3 & 3 & 6 & 3 & 7 & 1 & 5 & \\
\hline & \multirow[t]{2}{*}{ T6 } & 0.7 & 1.5 & 0.2 & 0.9 & - & 0.0 & 0.2 & 0.0 & 0.1 & 0.0 & 0.0 & 0.0 & 0.0 & 0.01 \\
\hline & & 7 & 4 & 4 & 7 & & 6 & 5 & 4 & 8 & 3 & 8 & 1 & 6 & \\
\hline & \multirow[t]{2}{*}{ T7 } & 1.2 & 3.1 & 0.4 & 1.6 & - & 0.1 & 0.4 & 0.0 & 0.3 & 0.0 & 0.1 & 0.0 & 0.1 & 0.02 \\
\hline & & 6 & 2 & 1 & 9 & & 0 & 1 & 6 & 1 & 6 & 5 & 2 & 1 & \\
\hline & \multirow[t]{2}{*}{ S2 } & 0.8 & 2.0 & 0.2 & 1.1 & - & 0.0 & 0.2 & 0.0 & 0.1 & 0.0 & 0.0 & 0.0 & 0.0 & 0.01 \\
\hline & & 5 & 2 & 8 & 6 & & 6 & 7 & 4 & 9 & 3 & 9 & 1 & 7 & \\
\hline & \multirow[t]{2}{*}{15} & 1.0 & 2.6 & 0.3 & 1.5 & - & 0.0 & 0.3 & 0.0 & 0.2 & 0.0 & 0.1 & 0.0 & 0.0 & 0.01 \\
\hline & & 8 & 0 & 7 & 4 & & 9 & 6 & 5 & 6 & 5 & 2 & 2 & 9 & \\
\hline & \multirow[t]{2}{*}{ T8 } & 1.1 & 2.7 & 0.3 & 1.6 & - & 0.0 & 0.4 & 0.0 & 0.2 & 0.0 & 0.1 & 0.0 & 0.0 & 0.01 \\
\hline & & 4 & 3 & 9 & 9 & & 9 & 0 & 6 & 8 & 5 & 3 & 2 & 9 & \\
\hline \multirow[t]{19}{*}{ LW } & \multirow[t]{2}{*}{$\mathrm{T} 1$} & 1.5 & 3.8 & 0.5 & 2.1 & - & 0.1 & 0.5 & 0.0 & 0.3 & 0.0 & 0.1 & 0.0 & 0.1 & 0.02 \\
\hline & & 4 & 1 & 0 & 5 & & 2 & 0 & 7 & 5 & 6 & 6 & 2 & 1 & \\
\hline & \multirow[t]{2}{*}{ T3 } & 0.9 & 2.1 & 0.2 & 1.2 & - & 0.0 & 0.3 & 0.0 & 0.2 & 0.0 & 0.1 & 0.0 & 0.0 & 0.01 \\
\hline & & 2 & 3 & 9 & 4 & & 7 & 0 & 4 & 1 & 4 & 0 & 1 & 7 & \\
\hline & \multirow{2}{*}{ T5 } & 1.2 & 3.0 & 0.3 & 1.6 & - & 0.0 & 0.4 & 0.0 & 0.2 & 0.0 & 0.1 & 0.0 & 0.0 & 0.01 \\
\hline & & 0 & 0 & 8 & 3 & & 9 & 0 & 6 & 9 & 5 & 3 & 2 & 9 & \\
\hline & \multirow[t]{2}{*}{ MG } & - & - & 0.2 & - & - & 0.0 & 0.3 & 0.0 & 0.2 & 0.0 & 0.1 & 0.0 & 0.0 & 0.01 \\
\hline & & & & 6 & & & 7 & 1 & 4 & 2 & 4 & 0 & 1 & 7 & \\
\hline & \multirow[t]{2}{*}{ M2 } & 0.7 & 3.6 & 0.2 & 1.0 & - & 0.0 & 0.2 & 0.0 & 0.1 & 0.0 & 0.0 & 0.0 & 0.0 & 0.01 \\
\hline & & 8 & 4 & 4 & 0 & & 6 & 6 & 4 & 8 & 3 & 8 & 1 & 6 & \\
\hline & \multirow[t]{2}{*}{ T6 } & 0.8 & 1.7 & 0.2 & 1.1 & - & 0.0 & 0.2 & 0.0 & 0.2 & 0.0 & 0.0 & 0.0 & 0.0 & 0.01 \\
\hline & & 4 & 6 & 6 & 2 & & 6 & 8 & 4 & 0 & 4 & 9 & 1 & 7 & \\
\hline & T7 & 1.2 & 3.1 & 0.4 & 1.7 & - & 0.1 & 0.4 & 0.0 & 0.3 & 0.0 & 0.1 & 0.0 & 0.1 & 0.02 \\
\hline & & 8 & 6 & 1 & 3 & & 0 & 2 & 6 & 1 & 6 & 5 & 2 & 1 & \\
\hline & S2 & 0.9 & 2.3 & 0.3 & 1.3 & - & 0.0 & 0.3 & 0.0 & 0.2 & 0.0 & 0.1 & 0.0 & 0.0 & 0.01 \\
\hline & & 3 & 0 & 1 & 1 & & 7 & 1 & 5 & 3 & 4 & 0 & 1 & 8 & \\
\hline & 15 & 1.2 & 2.9 & 0.4 & 1.7 & - & 0.1 & 0.4 & 0.0 & 0.3 & 0.0 & 0.1 & 0.0 & 0.1 & 0.01 \\
\hline & & 3 & 6 & 1 & 4 & & 0 & 1 & 6 & 0 & 5 & 4 & 2 & 0 & \\
\hline & T8 & 0.9 & 2.1 & 0.3 & 1.3 & - & 0.0 & 0.3 & 0.0 & 0.2 & 0.0 & 0.1 & 0.0 & 0.0 & 0.01 \\
\hline
\end{tabular}


The concentrations of REE extracted from the sediment with EDTA mentioned in Table 4

558 were in the order LREE > MREE > HREE.

559 The pattern of the percentage of extractable REE fractions relatively to the total concentration in sediments was calculated for the two hydrological conditions in 2014 (Fig. 4 A, B), and the ratio of these percentage is presented in Fig. 4 C, D for the various stations. Note that due to analytical detection limit, Sm is not mentioned.

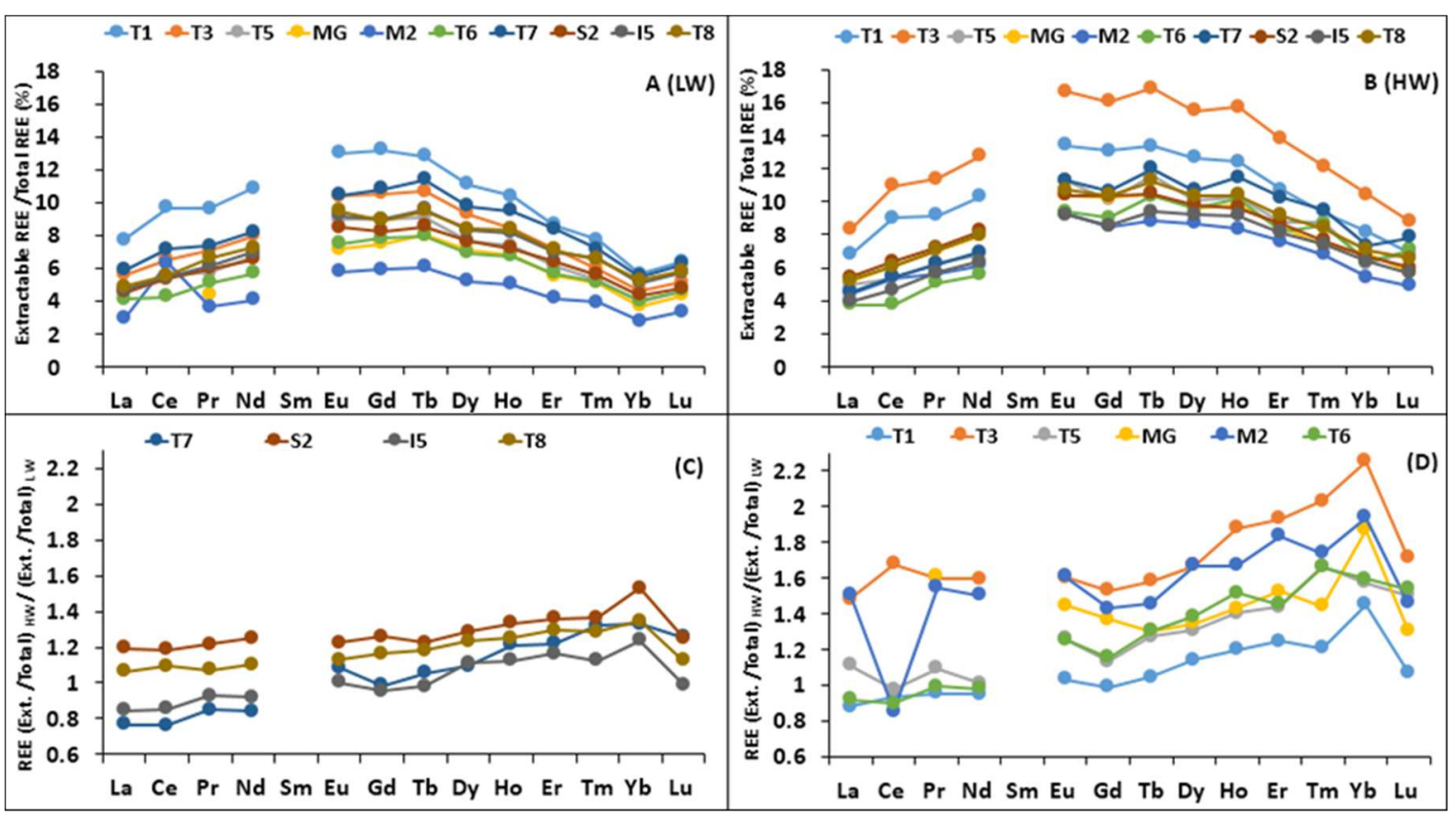

568 Fig. 4 A, B: Ratio between EDTA extractable REE (except Sm) and the total REE in the Tafna River 569 bed sediments (expressed in \%) during low water conditions (low water, LW, June 2014) and high 570 water conditions (HW, October 2014), respectively; C, D: ratio of the above ratio (high water 571 condition to low water condition) for right hand tributaries and major course stations of the Tafna, 572 respectively. Ext. means extractable. Note that due to the analytical detection limit, Sm was not 573 detected. 
574 Considering all the stations, the percentage of REE in the non-residual fraction was rather low 575 (mean $8 \%$ of the total REE, range 0 to $17 \%$ ) and quite homogenous (Fig. $4 \mathrm{~A}, \mathrm{~B}$ ). The 576 ranges of the extractable fraction did not have the same ranking as the concentrations, and 577 was as follows: MREE>HREE>LREE. This is consistent with the observations of Leleyter et 578 al. (1999) for the carbonated Sebou River. The highest values were observed during high flow 579 conditions (except for LREE for some stations: T1, T6, T7, and I5). The highest proportion of 580 extractable REE was found for T3 and T1 (Tafna upstream stations, Fig. 1), whereas the 581 lowest was found for MG, T6, and M2 (Fig. 4 A, B).

582 The proportion of extractable LREE varied (0 to $13 \%$ ), with $\mathrm{Nd}$ being the most extractable 583 element $(13 \%)$ in T3, except $\mathrm{Ce}$ in M2, and La the least extractable element (0 to $8 \%)$. For 584 MREE, Eu (6 and $17 \%)$ and Gd (6 and 16\%) were the most extractable elements. For HREE, 585 the most extractable REE were in the order $\mathrm{Tb}>\mathrm{Ho}>\mathrm{Dy}>\mathrm{Er}>\mathrm{Tm}>\mathrm{Yb}>\mathrm{Lu}$ (between $17 \%$ (Tb) 586 and $3 \%(\mathrm{Yb}=\mathrm{Lu}))$. From Fig. $4 \mathrm{C}, \mathrm{D}$, it is obvious that for all stations, HREE were the more 587 extractable during high water flow conditions than low water flow conditions. In contrast, no 588 difference between the flow conditions was observed for LREE (T5, T6, and T1) or LREE 589 were more extractable in low water conditions (I5, T7, and Ce in M2). For high water 590 conditions, the highest extractability was observed at stations T3 and M2 (1.4 to 2.2 times), 591 and to a lesser extent at MG, T6, and S2, particularly for MREE and HREE. Note also that Yb 592 was the most extractable REE during high water flow relative to the low water condition, for 593 all the stations except T6.

\section{Discussion}

As a whole, the REE concentrations in the Tafna sediments (Table 2) were in the range of 600 other rivers draining carbonates (Leleyter, 1998; N'Guessan, 2008), even if the sediments had a higher content of carbonates. However, the REE concentrations in the river sediments were higher than that of the mean Tafna bedrock, which itself was in the range of other carbonate rocks. The highest REE concentrations were observed at the I5 and DamB stations, and the lowest ones in the upper Tafna (T1, T3) were outliers compared to the other stations. The 605 REE concentrations in sediments and the normalisation to PAAS were not too dissimilar to 
those found in rivers draining mining waste (Delgado et al., 2012) and were consistent with other sediments draining carbonates normalised to PAAS (Sebou River, Leleyter et al., 1999; Gascogne Rivers, N'Guessan, 2008). However, the normalisation to local bedrock (Fig. 2 and 3) particularly indicated a high LREE enrichment and to a lesser extent an enrichment of MREE, and a strong fractionation between LREE, MREE, and HREE. The influence of the bedrock composition on the REE pattern was thus obvious, indicating that PAAS was not convenient as a reference, since except for MREE, it overestimated the sediment REE depletion. The normalisation pattern to local bedrock was indeed in agreement with the processes classically observed for river transport downstream and erosion (relative impoverishment of HREE) (Mao et al., 2014; Fiket et al., 2017). The LREE and MREE enrichments were rather homogenous and not very high, which argued for a main natural weathering origin (McLennan and Taylor, 2012). However, the strongest LREE and MREE enrichment for some stations might not exclude a contribution by local pollution (Borrego et al., 2004; Brito et al., 2018). An MREE enrichment has also been observed in a case of acid mine drainage contribution (Delgado et al., 2012). In the Tafna basin, no obvious mining exploration has been performed, however, some dust from Moroccan mines has been identified to be a source of atmospheric lead deposition in the basin (Benabdelkader et al., 2018). Therefore, the origin of REE from dust deposition in river sediments and the products of soil erosion could not be completely excluded.

On the whole, without considering hydrological conditions, the stations with the highest LREE and MREE enrichment were MG, M2, DamB, T5, and I5 (Fig. 3), and these stations also exhibited an enrichment of other metals, such as $\mathrm{Pb}, \mathrm{Cd}$, and $\mathrm{Zn}$ (Benadelkahader et al., 2018). Surprisingly, T6, which was a highly enriched station for most metals, presented only a mean REE enrichment compared to other stations, whereas station MG (in LW in 2014 and HW in 2015) was one of the most enriched station for LREE and MREE (Fig. 3 B, C). For $\mathrm{MG}$, this was consistent with the high contamination of $\mathrm{Pb}, \mathrm{Zn}, \mathrm{Cu}$, and $\mathrm{Cd}$ already evidenced as a result of the Maghnia industrial unit upstream (Taleb, 2004; Benabdelkader et al., 2018, Fig. 1) and potential agricultural inputs (namely phosphate fertilisers, Benabdelkader et al., 2018). The variety of industries drained by the tributaries Ourdeffou and El Abbes, with the punctual discharge of ores processing and wastewater into the watercourses, could be one of the origins of LREE and MREE enrichment, as already mentioned for other metals (Benabdelkader et al., 2018). 
The similar REE pattern and enrichment intensity of REE in M2 and MG sediments (even slightly lower for M2, except in LW in 2014; Fig. 3), was expected, since station M2 receives the inputs of MG (Fig. 3 and Fig. 1).

The very high enrichment of LREE and MREE in LW at the T5 station (Fig. 3 A, C) and in both hydrological conditions at I5 (to a lesser extent in LW 2015, Fig. 3 A') was questionable. Indeed, these stations were located close to the CERTAF and CERAMIR ceramic factories, respectively, with the punctual release of industrial wastes into the rivers. The ceramic factories used kaolin, which is enriched in REE and Yttrium (Höhn et al., 2014), and also in pure colourants containing REE (Preinfalk and Morteani, 1989). The high concentration of Y observed in I5 and T5 (Table 2), as well as the highest proportion of anthropogenic Gd (between 16 and $18 \%$, Di Leonardo et al., 2009), also argues for an anthropogenic contribution. This latter finding might originate from the release of waste waters (Bau et al., 2006; Mao et al., 2014), especially in the rivers flowing through densely populated and industrial areas (Tlemcen, Maghnia, and Oujda). Indeed, the increase in Gd in river water downstream of big cities was shown to come in particular from hospital medical waste due to its use as a contrasting agent in magnetic resonance imaging (Bau and Dulski, 1996; Moller et al., 2002), which is the case in Tlemcen and Maghnia (the regional centre for this instrumentation). As already mentioned, Gd was known to be transported mainly as a dissolved fraction in river water (Kulaksiz and Bau, 2013); the low enrichment attested to the low affinity of the solid fraction. Nevertheless, particularly at the stations receiving medical waste (MG and S2), the positive anomalies and the Gd anthropic contribution (reaching up to $16 \%$ ) attest to some anthropic influence, in agreement with other authors (Di Leornardo et al., 2009). The high S and P concentrations, especially in MG and S2 (5.75 and $2.98 \mathrm{mg} \mathrm{g}^{-1}$, 1.51 and $2.27 \mathrm{mg} \mathrm{g}^{-1}$ respectively, SM Table 1), might also attest to domestic waste influences or phosphogypsum waste contamination (Tranchida et al., 2011), which could have favoured Gd release. Otherwise, on the whole, sediment contamination by Gd remains low, as indicated by the rather low concentrations compared to those of other stream sediments from Europe (Migasweski and Galuszka, 2015). If any anthropogenic waste inputs contribute Gd, there is only a weak retention of $\mathrm{Gd}$ in river bed sediment of the whole basin.

Nevertheless, during the high flow conditions, the $(\mathrm{La} / \mathrm{Yb}) \mathrm{n}$ ratio was always higher than 2 (Table 3) for this group of stations (MG, M2, T5, and I5) which indicates that erosion was probably one of the main causes of the relative LREE and MREE enrichment. These stations are the outlets of the upper main Tafna course and of the main tributaries, where the slopes 
and erosion rates are the most important (Tidjani et al., 2006; Bouanani et al., 2013). The absence of a significant correlation between the REE and most of the trace metals having an anthropogenic source (Benabdelkader et al., 2018) suggests that the high erosion processes occurring in the upper catchments might have "hidden" the pollution influence, as already mentioned for the I5 station for metals (Benabdelkader et al., 2018). Only Ni and Co were strongly linearly related with LREE and MREE (the lighter the REE, the stronger the relationship) in the 2014 campaigns, suggesting a common control by clay minerals (McLennan, 2001).

The positive Eu-anomaly observed at all Tafna sampling sites (Table 3, Fig. 3) could be associated with the presence of feldspars (Ramesh et al., 2000; Aubert et al., 2001; Sow et al., 2018), which were enriched in the Tafna basin (Boukhedimi, 2009). The highest Eu-anomaly most frequently observed at upstream stations (Table 3, Fig. 6, see below) was consistent with the presence of less weathered material such as feldspar (Nyakairu and Koeberl, 2001), and was also related to the higher carbonate content than downstream (SM Table 1). Indeed, the $\mathrm{Eu}$ anomaly in sedimentary rocks was usually interpreted as being inherited from igneous source rocks (Taylor and McLennan, 1985; McLennan and Taylor, 1991; Awwiller, 1994) and has already been observed in carbonated sediments (Leleyter et al., 1999).

The $\mathrm{Ce}^{*}$ anomaly observed at $\mathrm{M} 2$, and to a lesser extent $\mathrm{I} 5$, could be explained by a complexation by Mn and Fe oxides at these stations (Braun et al. 1990; see SM Table 1) in combination with a higher $\mathrm{pH}$ (data not shown, Benabdelkader, $\mathrm{PhD}$ in process) and carbonate content. Moreover, during low water conditions in 2014, at M2, a high alga development associated with a silty/clayey sediment (Table 1) could also explain the $\mathrm{Ce}$ trapped in sediment.

The elevated concentration of LREE indicates their affinity for solid fractions (Ramesh et al. 1999). However, for all stations, the MREE and the lightest HREE (Eu, Gd, Tb, Dy, and Ho, Fig. 4, B) were the most extractable REE i.e. the fraction of REE leachable from sediments, relative to the total REE. Indeed, the most extractable REE relative to the total content (i.e. MREE and HREE) were generally complexed with Fe-Mn oxides, contrary to LREE, which were preferentially bound to the residue (see Leleyter et al. 1999 for a similar carbonated basin). Despite a weak enrichment, the highest REE extractability detected for the upper Tafna stations (T1, T3; Fig. 3 and Fig. 4 A, B) compared to M2, MG, and T6 was consistent with previous results for metal trace elements (Benabdelkader et al., 2018). It confirmed the 
idea that the extractability of these elements was not proportionally linked to their relative enrichment. Consequently, the stations with a high proportion of extractable REE (i.e. potentially available) might be more hazardous in term of metal accessibility for living organisms than more contaminated ones with less extractable metals.

\subsection{Influence of anthropogenic and natural factors on REE patterns along the river}

\subsubsection{Role of dams}

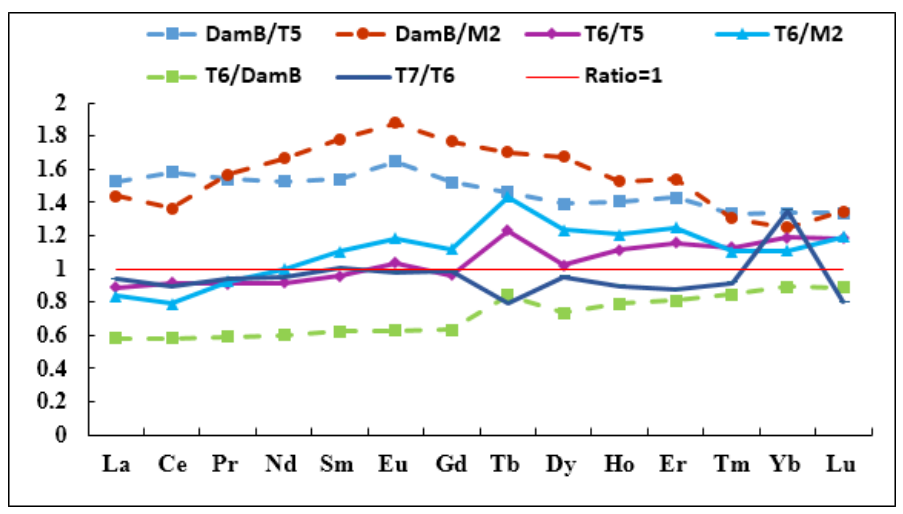

Fig. 5: REE concentration ratios between downstream and upstream stations of the Tafna River surrounded by DamB (see Fig. 1) in HW conditions (February 2015). DamB sediment was sampled in low water conditions. Dotted line indicates the stations influenced by (or influencing) the dam.

The ratio between the REE concentrations in the sediments from downstream and upstream stations surrounded by DamB and the two river inputs to the dam (T5 and M2) enabled us to evaluate the role of the dam in REE distributions (Fig. 5). This was not possible to do for DamS. The ratios (DamB/M2 and DamB/T5) indicated the most enriched pattern (in decreasing order, except $\mathrm{La}, \mathrm{Ce}$ and $\mathrm{Yb}$ ) in the dam mainly for MREE and LREE, and particularly for MREE in the dam relatively to the M2 station. Consequently, despite a lower discharge, the upper Tafna River (T5 station) had a greater influence on the REE composition of DamB than the tributary Mouillah (M2 station), as has already been observed for other trace metals (Benabdelkader et al., 2018).

The ratio between the REE concentrations in sediments from the T6 station (located immediately downstream) and those of the upper stations (T5, M2) and DamB evidenced the influence of DamB on the REE pattern downstream the Tafna river. The three patterns of ratios indicated a slight (T6/T5 and T6/M2) and a more pronounced depletion of LREE (T6/DamB). For MREE and HREE, the enrichment patterns relative to LREE were consistent, 
however, although T6 was strongly depleted compared to DamB, it was enriched compared to T5 and M2 (ratio >1). Consistent with the above observations, the enrichment was more pronounced relatively to M2. We can thus conclude that DamB accumulated LREE, and to a lesser extent MREE, originating in the upper Tafna (T5). Moreover, M2 was diluted by the inputs of the Mouillah basin. This contributed to the maintenance of the REE composition after the Dam, not too far from the upper river inputs (ratios T6/T5 and T6/M2 around 1). In contrast, from $\mathrm{Gd}$ to $\mathrm{Lu}$ (and even $\mathrm{Sm}$ and $\mathrm{Eu}$ for the T6/M2 ratio), a ratio higher than 1 -or increasing in a similar way (likeT6/DamB compared with T6/T5 and T6/M2)- indicated a removal of REE (by mechanical erosion or resuspension with dam releases) previously accumulated in the dam, which enriched the station T6 downstream. This has already been observed for other dams for REE (LREE retention, as noticed by Audry et al., 2004) or other metals (Varol, 2013; Coynel et al., 2007; Benalbelkader et al., 2018).

Finally, downstream the Tafna course, the ratio between the T7 and T6 stations indicated that the LREE did not change (ratio close to 1, no extra inputs), contrary to the HREE (from Tb to $\mathrm{Lu}$ ), which continued to be depleted following erosion processes. The positive ratio (T6/DamB, T6/T5, and T6/M2, Fig. 5) indicated that the enrichment observed for Tb at the T6 station (§3.3.2) did not resulting from an input from the dam and the upstream stations (T5 or M2). Without any other identified sources, a local contamination by electronic waste between DamB and the T6 station cannot be excluded, since, for example, Tb was used in the manufacture of screen and electronic products. The negative anomaly at T7 indicates a dilution downstream. In contrast, the enrichment of $\mathrm{Yb}$ observed at $\mathrm{T} 7$, as indicated by the positive T7/T6 ratio (Fig. 5), might be due to fertiliser inputs (Kabata-Pendias, 2010), as already mentioned for the $\mathrm{Cd}$ and $\mathrm{Cu}$ enrichment in this area (Benabdelkader et al., 2018).

Without any hydrological breakdown along rivers, the $(\mathrm{La} / \mathrm{Yb}) \mathrm{n}$ ratio usually increases from upstream to downstream (Mao et al., 2014), illustrating the relative depletion of HREE. In the Tafna basin, this was the case in the upper Tafna, however, DamB led to a decrease in this ratio (as shown at T6, except in HW in 2014, Table 3). LREE removal from a dam located upstream of the T5 station (DamE, not sampled, Fig. 1) might also explain the increased enrichment in LREE for this station in high water conditions.

\subsubsection{Role of hydrology and erosion}




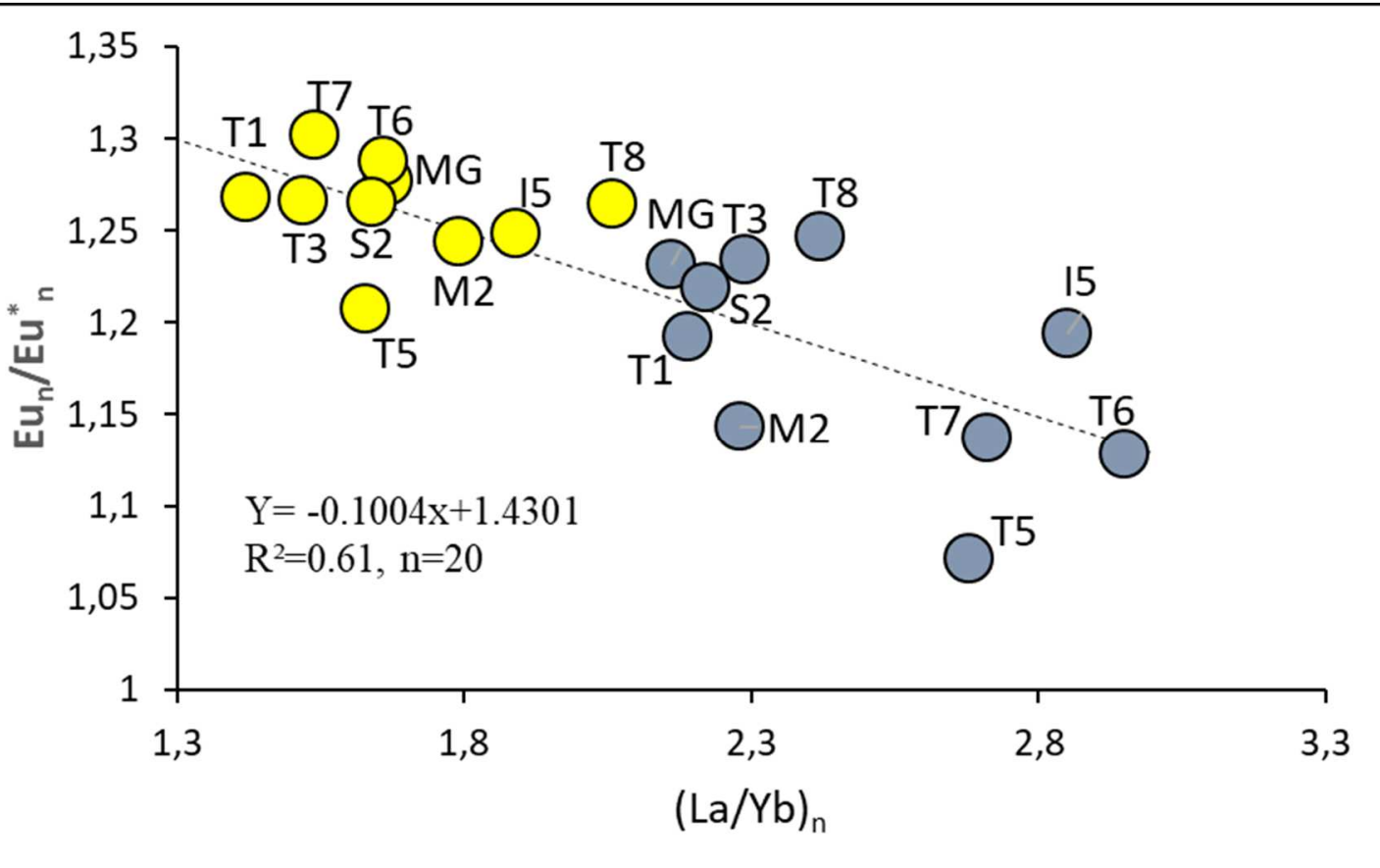

767

768

769

770

771

772

773

774

775

776

777

778

779

780

781

782

783

784

785

786

Fig. 6: Relationship between the Eu anomaly and $\mathrm{La} / \mathrm{Yb}$ ratio in sediments from the different Tafna stations during two contrasting hydrological conditions during the 2014 campaign (high water in yellow and low water in blue).

Differences were observed for REE enrichment, the REE normalised ratio, and REE anomalies with different flow conditions. The decrease in REE enrichment (Fig. 3) observed during the highest flow conditions (i.e. HW 2015) could be related to the main dilution process by particle erosion (Benoit and Rozan, 1999), which might also explain the fractionation decrease (HW 2015 and HW 2014) for the upstream stations T1 and T5. In contrast, the increasing enrichment observed at MG, M2, I5, and S2 in 2015 might be related to the remobilisation of REE due to the high discharge in combination with erosion processes (see 4.1). In 2014, the lowest discharge during the high flow period compared to that of 2015 was less efficient in term of the erosion or remobilisation processes for these stations. The stronger fractionation between LREE, MREE, and HREE observed between the high water and low water conditions as indicated by the increase in $(\mathrm{La} / \mathrm{Yb})_{\mathrm{n}}$ and $(\mathrm{Sm} / \mathrm{Yb})$ ratios (Fig. 3; Table 3), revealed that the main remobilisation of LREE-MREE was due to particle erosion with a high discharge. However, as already mentioned, a potential anthropogenic contribution cannot be excluded for MG and M2, consistent with other metals (Benabdelkader et al., 2018). This fractionation demonstrated by the higher positive ratios $(\mathrm{La} / \mathrm{Yb}) \mathrm{n}$ and $(\mathrm{Sm} / \mathrm{Yb}) \mathrm{n}$ with high flow, might illustrate the progressive contribution of intermediate and felsic rocks by erosion processes (McLennan, 1989; Ramesh et al., 1999; Brito et al., 2018). Nevertheless, 
the slight depletion of HREE in sediments would also result in their greater tendency to form stable soluble complexes than LREE and MREE, and thus to be preferentially transported in overlying water instead of accumulating in the sediments (Fleet, 1984; Millero, 1992; Kuss et al., 2001; Sappal et al., 2014).

The most important fractionation was observed for T6, I5, T7, and T5 during the 2014 campaign, as indicated by the significant negative relationship between the Eu anomaly and $\mathrm{La} / \mathrm{Yb}$ ratio (Fig. 6). This relationship was, however, not significant for the 2015 campaign. As well as for $\mathrm{T} 5$, the fractionation increase at station I5 was also related to the increase in particulate erosion in this tributary (as demonstrated for other metals by Benalbelkader et al., 2018). A dilution by the sediments removed from DamS in this active erosive part of the basin was also possible since we demonstrated that dams more easily retained LREE than others REE (as also shown by Audry et al., 2004). Moreover, high flow also contributed to the decrease in the positive Eu anomaly (Fig. 6 for the 2014 campaign; observable in Table 3 for the 2015 campaign, even though the relationship was not significant). This illustrated changes in the texture and/or mineralogy of the sediment, noticeably the relative importance of feldspar in the sediment fraction (i.e. M2 and T5, such stations being located at the outlet of high erosive areas, Tidjani et al., 2006; Bouanani et al., 2013).

The influence of hydrological conditions on the Gd anomaly for the MG and S2 stations was not clearly detected. In contrast, the low water conditions greatly increased the $\mathrm{Ce}^{*}$ at the M2 station, since they favoured changes in oxido-reduction and other environmental conditions (see. 4.1). The leaching of upstream electronic waste and fertiliser inputs might be a hypothesis to explain the high anomalies observed for $\mathrm{Tb}$ (T6) and $\mathrm{Yb}$ (T7) during high flow conditions, respectively.

The similarity of REE patterns between the outlet station T8, DamS, and T7, as well as for I5 particularly during high flow conditions (to a lesser extent for LREE and MREE, Fig. 3), indicates the strong influence of the Tafna main course on the outlet REE enrichment and the similarity of the exported material during high water conditions. However, as mentioned for other metals (Benalbelkader et al., 2018), the geomorphology (shallower slope with the presence of very significant meanders) and sedimentation process might have contributed to metal storage, and thus slightly modified the $\mathrm{La} / \mathrm{Yb}$ ratio between the $\mathrm{T} 6$ and $\mathrm{T} 7$ stations (Fig. 6; Table 3). 
Finally, the extractability of REE in the order MREE>HREE>LREE (consistent with other studies, Zhang and Gao, 2015) increased during high flow conditions due to remobilisation following desorption processes with a change in physicochemical conditions, particularly for HREE (namely Yb, Fig. 4 C, D) (Xu et al., 2012).

\subsubsection{Role of particle size and chemical characteristics}

The influence of the main physico-chemical factors on the REE distribution in sediments from the Tafna basin was evaluated by correlating the concentrations of REE with major and trace elements $(\mathrm{Ca}, \mathrm{Al}, \mathrm{Fe}, \mathrm{Mn}, \mathrm{Th}, \mathrm{Y}$, and $\mathrm{U})$, as well as with organic content (POC) and texture (fraction $<63 \mu \mathrm{m}$ ), using a PCA on the contrasting 2015 sampling conditions (Fig. 6, A, B, SM Table 1). These elements and parameters were considered since they are classically known to be key explaining factors of REE behaviour in sediments (Ramesh et al., 1999; Polyakov and Nearing, 2004; Egashira et al., 1997; Bau, 1999; Marmolejo-Rodríguez et al., 2007).

REE usually have a high affinity for carbonates (Elderfield et al., 1990). The Tafna River drained mainly carbonated areas, however, in the Tafna sediments, the REE negatively correlated with $\mathrm{Ca}$. In contrast, they were significantly positively correlated with the clay and silt content (Axis 1; Fig. 6; SM Table 2). The trivalent state and ionic radii ranging between $0.861 \mathrm{~A}^{\circ}\left(\mathrm{Lu}^{3+}\right)$ and $1.03 \mathrm{~A}^{\circ}\left(\mathrm{La}^{3+}\right)$ were similar to those of $\mathrm{Ca}^{2+}$. The REE could thus be easily adsorbed by clay and substitute the Ca present in carbonates (Polyakov and Nearing 2004; Xu et al., 2012; Franchi et al., 2016). Indeed, the strong correlation with silt and clay explained why the REE concentration in sediments was much higher than the local bedrock, which exhibited a higher Ca content (Table 2).

As stated by several authors, we found that the REE concentrations were mainly controlled by grain size and mineralogy (Fig. 7). Usually, the content of REE in terrigenous sediments increased in the silt-clay series and increased when moving from shelf to pelagic areas (Sholkovitz, 1988; Dubinin, 2004; Tranchida et al., 2011). Indeed, consistent with Yang et al. (2002), a higher association of LREE with clay (correlation with axis 2, R between -0.30 and -0.88, SM Table 3) and HREE with coarse silt fractions (correlation with axis 2, R reached 0.66, SM Table 3) was observed. A common geogenic origin and/or control by similar factors (i.e. the texture, organic matter, iron oxides; Aubert et al., 2004) might explain the positive correlation of uranium with HREE (particularly Ytterbium with axis 1, Fig. 7 ) on one side 
850 and of Th with LREE (axis 2) on the other side. The LREE were not increased from 851 phosphatic minerals when the Tafna crossed the area of salt soils between the T6 and T7 852 stations (see Fig. 5). Consequently, grain size controls this relationship rather than the 853 common biogenic, authigenic, and diagenetic origin (Aly and Mohammed, 1999; Borrego et 854 al., 2004). During HW conditions, Fe and Al were also strongly associated with the clay 855 content and LREE, which evidenced the strong control by clay and/or by $\mathrm{Al}$ and Fe-oxides 856 (Egashira et al., 1997; Bau, 1999; Marmolejo-Rodríguez et al., 2007), whereas Mn oxides 857 were not involved (Fig. 7 A, B), as has previously been observed in some soil profiles (Aubert 858 et al., 2004). The opposite pattern between $\mathrm{Ca}$ content and Eu content along axis 1 was 859 consistent with the silicate control of the MREE. The actinides $U$ and Th were often 860 associated with REE as an indicator of origin (Seaborg and Loveland, 1990; Seaborg, 1993). 861 Indeed, the Tafna observations indicated that these two actinides were associated with various 862 REE and physical components: HREE and coarse silt with $U$ and Al-Fe-oxides and LREE 863 with Th. Moreover, it was apparent that POC was not the main controlling factor irrespective 864 of the hydrological condition (Fig. 7). 
865

866

867

868

869

870

871

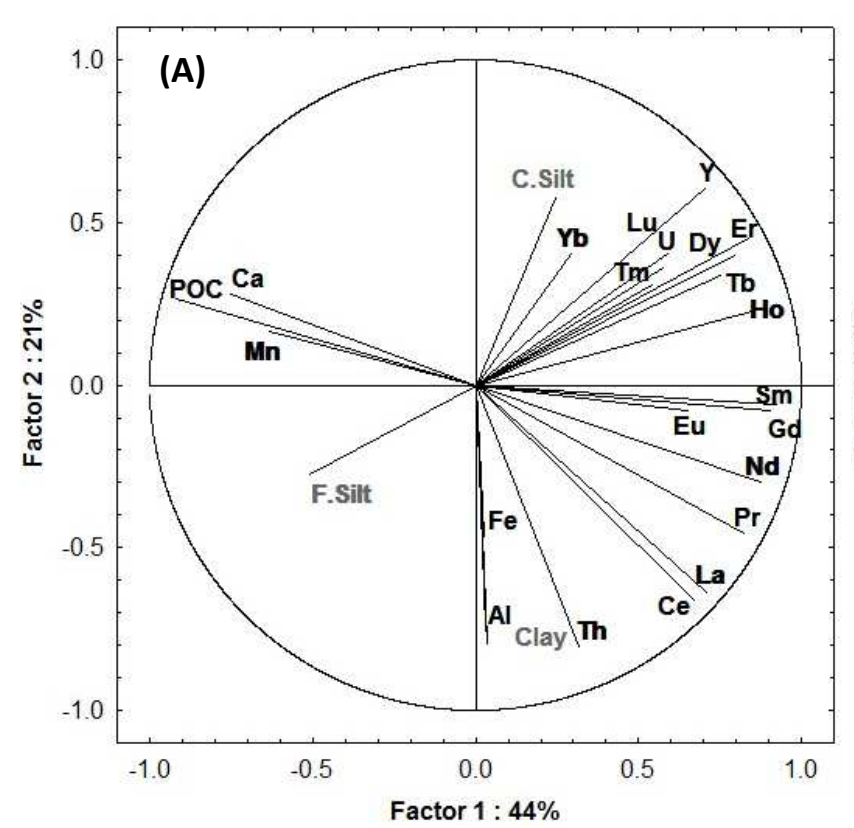

872 hydrological conditions. However, the MG

Compared to the other stations, during high water flow conditions (Fig. 3), a higher REE enrichment was noticed in sediments from station I5 (and to a lesser extent M2 and S2), which could be related to a high fine fraction content. Apart from I5, the clay and fine silt content was higher in low water conditions than in high water conditions, which could explain the higher REE enrichment due to an increased surface adsorption, particularly for LREE (Ramesh et al., 1999; Censi et al., 2004; Dubinin, 2004; Prasad and Ramanathan, 2008). Grain size thus played a key role in controlling the REE distribution in the different

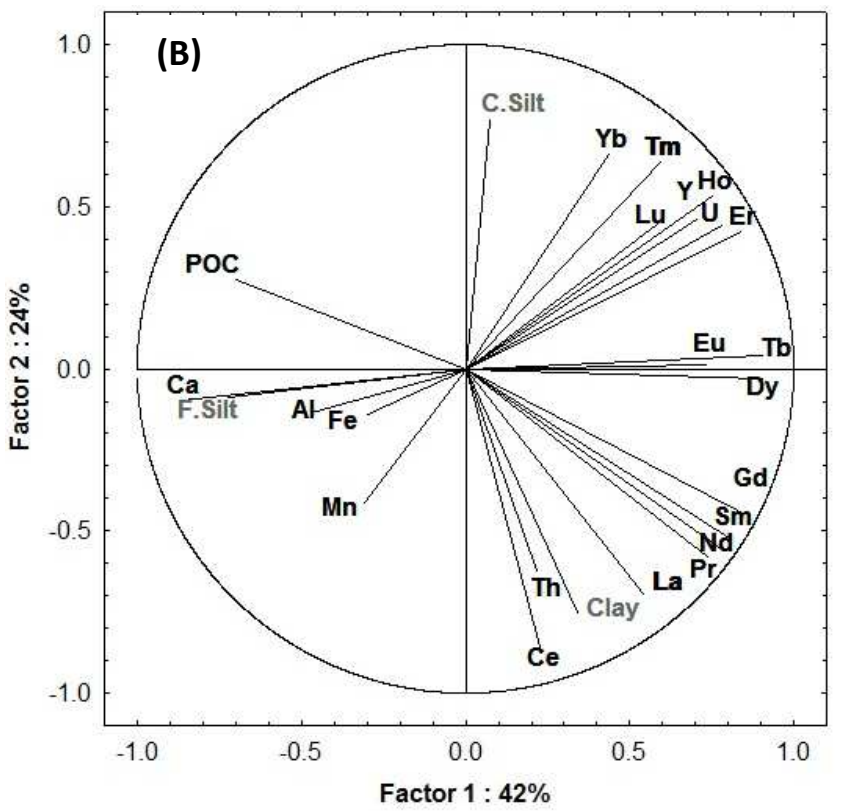

873 station did not follow this rule (high REE enrichment/low fine fraction), even though it received significant anthropogenic inputs. This suggests the control of non-residual REE at this station by parameters other than texture alone (see $\S 4.1$ ).

876

877

878

879

880

881

882

Fig. 7: PCA for REE elements, trace elements (Th, Y, and U), and major elements ( $\mathrm{Al}$ and $\mathrm{Fe}$ ) with grain size and POC (A: high water and B: low water condition).

\section{Conclusion}

The spatial investigation of rare earth elements in the Tafna bed sediments collected during two years with two contrasting hydrological conditions allowed us to evaluate: (i) the range of REE concentrations, (ii) the variation along the river course with regard to low and high water flow conditions, and (iii) the potential contribution of natural and anthropogenic sources, as 
well as the factors explaining their distributions. On the whole, the concentrations were in the range of other carbonated basins, in the following order of abundance $\mathrm{Ce}>\mathrm{La}>\mathrm{Nd}>\mathrm{Pr}>\mathrm{Sm}>\mathrm{Gd}>\mathrm{Dy}>\mathrm{Yb}>\mathrm{Er}>\mathrm{Eu}>\mathrm{Ho}>\mathrm{Tb}>\mathrm{Tm}=\mathrm{Lu}$, and with a high enrichment in LREE and MREE vs. HREE.

Anomalies and various REE ratios were powerful for illustrating REE origins and fractionation processes. The process of erosion was the main driver of the REE distribution patterns and of the fractionation between LREE and HREE from upstream to downstream, which might hide the contribution of some anthropogenic sources, depending on discharge conditions.

A moderate contamination could not be excluded for some LREE and MREE, mostly locally related to several industrial activities, and domestic or medical waste. DamB and the stations MG, S2, I5, and T5 in particular presented some enrichment and/or REE anomalies (MG and $\mathrm{S} 2$ for $\mathrm{Gd}, \mathrm{T} 6$ for $\mathrm{Tb}$, and $\mathrm{T} 7$ for $\mathrm{Yb}$ ) and there was a suspected contribution from anthropogenic activities. Some of these stations had already been identified as contaminated with other metals (Benalbelkader et al., 2018). However, if any contamination was present, the river bed sediments were not major sinks for anthropogenic REE. Non residual LREE were the most concentrated, however MREE and HREE were the most proportionally extractable REE with respect to the total sediment concentration, particularly during high flow conditions. The stations with the most extractable proportion of REE, however, were not those associated with the most enriched sediments.

The hydrological condition influenced the REE distribution and transport downstream depending on the source of the REE and the inner geochemical processes, and by playing a significant role in the determination of grain size. The higher REE enrichment relative to local bedrock, the negative correlation between $\mathrm{REE}$ and $\mathrm{Ca}$ in sediment, and the main control of LREE and HREE by clay and coarse silt, respectively, were explained by the erosion process and clay/carbonate content, the similar geochemical characteristics of REE and $\mathrm{Ca}(\mathrm{Ca}$ substitution), and the easier REE adsorption by clay favouring the enrichment of REE. Finally, dams were evidenced to play a role in REE retention (LREE) and to delay the release (MREE and HREE) downstream, constituting a disruption to the natural erosion pattern from upstream to downstream, as illustrated by the $\mathrm{La} / \mathrm{Yb}$ ratio.

These data aimed to contribute to the assessment of continental erosion (which is of great concern to North African countries under hazardous climatic conditions) and the quality of 
river sediment transported by rivers to the Mediterranean Sea, as well as aiding our understanding of the present-day disturbance linked to anthropogenic activities along such rivers.

\section{Authors contribution}

The sampling sites were selected by A. Taleb and N. Belaidi during an early step of the project and validated by A. Probst and A. Benabdelkader for his PhD work. A. Benabdelkader and A. Taleb participated in the sediment sampling and environmental data investigations. A. Benabdelkader and A. Probst managed the sediment preparation, the REE analytical work, and the treatment of the data. A. Benabdelkader and A. Probst contributed equally to writing the paper. A. Taleb, N. Belaidi and J.L. Probst read and annotated the paper.

\section{Acknowledgements}

The authors would like to thank the technicians and engineers from the EcoLab technical platforms (Marie-José Tavella, Virginie Payre-Suc, Frédéric Julien, and David Baqué) and from the ICPMS platform at OMP (Aurélie Lanzanova and Frédéric Candaudap) for their help with preparing samples and/or for elemental analysis, and for their assistance during the ICP analyses and the cleanroom dissolution procedure. Ibrahim Zenagui, Hannane Sebbagh, and Zineb Benkebil are also thanked for their help with field sampling. Anomymous reviewers are thanked for their comments, which contributed to improve the paper.

Amine Benabdelkader received a financial fellowship from The Algerian Ministry of Higher Education. This work was supported by the CNRS in France at EcoLab and the University of Tlemcen in Algeria.

\section{References}

Algerian Ministry of Agriculture, 2011. Type et superficie de l'agriculture de la wilaya de Tlemcen et Ain Temouchent. Alger, Algérie 2011 (in french). 
Aly, M. M., Mohammed, N. A., 1999. Recovery of lanthanides from Abu Tartur phosphate rock, Egypt. Hydrometallurgy, 52, 2, 199-206.

Aubert, D., Stille, P., Probst A., 2001. REE fractionation during granite weathering and removal by waters and suspended loads: $\mathrm{Sr}$ and $\mathrm{Nd}$ isotopic evidence. Geochim. Cosmochim. Acta, 65, 3, 387-406.

Aubert, D., Probst, A., Stille, P., 2004. Distribution and origin of major and trace elements (particularly REE, $\mathrm{U}$ and $\mathrm{Th}$ ) into labile and residual phases in an acid soil profile (Vosges Mountains, France). Applied Geochemistry, 19, 6, 899-916.

Audry, S., Schäfer, J., Blanc, G., Jouanneau, J.M., 2004. Fifty-year sedimentary record of heavy metal pollution $(\mathrm{Cd}, \mathrm{Zn}, \mathrm{Cu}, \mathrm{Pb})$ in the Lot River Reservoirs. Environ. Pollut., 132, 413-426.

Awwiller, D.N., 1994. Geochronology and mass transfer in Gulf Coast mudrocks (southcentral Texas, U.S.A.): Rb - Sr, Sm -Nd and REE systematics. Chem. Geol., 116, 61 - 84.

Baba, Y., Kubota, F., Kamiya, N., Goto, M., 2011. Recent advances in extraction and separation of rare-earth metals using ionic liquids, J. Chem. Eng. Jpn., 44, 679-685.

Bau, M., 1999. Scavenging of dissolved yttrium and rare earths by precipitating iron oxyhydroxide: experimental evidence for Ce oxidation, Y-Ho fractionation, and lanthanide tetrad effect. Geochim. Cosmochim. Acta, 63, 67-77.

Bau, M., Dulski, P., 1996. Anthropogenic origin of positive gadolinium anomalies in river waters. Earth and Planetary Science Letters, 143, 245-255.

Bau, M., Knappe, A., Dulski, P., 2006. Anthropogenic gadolinium as a micropollutant in river waters in Pennsylvania and in Lake Erie, northeastern United States. Chemie der Erde, 66, 143-152.

Bayon, G., Toucanne, S., Skonieczny, C., André, L., Bermell, S., Cheron, S., Germain, Y., 2015. Rare earth elements and neodymium isotopes in world river sediments revisited. Geochim. Cosmochim. Acta, 170, 17-38.

Beckett, P.H.T., 1989. The use of extractants in studies on trace metals in soils, sewage sludge, and sludge-treated soils. Adv. Soil Sci., 9, 143-176.

Benabadji, N., Bouazza, M., 2001. L'impact de l'homme sur la forêt dans la région de Tlemcen, (Oranie - Algérie). Forêt Méditerranéenne. T. XXII, 3, 264 - 274. 
976 Benabdelkader, A., Taleb, A., Probst, J.L., Belaidi, N., Probst, A., 2018. Anthropogenic contribution and influencing factors on metal features in fluvial sediments from a semi-arid Mediterranean river basin (Tafna River, Algeria): A multi-indices approach. Science of the Total Environment, 626, 899-914.

Benoit, G., Rozan, T.F., 1999. The influence of size distribution on the particle concentration effect and trace metal partitioning in rivers. Geochim. Cosmochim.a Acta, 63, 113-127.

Bentellis-Mosbah, A., Azzoug R., Rached, O., Gharzouli R., Soltani, A., 2003. Évaluation du niveau de contamination métallique des sols des berges de l'oued Rhume et étude de son impact sur la végétation riveraine (en amont de la confluence Oued Rhumel-Boumerzoug) (Constantine - Algérie). Sciences \& Technologie, 20, 25-38.

Blomqvist, S., 1990. Sampling performance of Ekman grabs in situ observations and design improvements. Hydrobiologia,. 206, 245-254.

Borrego, J., Lopez-Gonzàlez, N., Carro, B., Lozano-Soria, O., 2004. Origin of the anomalies in light and middle REE in sediments of an estuary affected by phosphogypsum wastes (south-western Spain). Marine Pollution Bulletin, 49, 1045-1053.

Bouanani, A., Baba-Hamed, K., Fandi, W., 2013. Production et transport des sédiments en suspension dans l'oued Sikkak (Tafna - nord-ouest Algérie). Revue des sciences de l'eau, 26, $119-132$.

Boukhedimi, M.A., 2009. Origine du processus de bentonitisation des terrains volcanogènes rhyolitiques de Hammam Boughrara (Maghnia ; Algérie nord occidentale). Magister in Algeria, 101 p. (in French).

Bounouira, H., Choukri, A., Cherkaoui El Moursli, R., Chakiri, S., Said, F., Bounakhla, M., Embarch, K., 2013. Geochemical behaviour of major and trace elements in dissolved and particulate phases of the Bouregreg river (Morocco). J. Radio Anal. Nucl. Chem., 295, 10671083.

Bounouira, H., Choukri, A., Cherkaoui, R., Gaudry, A., Delmas, R., Mariet, C., Hakam, H. K., Chakiri, S., 2008. Multielement analytical procedure coupling INAA, ICP-MS and ICPAES: Application to the determination of major and trace elements in sediment samples of the Bouregreg River (Morocco). J. Radio Anal. Nucl. Chem., 278, 1, 65-79.

Bouraoui, F., Benabdallah, S., Jrad, A., Bidoglio, G., 2005. Application of the SWAT model on the Medjerda river basin (Tunisia). Phys. Chem. Earth, 30, 497-507. 
Braun, J.J., Pagel, M., Muller, J.P., Bilong, P., Michard, A., Guillet, B., 1990. Cerium anomalies in lateritic profiles. Geochem. Cosmochim. Acta, 54, 781-795.

Brito, P., Prego, R., Mil-Homens, M., Caçador, I., Caetano, M., 2018. Sources and distribution of yttrium and rare earth elements in surface sediments from Tagus estuary, Portugal. Science of the Total Environment, 621, 317-325.

Caetano, M., Vale, C., Anes, B., Raimundo, J., Drago, T., Schimdt, S., Nogueira, M., Oliveira, A., Prego, R., 2013. The Condor seamount at Mid-Atlantic Ridge as a supplementary source of trace and rare earth elements to the sediments. Deep. Res. Part II Top. Stud. Oceanogr., 98, 24-37.

Carignan, J., Hild, P., Mevelle, G., Morel, J., \& Yeghicheyan, D., 2001. Routine analyses of trace elements in geological samples using flow injection and low pressure on-line liquid chromatography coupled to ICP-MS: A study of geochemical reference materials BR, DR-N, UB-N, AN-G and GH. Geostandards Newsletter, 25, 187-198.

Censi, P., Mazzola, S., Sprovieri, M., Bonanno, A., Patti, B., Punturo, R., Spoto, S., Saiano, F., Alonzo, G., 2004. Rare earth elements distribution in seawater and suspended particulate of the Central Mediterranean Sea. Chemistry and Ecology, 20, 323-343.

Center for petrographic and geochemical research (CRPG), 2017. Nancy, France. http:// www.crpg.cnrs-nancy.fr/index.php.

Condie, K.C., 1993. Chemical composition and evolution of the upper continental crust: Contrasting results from surface samples and shales. Chemical Geology, 104, 1-37.

Coynel, A., Schafer, J., Blanc, G., Bossy, C., 2007. Scenario of particulate trace metal and metalloid transport during a major flood event inferred from transient geochemical signals. Appl. Geochem., 22, 821-836.

Cullers, R. L., Chaudhuri, S., Arnold, B., Lee, M., Wolf, C.W., 1975. Rare earth distributions in clay minerals and in the clay sized fraction of the Lower Permian Havensville and Eskridge shales of Kansas and Oklahoma. Geochim. Cosmochim. Acta, 39, 12, 1691-1703.

Davranche, M., Pourret, O., Gruau, G., Dia, A., Jin, D., Gaertner, D., 2008. Competitive binding of REE to humic acid and manganese oxide: Impact of reaction kinetics on development of cerium anomaly and REE adsorption. Chemical Geology, 247, 154-170. 
De Baar, H. J. W., Brewer, P. G., Bacon, M. P., 1985. Anomalies in rare earth distributions in seawater: Gd and Tb. Geochim. Cosmochim. Acta, 49, 9, 1961-1969.

Delgado, J., Pérez-López, R., Galván, L., Nieto, J. M., Boski, T., 2012. Enrichment of rare earth elements as environmental tracers of contamination by acid mine drainage in salt marshes: A new perspective. Marine Pollution Bulletin, 64, 9, 1799-1808.

Depetris, P. J., Probst, J. L., Pasquini, A. I., Gaiero, D. M., 2003. The geochemical characteristics of the Paraná River suspended sediment load: an initial assessment. Hydrological Processes, 17, 7, 1267-1277.

Diehl, L. O., Gatiboni, T. L., Maello, P. A., Muller, E. I., Duarte, F, A., 2018. Ultrasound assisted extraction of rare-earth elements from carbonatite rocks. Ultrasonics Sonochemistry, 40, 24-29.

Di Leonardo, R., Bellanca, A., Neri, R., Tranchida, G., Mazzola, S., 2009. Distribution of REEs in box-core sediments offshore an industrial area in SE Sicily, Ionian Sea: evidence of anomalous sedimentary inputs. Chemosphere, 77, 778-784.

Dubinin, A., 2004, Geochemistry of rare earth elements in the ocean: Lithology and Mineral Resources, 39, 289-307.

Ebrahimi, P., Barbieri, M., 2019. Gadolinium as an emerging micro contaminant in water resources: threats and opportunities. Geosciences, 9, 2, 93.

Feng, J. L., 2010. Behaviour of rare earth elements and yttrium in ferromanganese concretions, gibbsite spots, and the surrounding terra rossa over dolomite during chemical weathering. Chemical Geology, 271, 3, 112-132.

Ekman, S., 1911. Neue Apparate zur qualitativen und quantitativen Erforschung der Bodenfauna der Seen. Int. Revueges. Hydrobiol. Hydrogr., 3, 553-561.

Elbaz-Poulichet, F., Seidel, J. L., Othoniel, C., 2002. Occurrence of an anthropogenic gadolinium anomaly in river and coastal waters of Southern France. Wat. Res., 36, 4, 11021105.

Elderfield, H., Greaves, M. J., 1982. The rare earth elements in seawater. Nature, 296, 214 219. 
1064

1065

1066

1067

1068

1069

1070

1071

1072

1073

1074

1075

1076

1077

1078

1079

1080

1081

1082

1083

1084

1085

1086

1087

1088

1089

1090

1091

1092

1093

Elderfield, H., Upstill-Goddard, R., Sholkovitz, E. R., 1990. The rare earth elements in rivers, estuaries, and coastal seas and their significance to the composition of ocean waters. Geochim. Cosmochim. Acta, 54, 4, 971-991.

Egashira, K., Fuji, K., Yamaski, S., Virakornphanich, P., 1997. Rare earth element and clay minerals of paddy soils from the central region of the Mekong River, Laos. Geederma, 78, 237-249.

Fernandez, R. G., Alonso, J. I., 2008. Separation of rare earth elements by anion-exchange chromatography using ethylenediaminetetraacetic acid as mobile phase. Journal of Chromatography A, 1180, 59-65.

Fiket, Z., Mikac, N., Kniewald, G., 2017. Influence of the geological setting on the REE geochemistry of estuarine sediments: A case study of the Zrmanja River estuary (eastern Adriatic coast). Journal of Geochemical Exploration, 182, 70-79.

Fleet, A., 1984, Aqueous and sedimentary geochemistry of the rare earth elements: Rare Earth Element. Geochemistry, 2, 343-369.

Franchi, F., Turetta, C., Cavalazzi, B., Corami, F., Barbieri, R., 2016. Trace elements and REE geochemistry of Middle Devonian carbonate mounds (Maïder Basin, Eastern Anti-Atlas, Morocco): Implications for early diagenetic processes. Sedimentary Geology, 343, 56-71.

Franklin, R. L., Fávaro, D. I. T., Damatto, S. R., 2016. Trace metal and rare earth elements in a sediment profile from the Rio Grande Reservoir, Sao Paulo, Brazil: determination of anthropogenic contamination, dating, and sedimentation rates. J. Radioanal. Nuclear Chem., $307,1,99-110$.

Fuganti, A., Möller, P., Morteani, G., and Dulski, P., 1996. Gadolinio ed altre terre rare usabili come trac- cianti per stabilire l' eta il movimento ed i rischi delle acque sotterranee: esempio dell area di Trento. Geol. Tec. Ambien., 4, 13-18.

Gallello, G., Pastor, A., Diez, A., La Roca, N., Bernabeu, N., 2013. Anthropogenic units fingerprinted by REE in archaeological stratigraphy: Mas d'Is (Spain) case. Journal of Archaeological Science, 40, 799-809.

Garzanti, E., Andòn, S., France-Lanord, C., Vezzoli, G., Censi, P., Galy, V., Najman, Y., 2010. Mineralogical and chemical variability of fluvial sediments. Earth Planet. Sci. Lett., 299, 368-381. 
1094

1095

1096

1097

1098

1099

1100

1101

1102

1103

1104

1105

1106

1107

1108

1109

1110

1111

1112

1113

1114

1115

1116

1117

1118

1119

1120

1121

1122

Ghestem, J. P., Bermond, A., 1998. Extractability of trace metals in polluted soils: a chemical- physical study. Journal of. Environ. Technol., 19, 409-416.

Gonzalez, V., Vignati, D.A.L., Leyval, C., Giamberini, L., 2014. Environmental fate and ecotoxicity of lanthanides: Are they a uniform group beyond chemistry?. Environment International, 71, 148-157.

Govindaraju, K., Mevelle, G., 1987. Fully automated dissolution and separation methods for inductively coupled plasma-atomic emission spectrometry rock analysis. Application to the determination of rare earth elements. Anal. Atom. Spectrom., 2, 615-621.

Gu, Z. M., Wang, X. R., Gu, X. Y., Cheng, J., Wang, L. S., Dai, L. M., Cao, M., 2001. Determination of stability constants for rare earth elements and fulvic acids extracted from different soils. Talanta, 53, 1163-1170.

Guardia, P., 1975. Géodynamique de la Marge Alpine du Continent Africain. D’après l'Etude de l'Oranie NordOccidentale. Relations Structurales et Paléogéographiques Entre le tell Extrème et L'avant Pays Atlassique+Carte au 1/100 000. Thèse de doctorat, Université de Nice, Nice, France, p. 285. (In French).

Gwenzi, W., Mangori, L., Danha, C., Chaukura, N., Dunjana, N., Sanganyado, E., 2018. Sources, behaviour, and environmental and human health risks of high-technology rare earth elements as emerging contaminants. Science of the total environment, 636, 299-313.

Hissler, C., Stille, P., Guignard, C., Iffly, J.F., Pfister, L., 2014. Rare Earth Elements as hydrological tracers of anthropogenic and critical zone contributions: a case study at the Alzette River basin scale. Procedia Earth and Planetary Science, 10, 349 - 352.

Höhn, S., Frimmel, H. E., Pašava, J., 2014. The rare earth element potential of kaolin deposits in the Bohemian Massif (Czech Republic, Austria). Mineralium deposita, 49, 967-986.

Hu, Z. Y., Haneklaus, S., Sparovek, G., Schnug, E., 2006. Rare earth elements in soils. Commun. Soil Sci. Plant Anal., 37, 1381-1420.

Inguaggiato, C., Burbano, V., Rouwet, D., Garzon, D., 2017. Geochemical processes assessed by Rare Earth Elements fractionation at "Laguna Verde" acidic-sulphate crater lake (Azufral volcano, Colombia). Applied Geochemistry, 79, 65-74.

Ferranti, B.A., 2014. Newburgh, United Kingdom. http://www.viewfinderpanoramas.org. 
1123 Kabata-Pendias, A., 2010. Trace Elements in Soils and Plants. Fourth Edition. C. R. C. Press., 1124 p 548.

1125 Khaldi, A., 2005. Impacts de la Sécheresse sur le Régime des Ecoulements Souterrains Dans 1126 les Massifs Calcairesde l'Ouest Algérien "Monts de Tlemcen-Saida". Thèse de doctorat, 1127 Université d'Oran, Oran, Algérie, p. 239. (in French).

1128 Kulaksiz, S., Bau, M., 2007. Contrasting behaviour of anthropogenic gadolinium and natural 1129 rare earth elements in estuaries and the gadolinium input into the North Sea. Earth and 1130 Planetary Science Letters, 260, 1-2, 361-371.

1131 Kulaksiz, S., Bau, M., 2013. Anthropogenic dissolved and colloid/nanoparticle-bound 1132 samarium, lanthanum and gadolinium in the Rhine River and the impending destruction of the 1133 natural rare earth element distribution in rivers. Earth and Planetary Science Letters, 362, 43113450.

1135 Kuss, J., Garbe-Schonberg, C. D., Kremling, K., 2001. Rare earth elements in suspended 1136 particulate material of North Atlantic surface waters: Geochim. Cosmochim. Acta, 65, 1871137199.

1138 Lahlou, A., 1994. Relationship between erosion and energy in North Africa. Renewable 1139 Energy, 5, 1520-1529.

1140 Lawrence, M. G., Ort, C., Keller, J., 2009. Detection of anthropogenic gadolinium in treated 1141 Wastewater in South East Queensland, Australia. water research, 43, 14, 3534-3540.

1142 Lee, S. G., Kim, J. K., Yang, D. Y., Kim, J. Y., 2008. Rare earth element geochemistry and $1143 \mathrm{Nd}$ isotope composition of stream sediments, south Han River drainage basin, Korea. 1144 Quaternary International, 176, 121-134.

1145 Leleyter, L., 1998. Spéciation chimique des éléments majeurs, traces et des terres rares dans 1146 les matières en suspension et dans les sédiments de fonds de cours d'eau : application aux 1147 fleuves de Patagonie (Argentine), à la Piracicaba (Brésil), à l'oued Sebou (Maroc) et à l'Ill 1148 (France). PhD Thesis, Univ. Louis Pasteur, Strasbourg. 297 p. (in french).

1149 Leleyter, L., Probst, J.L., Depetris, P., Haida, S., Mortatti, J., Rouault, R., Samuel, J., 1999. 1150 REE distribution pattern in river sediments: partitioning into residual and labile fractions. C. 1151 R. Acad. Sci., Series IIA, 329, 45-52. 
1152 Leleyter, L., Rousseau, C., Biree, L., Baraud, F., 2012. Comparison of EDTA, HCl and 1153 sequential extraction procedures for selected metals $(\mathrm{Cu}, \mathrm{Mn}, \mathrm{Pb}, \mathrm{Zn})$ in soils, riverine and marine sediments. J. Geochem. Explor., 116-117, 51-59.

1155

1156

1157

1158

1159

1160

1161

1162

1163

1164

1165

1166

1167

1168

1169

1170

1171

1172

1173

1174

1175

1176

1177

1178

1179

1180

1181

Lerat-Hardy, A., Coynel, A., Dutruch, L., Pereto, C., Bossy, C., Gil-Diaz, T., Schäfer, J., 2019. Rare Earth Element fluxes over 15 years into a major European Estuary (GaronneGironde, SW France): Hospital effluents as a source of increasing gadolinium anomalies. Science of The Total Environment, 656, 409-420.

Leybourne, M. I., Johannesson, K. H., 2008. Rare earth elements (REE) and yttrium in stream waters, stream sediments, and Fe-Mn oxyhydroxides: Fractionation, speciation, and controls over REE + Y patterns in the surface environment. Geochim. Cosmochim. Acta, 72, 59625983.

Ma, L., Jin, L., Brantley, S. L., 2011. How mineralogy and slope aspect affect REE release and fractionation during shale weathering in the Susquehanna/Shale Hills Critical Zone Observatory. Chemical Geology, 290, 31-49.

Mao, L., Mo, D., Yang, J., Guo, Y., Lv, H., 2014. Rare earth elements geochemistry in surface floodplain sediments from the Xiangjiang River, middle reach of Changjiang River, China. Quaternary International, 336, 80-88.

Marin, B., 1998. Répartition et fractionnement géochimique des éléments traces dans les sédiments marins. Application à la marge continentale du Golfe du Lion (Méditerranée NordOuest, France). Thèse de doctorat. Université de Perpignan, p 393. (in french).

Marmolejo-Rodríguez, A. J., Prego, R., Meyer-Willerer, A., Shumilin, E., Sapozhnikov, D., 2007. Rare earth elements in iron oxy-hydroxide rich sediments from the Marabasco RiverEstuary System (pacific coast of Mexico). REE affinity with iron and aluminium. J. Geochem. Explor., 94, 43-51.

Martínez-Santos, M., Probst, A., García-García, J., Ruiz-Romera, E., 2015. Influence of anthropogenic inputs and a high-magnitude flood event on metal contamination pattern in surface bottom sediments from the Deba River urban catchment. Sci. Total Environ., 514, 1025.

McLennan, S. M., 1989. Rare Earth Elements in Sedimentary Rocks: Influence of Provenance and Sedimentary Process. Review of Mineralogy, 21, 169-200. 
McLennan, S. M., 2001. Relationships between the Trace Element Composition of Sedimentary Rocks and upper Continental Crust. Geochemistry Geophysics Geosystems, 2, 4, $1-24$.

McLennan, S. M., Nance, W.B., Taylor, S.R., 1980. Rare earth element-thorium correlations in sedimentary rocks, and the composition of the continental crust. Geochim. Cosmochim. Acta, 44, 11, 1833-1839.

McLennan, S. M., Taylor, S. R., 1991. Sedimentary rocks and crustal evolution: tectonic setting and secular trends. J. Geol., 99, 1-21.

McLennan, S.M., Taylor, S.R., 2012. Geology, geochemistry, and natural abundances of the rare earth elements. In: Encyclopedia of Inorganic and Bioinorganic Chemistry. John Wiley \& Sons, Ltd.

Migaszewski, Z. M., Gałuszka, A., 2015. The characteristics, occurrence, and geochemical behavior of rare earth elements in the environment: a review. Critical Reviews in Environmental Science and Technology, 455, 429-471.

Millero, F. J., 1992, Stability constants for the formation of rare earth-inorganic complexes as a function of ionic strength: Geochim. Cosmochim. Acta, 56, 3123-3132.

Ministry of Energy and Mining of Algeria, 2007. Annaire de l'énergie et des mines. (https://fr.scribd.com/document/280974899/Annuaire-Energie-Mines-Francais).

Moller, P., Paces, T., Dulski, Morteani, G., 2002. Anthropogenic Gd in Surface Water, Drainage System, and the Water Supply of the City of Prague, Czech Republic. Environmental Science \& Technology, 36, 11, 2387-2394.

N'Guessan, Y. M., 2008. Dynamique des éléments traces dans les eaux de surface des bassins versants agricoles de Gascogne. Doctorate thesis, Toulouse University, p. 204. (in French).

N'Guessan, Y.M., Probst, J.L., Bur, T., Probst, A., 2009. Trace elements in stream bed sediments from agricultural catchments (Gascogne region, S-W France): where do they come from? Sci. Total Environ., 407, 2939-2952.

National Agency for Dams and Transfers (ANBT), 2015. Dams daily Data from 2000 to 2015, ANBT: Ager, Algeria. http://anbt-dz.com/.

National Agency of Hydrologic Resources (ANRH), 2016. Daily Data Flow in the Outlet of Tafna Catchment from 2000 to 2016, ANRH: Alger, Algeria. anrh.dz/contact.htm. 
1212 Nozaki, Y., Lerche, D., Alibo, DS., Tsutsumi, M., 2000. Dissolved indium and rare earth 1213 elements in three Japanese rivers and Tokyo Bay: Evidence for anthropogenic Gd and In. 1214 Geochim. Cosmochim. Acta, 64, 23, 3975-3982.

1215 Nyakairu, G., Koeberl, C., 2001. Mineralogical and chemical composition and distribution of 1216 rare earth elements in clay-rich sediments from central Uganda. Geochemical Journal, 35, 13121728.

1218 Olivarez, A. M., Owen, R. M., Rea, D. K., 1991. Geochemistry of eolian dust in Pacific 1219 pelagic sediments: Implications for paleoclimatic interpretations. Geochim. Cosmochim. 1220 Acta, 55, 2147-2158.

1221 Oliveira, S. M. B., Larizzatti, F. E., varo, D. I. T. F., Moreira, S. R. D., Mazzilli, B. P., 1222 Piovano, E. L., 2003. Rare earth element patterns in lake sediments as studied by neutron 1223 activation analysis. J. Radioanal Nuclear Chem., 258, 3, 531-535.

Polyakov, V. O, Nearing, M. A., 2004. Rare earth element oxides for tracing sediment movement. Catena, 55, $255-276$.

1226

Prasad, M. B. K., Ramanathan, AL., 2008. Distribution of rare earth elements in the 1227 Pichavaram Mangrove sediments of the southeast coast of India: Journal of Coastal Research, $1228 \quad 24,126-134$.

1229 Preinfalk, C., Morteani, G., 1989. The Industrial Applications of Rare Earth Elements. 1230 Lanthanides, Lanthanides, Tantalum and Niobium, 359-370.

1231 Probst J.L., Messaïtfa A., Krempp G., Behra P. 1999. Fluvial Transports of Mercury Pollution in the III River Basin (Northeastern France): Partitioning into Aqueous Phases, Suspended Matter and Bottom Sediments. In: Ebinghaus R., Turner R.R., de Lacerda L.D., Vasiliev O., Salomons W. (eds) Mercury Contaminated Sites. Environmental Science. Springer, Berlin, 1235 Heidelberg. P 539.

1236 Rabiet, M., Brissaud, F., Seidel, J. L., Pistre, S., Elbaz-Poulichet F., 2009. Positive 1237 gadolinium anomalies in wastewater treatment plant effluents and aquatic environment in the 1238 Hérault watershed (South France). Chemosphere, 75, 1057-1064.

1239 Ramesh, R., Ramanathan, A. L., James, R. A., Subramanian, V., Jacobsen, S., Holland, H., 1240 1999. Rare earth elements and heavy metal distribution in estuarine sediments of east coast of 1241 India. Hydrobiologia, 397, 89-99. 

of rare earth elements and heavy metals in the surficial sediments of the Himalayan river system. Geochem. J., 34, 295-319.

Rogowska, J., Olkowska, E., Ratajczyk, W., \& Wolska, L., 2018. Gadolinium as a new emerging contaminant of aquatic environments. Environmental toxicology and chemistry, 37, $6,1523-1534$.

Romero-Freire, A., Minguez, L., Pelletier, M., Cayer, A., Caillet, C., Devina, S., Gross, EM., Guérold, F., Pain-Devin, S., Vignati, D.A.L., Giamberini, L., 2018. Science of the total environment, 612, 831-839.

1251

Roussiez, V., Aubert, D., Heussner, S., 2013. Continental sources of particles escaping the Gulf of Lion evidenced by rare earth elements: Flood vs. normal conditions. Marine Chemistry, 153, 31-38.

Saint-Martin, J. P., Cornee, J. C., Conesa, G., Bessedik, M., Belkebir, L., Mansour, B., Moissette, P., Anglada, R., 1992. Un dispositif particulier de plate-forme carbonatée messinienne : la bordure méridionale du bassin du Bas-Chelif, Algérie. C. R. Acad. Sci. Paris, 315, Série II, 1365-1372.

Sappal, S. M., Ramanathan, A. L., Ranjan, R. K., Singh G., Kumar, A., 2014. Rare earth elements as biogeochemical indicators in Mangrove ecosystems (Pichavaram, Tamilnadu, India). Journal of Sedimentary Research, 84, 781-791.

Seaborg, G.T., 1993. Overview of the Actinide and Lanthanide (the f) elements. Radiochim. Acta, 61, 115-122.

Seaborg, G. T., Loveland, W. D., 1990. The Elements Beyond Uranium, John Wiley and Sons Ltd, New York. 368p.

Sholkovitz, E. R., 1988. Rare earth elements in the sediments of the North Atlantic Ocean, Amazon Delta, and East China Sea: reinterpretation of terrigenous input patterns to the ocean. Am. J. Sci., 288, 236-281.

Sholkovitz, E. R., 1995. The aquatic chemistry of rare earth elements in Rivers and estuaries. Aquatic geochemistry, 1, 1-34.

Song, J. M., Li, P. C., 1998. Vertical transferring process of rare elements in coral reef lagoons of Nansha Islands, South China Sea. Science in China Series D-Earth Sciences, 41, 1, 42-48. 
1273 Sow, M.A., Payre-Suc, V., Julien, F., Camara, M., Baque, D., Probst, A., Sidibe, K., Probst,

1274

1275

1276

1277

1278

1279

1280

1281

1282

1283

1284

1285

1286

1287

1288

1289

1290

1291

1292

1293

1294

1295

1296

1297

1298

1299

1300

1301 J.L., 2018. Geochemical composition of fluvial sediments in the Milo River basin (Guinea): is there any impact of artisanal mining and of a big African city, Kankan? Journal of African Earth Sciences, 145, 102-114.

Suja, S., Fernandes, L. L., Rao, V. P., 2017. Distribution and fractionation of rare earth elements and Yttrium in suspended and bottom sediments of the Kali estuary, western India. Environmental earth sciences, 76, 4, 174.

Taibi, S., Meddi, M., Mahé, G., 2015. Evolution des pluies extrêmes dans le bassin du Chéliff (Algérie) au cours des 40 dernières années 1971-2010. Proc. IAHS, 369, 175-180.

Taleb, A., Belaidia, N., Gagneur, J., 2004. Water quality before and after dam building on a heavily polluted river in semi-arid Algeria. River Res. Appl., 20, 1-14.

Taylor, S. R., Mclennan, S. M., 1985. The continental crust, its composition and evolution: an examination of the geochemical record preserved in sedimentary rocks / Stuart Ross Taylor, Scott M. McLennan. English, Book, Illustrated edition. 312 p.

Tekken, V., Kropp, J. P., 2012. Climate-driven or human-induced: indicating severe water scarcity in the Moulouya River Basin (Morocco). Water, 4, 959-982.

Tidjani, A. E. B., Yebdri, D., Roth, J. C., Derriche, Z., 2006. Exploration des séries chronologiques d'analyse de la qualité des eaux de surface dans le bassin de la Tafna (Algérie). Revue des Sciences de l'Eau, 19, 4, 315-324.

Tovar-Sanchez, A., Basterretxea, G., Ben Omar, M., Jordi A., Sanchez-Quiles, D., Makhani, M., Mouna, D., Muya, C., Angles, S., 2016. Nutrients, trace metals and B-vitamin composition of the Moulouya River: A major North African river discharging into the Mediterranean Sea, Estuarine, Coastal and Shelf Science, 176, 47-57.

Tranchida, G., Oliveri, E., Angelone, M., Bellanca, A., Censi, P., D’Elia, M., Neri, R., Placenti, F., Sprovieri, M., Mazzola, S., 2011. Distribution of rare earth elements in marine sediments from the Strait of Sicily (western Mediterranean Sea): Evidence of phosphogypsum waste contamination. Marine Pollution Bulletin, 62, 182-191.

Turekian, K. K. and Wedepohl, K. H., 1961. Distribution of the Elements in some major units of the Earth's crust. Geological Society of America Bulletin, 72, 175-192. 
United States Environmental Protection Agency (USEPA), 2012. Rare Earth Elements: A Review of Production, Processing, Recycling, and Associated Environmental Issues. EPA 600/R-12/572. www.epa.gov/ord.

Varol, M., 2013. Dissolved heavy metal concentrations of the Kralkızı, Dicle and Batman dam reservoirs in the Tigris River basin, Turkey. Chemosphere, 93, 954-962.

Wang, L., Liang, T., 2015. Geochemical fractions of rare earth elements in soil around a mine tailing in Baotou. China Sci. Rep., 5, 12483.

Xie, F., Zhang, T.A., Dreisinger, D., Doyle, F., 2014. A critical review on solvent extraction of rare earths from aqueous solutions. Miner. Eng., 56, 10-28.

Xu, Z., Lim, D., Choi, J., Yang, S., Jung, H., 2009. Rare earth elements in bottom sediments of major rivers around the Yellow Sea: implications for sediment provenance. Geo-Marine Letters, 29, 5, 291-300.

Xu,Y., Song, J., Duan, L., Li, X., Yuan, H., Li, N., Zhang, P., Zhang, Y., Xu, S., Zhang, M., $\mathrm{Wu}, \mathrm{X}$., Yin, X., 2012. Fraction characteristics of rare earth elements in the surface sediment of Bohai Bay, North China. Environ Monit. Assess., 184, 7275-7292.

Yang, S.Y., Jung, H. S., Choi, M.S., Li, C.X., 2002. The rare earth element compositions of the Changjiang (Yangtze) and Huanghe (Yellow) river sediments. Earth and Planetary Science Letters, 201, 407-419.

Zettam, A., Taleb, A., Sauvage, S., Boithias, L., Belaidi, N., Sánchez-Pérez, J.M., 2017. Modelling hydrology and sediment transport in a semi-arid and anthropized catchment using the SWAT model: the case of the Tafna River (Northwest Algeria). Water, 9, 216.

Zhang, X., Gao, X., 2015. Rare earth elements in surface sediments of a marine coast under heavy anthropogenic influence: The Bohai Bay, China. Estuarine Coastal and Shelf Science. $164,86-93$.

Zhang, Y., Gao, X., Chen, C.T. A., 2014. Rare earth elements in intertidal sediments of Bohai Bay, China: Concentration, fractionation and the influence of sediment texture. Ecotoxicology and Environmental Safety, 105, 2014, 72-79.

Zhang, C., Wang, L., Zhang, S., 1998. Geochemistry of rare earth elements in the mainstream of the Yangtze River, China. Applied Geochemistry, 13, 4, 451-462. 
1331 Zhu, M., Tan, S., Dang, H., Zhang, Q., 2011. Rare earth elements tracing the soil erosion 1332 processes on slope surface under natural rainfall. Journal of Environmental Radioactivity, $1333102,1078-1084$.

1334

1335

1336 


\section{List of Tables}

Table 1: Mean relative texture composition (in \%) of the bulk sediment $(<2000 \mu \mathrm{m})$ and of the fine fraction $(<63 \mu \mathrm{m}$, used to determine REE concentrations), during two contrasting hydrological conditions (LW: low water and HW: high water) in the 2014 and 2015 campaigns (except for the dams which were only sampled in LW in 2015) at the sampled stations (see Fig. 1). Clay: $<2 \mu \mathrm{m}$; fine silt: $2-20 \mu \mathrm{m}$; coarse silt: $20-63 \mu \mathrm{m}$; silt: $2-63 \mu \mathrm{m}$; sand: 63-2000 $\mu \mathrm{m}$; na: no data.

Table 2: Rare earth element and trace element (Th, Y, Sc, and U) concentrations in sediments from each sampling sites (mean $(\overline{\mathrm{x}})$, standard deviation $(\sigma)$ ) collected during the four sampling periods, except for the dams (DamB and DamS), which were only sampled once in LW in 2015. The mean value for the Tafna sediment (this study, mean Tafna sed, $n=40$ ) was the average of the river stations, except the dams. The REE composition of other carbonate rivers is indicated: the Sebou River ${ }^{1}$ from the Maghreb area (Morocco, Leleyter, 1998) and the Gascogne Rivers ${ }^{2}$ (SW France, N'Guessan, 2008). The REE concentration in the local Tafna bedrock (mean value, $\mathrm{n}=10$ ), the $\mathrm{PAAS}^{3}$ (McLennan, 2001) and the carbonate bedrocks $^{4}$ (Turekian and Wedepohl, 1961) are shown. (-): not determined. $\mathrm{R}=$ river, $\mathrm{BR}=$ bedrock.

Table 3: REE ratios $(\mathrm{La} / \mathrm{Yb}, \mathrm{La} / \mathrm{Sm}, \mathrm{Sm} / \mathrm{Yb})$ and $\mathrm{REE}$ anomaly $\left(\mathrm{Eu} / \mathrm{Eu}^{*}\right)$ during four campaigns (in 2014 and 2015) associated with two contrasting hydrological conditions (HW: high water; LW: low water), normalised to mean local bedrock.

Table 4: Concentrations of EDTA extractable REE (except Sm and La, Ce, and Nd in MG, which were below the detection limit) in Tafna River bed sediments (\% of total content) from the sampling stations during two contrasting hydrological conditions (high water, HW, October 2014) and (low water, LW, June 2014). 


\section{List of Figures}

Fig. 1: Study area, elevation, and sediment sampling sites in the Tafna river basin (northwestern Algeria) (treated map of digital elevation data source, de Ferranti, 2014 (http://www.viewfinderpanoramas.org).

Fig. 2: Normalised REE patterns for each Tafna site (mean for the four sampling periods) using PAAS (A) and the mean local bedrock (B) as normalisers.

Fig. 3: Normalised REE patterns for each Tafna site and for the four sampling periods using the mean local bedrock as a normaliser (A, A': low water (LW) in February 2015; B, B': high water (HW) in February 2015; C, C': low water (LW) in June 2014; D, D': high water (HW) in October 2014), calculated by dividing the basin into two parts: A, B, C, D the Tafna river with T1, T3, T5, MG, M2, T6, and T7 stations; A', B', C', D' the right hand tributary including the Isser River with S2, DamS, and I5 and the Tafna downstream part T8 and T7 (the T7 station was included also in this group to evaluate its influence on the outlet station).

Fig. 4 A, B: Ratio between EDTA extractable REE (except Sm) and the total REE in the Tafna River bed sediments (expressed in \%) during low water conditions (low water, LW, June 2014) and high water conditions (HW, October 2014), respectively; C, D: ratio of the above ratio (high water condition to low water condition) for right hand tributaries and major course stations of the Tafna, respectively. Ext. means extractable. Note that due to the analytical detection limit, Sm was not detected.

Fig. 5: REE concentration ratios between downstream and upstream stations of the Tafna River surrounded by DamB (see Fig. 1) in HW conditions (February 2015). DamB sediment was sampled in low water conditions. Dotted line indicates the stations influenced by (or influencing) the dam.

Fig. 6: Relationship between the Eu anomaly and $\mathrm{La} / \mathrm{Yb}$ ratio in sediments from the different Tafna stations during two contrasting hydrological conditions during the 2014 campaign (high water in yellow and low water in blue).

Fig. 7: PCA for REE elements, trace elements (Th, $\mathrm{Y}$, and $\mathrm{U})$, and major elements ( $\mathrm{Al}$ and $\mathrm{Fe}$ ) with grain size and POC (A: high water and B: low water condition). 
Figures 


\section{Figure 1}

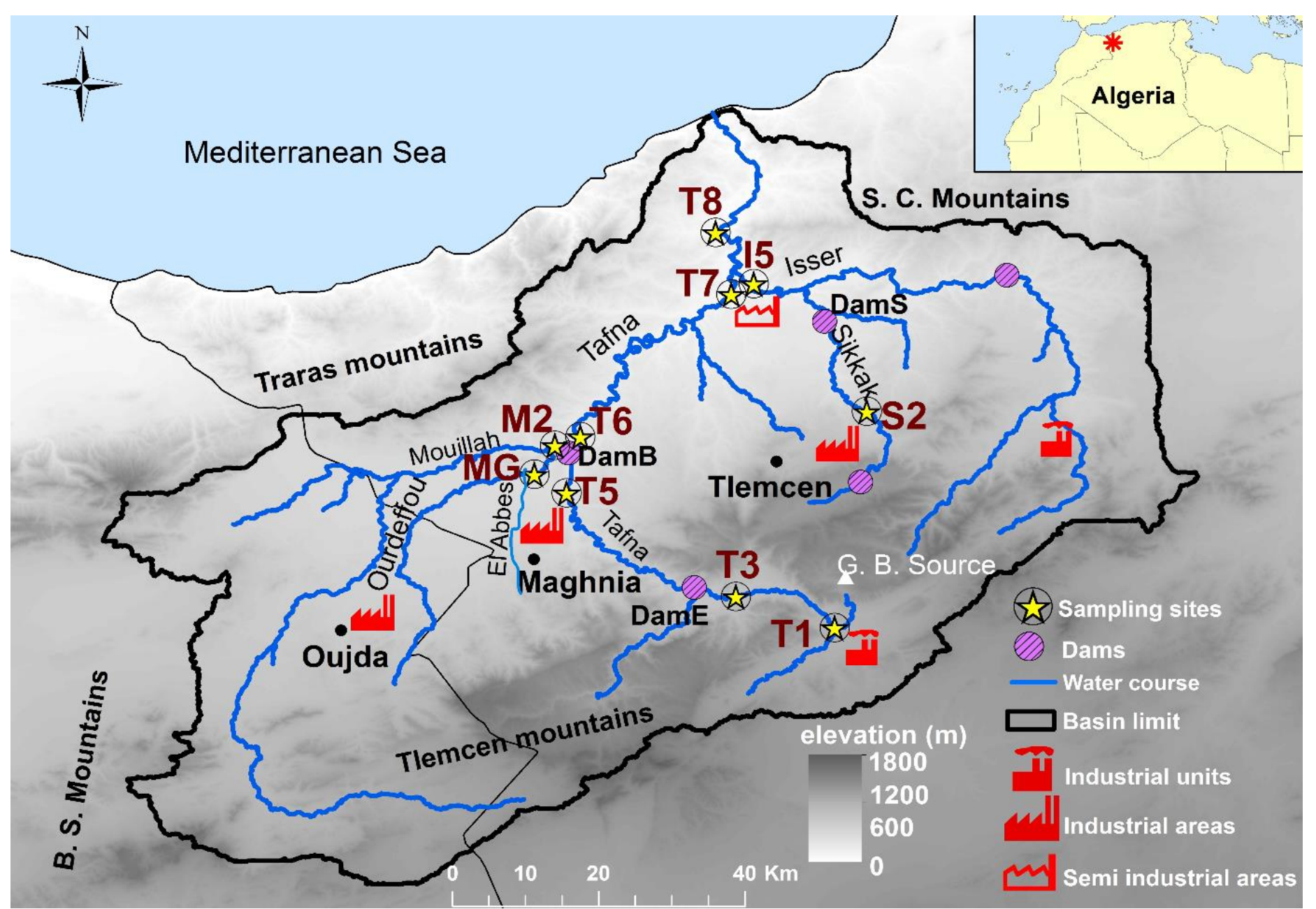

Fig. 1: Study area, elevation, and sediment sampling sites in the Tafna river basin (northwestern Algeria) (treated map of digital elevation data source, de Ferranti, 2014 (http://www.viewfinderpanoramas.org). 


\section{Figure 2}

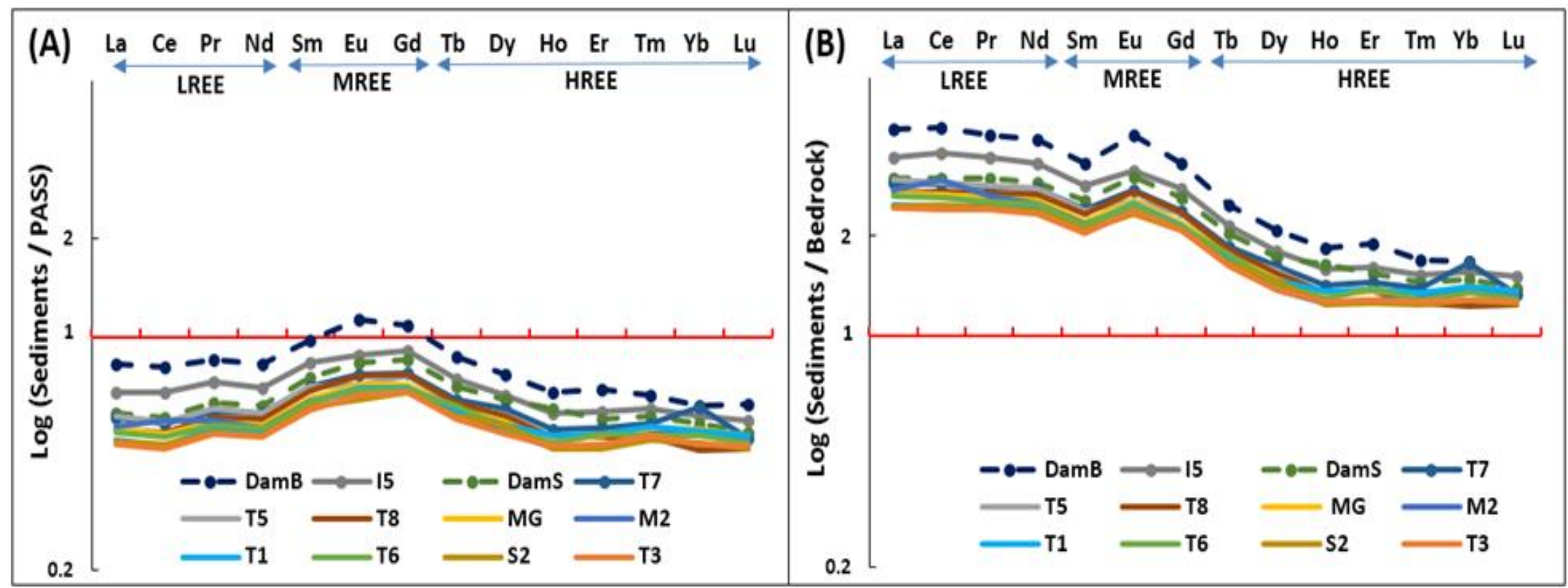

Fig.2: Normalised REE patterns for each Tafna site (mean for the four sampling periods) using PAAS (A) and the mean local bedrock (B) as normalisers. 


\section{Figure 3}
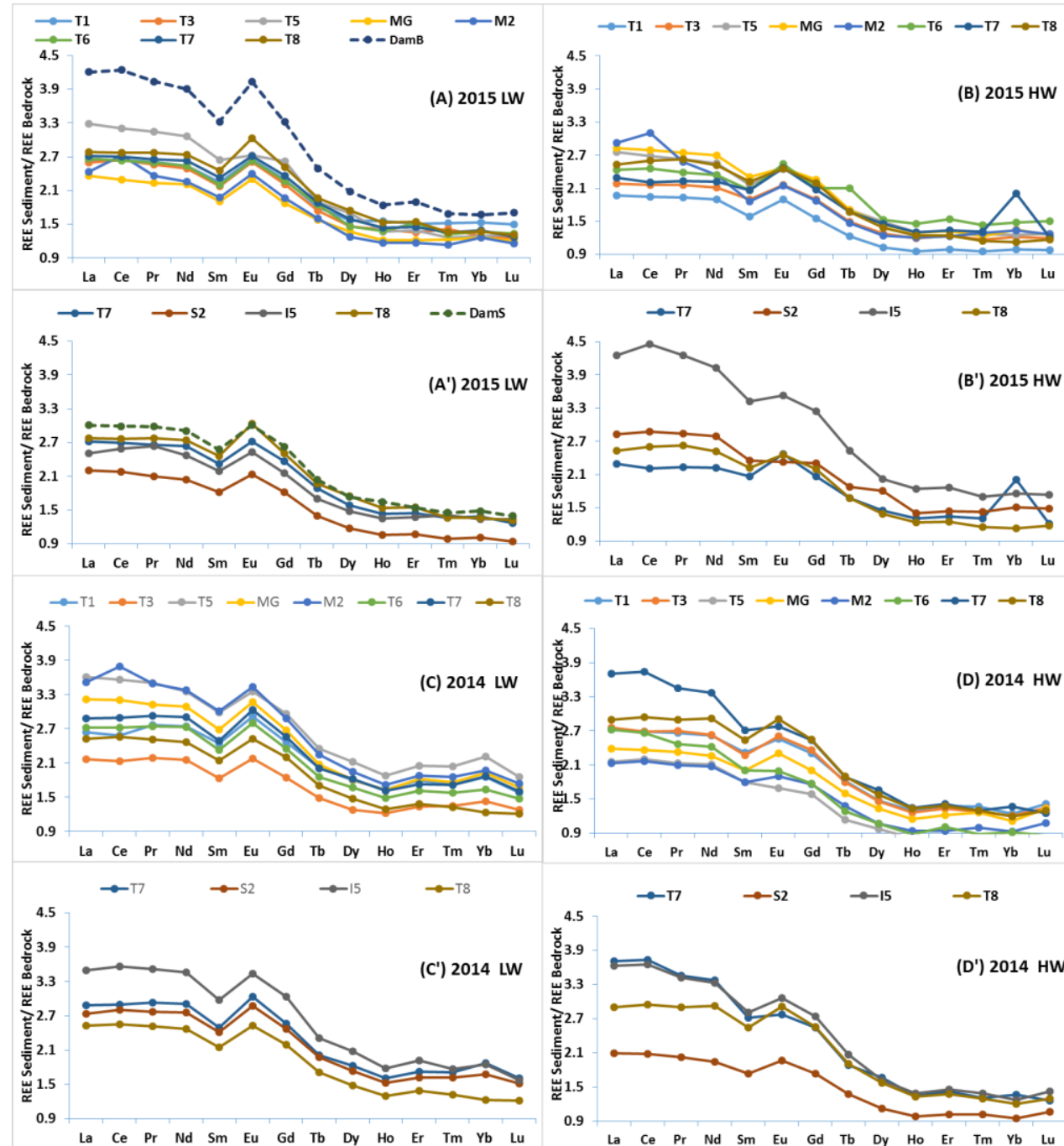

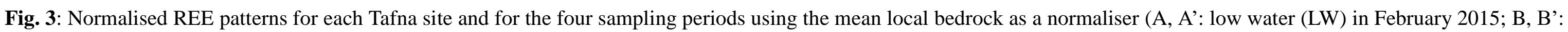

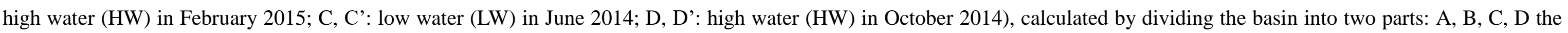

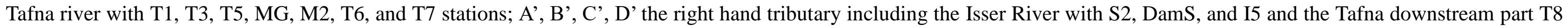
and T7 (the T7 station was included also in this group to evaluate its influence on the outlet station). 


\section{Figure 4}

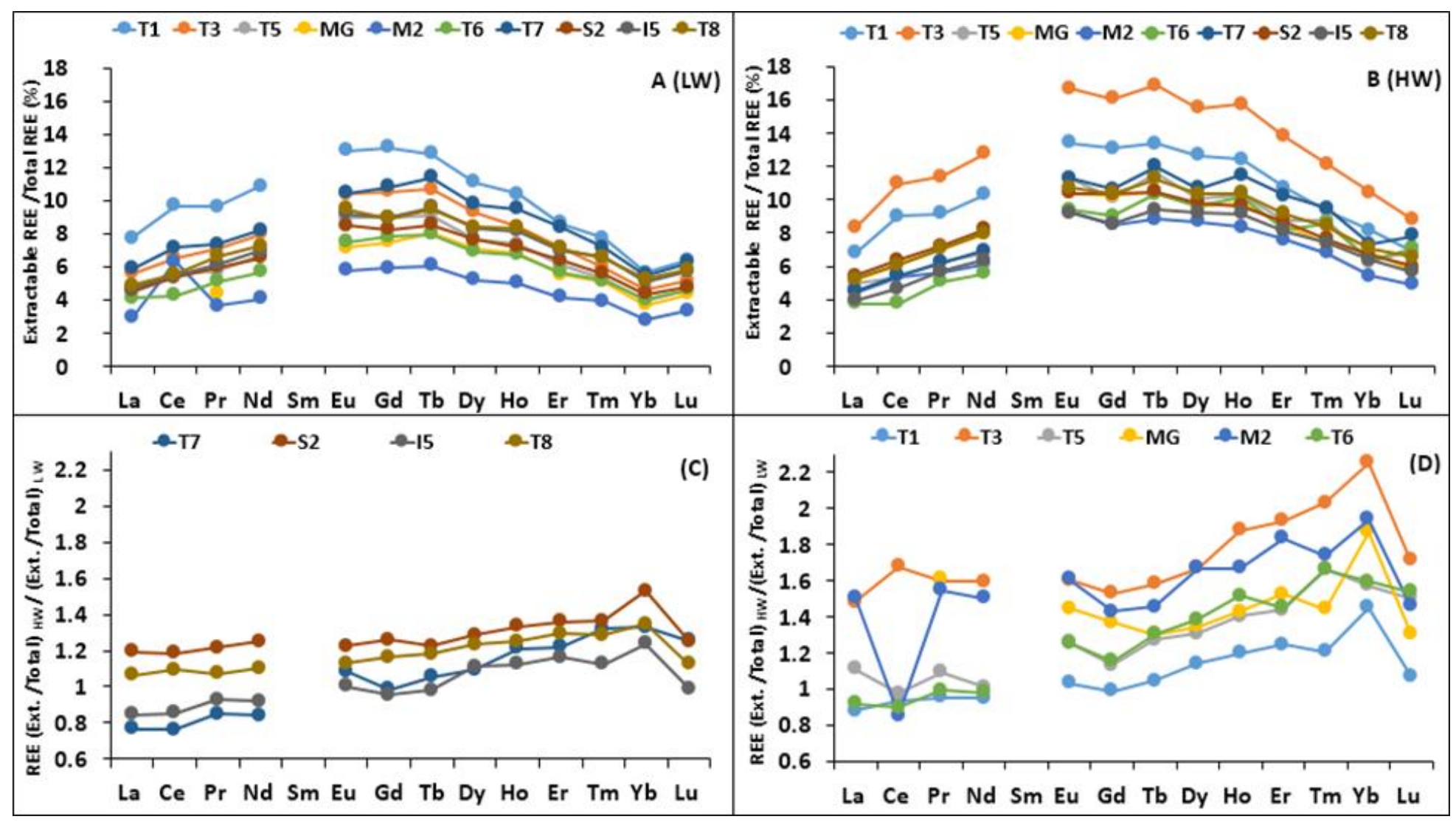

Fig. 4 A, B: Ratio between EDTA extractable REE (except Sm) and the total REE in the Tafna River bed sediments (expressed in \%) during low water conditions (low water, LW, June 2014) and high water conditions (HW, October 2014), respectively; C, D: ratio of the above ratio (high water condition to low water condition) for right hand tributaries and major course stations of the Tafna, respectively. Ext. means extractable. Note that due to the analytical detection limit, Sm was not detected. 


\section{Figure 5}

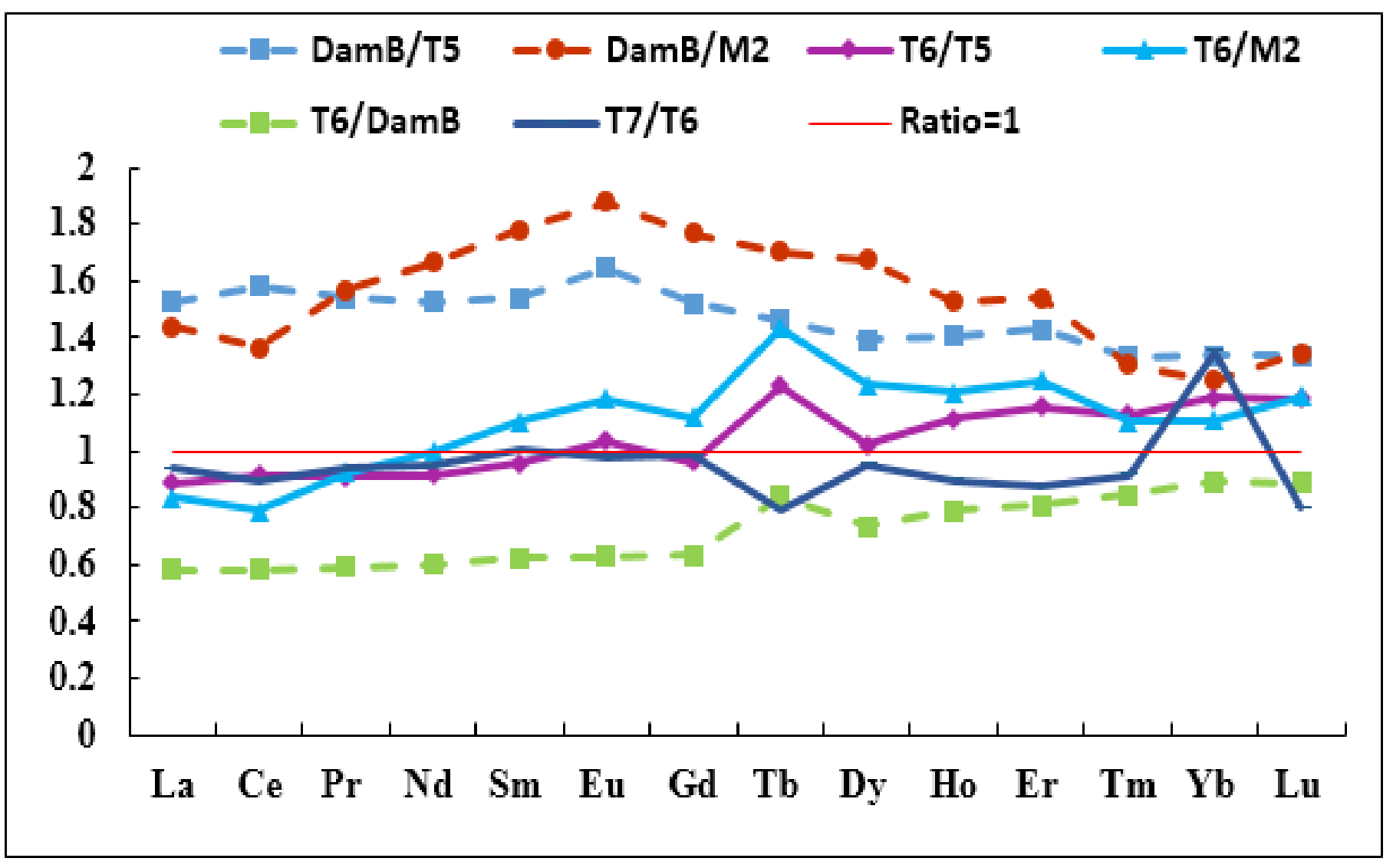

Fig.5: REE concentration ratios between downstream and upstream stations of the Tafna River surrounded by DamB (see Fig. 1) in HW conditions (February 2015). DamB sediment was sampled in low water conditions. Dotted line indicates the stations influenced by (or influencing) the dam. 


\section{Figure 6}

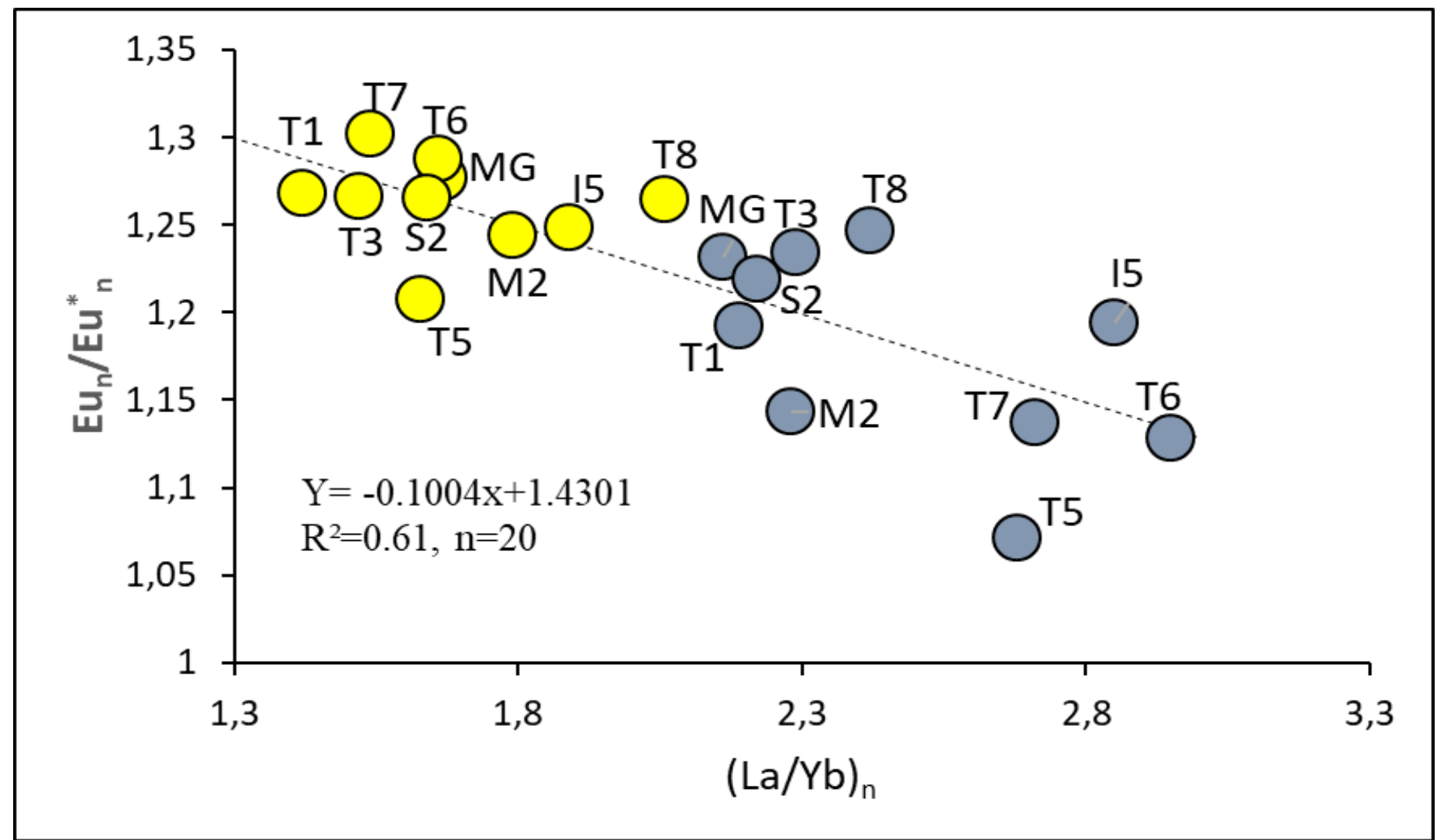

Fig. 6: Relationship between the Eu anomaly and $\mathrm{La} / \mathrm{Yb}$ ratio in sediments from the different Tafna stations during two contrasting hydrological conditions during the 2014 campaign (high water in yellow and low water in blue). 


\section{Figure 7}
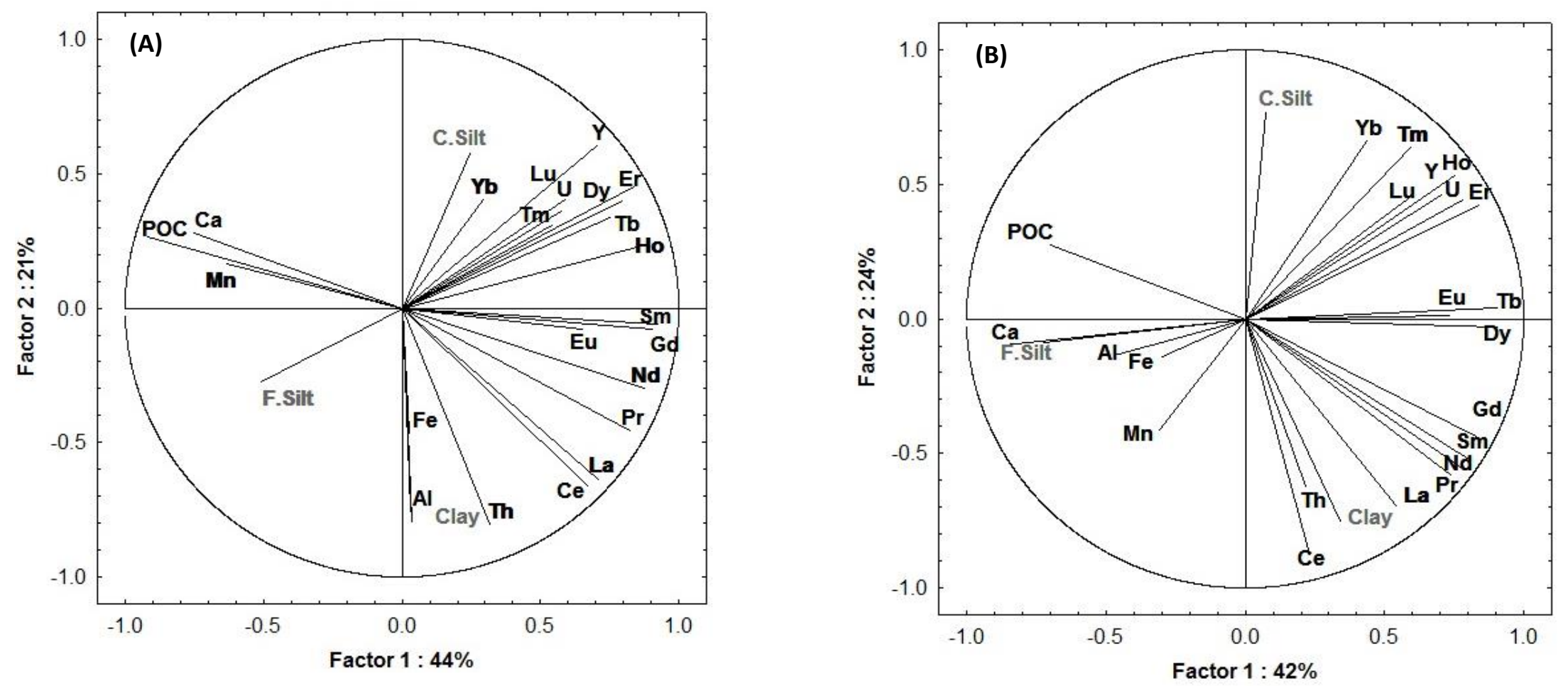

Fig.7: PCA for REE elements, trace elements (Th, Y, and U), and major elements ( $\mathrm{Al}$ and $\mathrm{Fe}$ ) with grain size and POC (A: high water and B: low water condition). 
Tables 


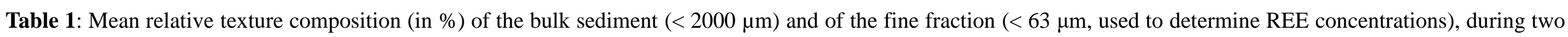

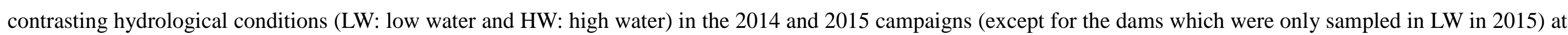

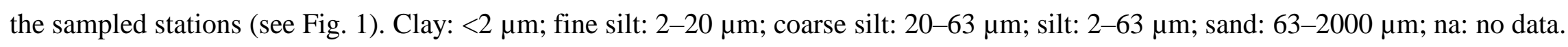

\begin{tabular}{|c|c|c|c|c|c|c|c|c|c|c|c|c|}
\hline \multirow[b]{2}{*}{ Station } & \multicolumn{6}{|c|}{ Bulk sediment $(<2000 \mu \mathrm{m})$} & \multicolumn{6}{|c|}{ Fine fraction $(<63 \mu \mathrm{m})$} \\
\hline & \multicolumn{2}{|c|}{ Clay (\%) } & \multicolumn{2}{|c|}{ Silt (\%) } & \multicolumn{2}{|c|}{ Sand (\%) } & \multicolumn{2}{|c|}{ Clay (\%) } & \multicolumn{2}{|c|}{ Fine Silt (\%) } & \multicolumn{2}{|c|}{ Coarse Silt (\%) } \\
\hline & $\mathrm{HW}$ & LW & $\mathrm{HW}$ & LW & $\mathrm{HW}$ & LW & $\mathrm{HW}$ & LW & $\mathrm{HW}$ & LW & $\mathrm{HW}$ & LW \\
\hline T1 & 2 & 10 & 12 & 64 & 86 & 26 & 13 & 14 & 59 & 57 & 28 & 29 \\
\hline T3 & 1 & 6 & 20 & 52 & 79 & 42 & 6 & 11 & 51 & 59 & 43 & 30 \\
\hline T5 & 15 & 21 & 51 & 47 & 34 & 32 & 22 & 29 & 50 & 49 & 28 & 22 \\
\hline MG & 1 & 1 & 13 & 34 & 86 & 65 & 4 & 5 & 40 & 51 & 56 & 44 \\
\hline M2 & 17 & 27 & 43 & 62 & 40 & 11 & 27 & 25 & 58 & 64 & 15 & 11 \\
\hline T6 & 0 & 12 & 11 & 59 & 89 & 29 & 8 & 17 & 65 & 55 & 27 & 28 \\
\hline T7 & 5 & 23 & 39 & 74 & 56 & 3 & 15 & 27 & 48 & 51 & 37 & 22 \\
\hline S2 & 2 & 4 & 15 & 60 & 83 & 36 & 7 & 6 & 43 & 58 & 50 & 36 \\
\hline 15 & 23 & 9 & 67 & 51 & 10 & 40 & 22 & 17 & 57 & 50 & 21 & 33 \\
\hline т8 & 10 & 19 & 38 & 69 & 52 & 12 & 20 & 22 & 45 & 50 & 35 & 28 \\
\hline DamB & na & 25 & na & 75 & na & 0 & na & 25 & na & 73 & na & 2 \\
\hline Dams & na & 25 & na & 65 & na & 10 & na & 31 & na & 52 & na & 17 \\
\hline
\end{tabular}


Table 2: Rare earth element and trace element (Th, Y, Sc, and U) concentrations in sediments from each sampling sites $($ mean $(\overline{\mathrm{x}})$, standard deviation $(\sigma))$ collected during the four sampling periods, except for the dams (DamB and DamS), which were only sampled once in LW in 2015. The mean value for the Tafna sediment (this study, mean Tafna sed, $n=40$ ) was the average of the river stations, except the dams. The REE composition of other carbonate rivers is indicated: the Sebou River1 from the Maghreb area (Morocco, Leleyter, 1998) and the Gascogne Rivers2 (SW France, N'Guessan, 2008). The REE concentration in the local Tafna bedrock (mean value, $\mathrm{n}=10$ ), the PAAS3 (McLennan, 2001) and the carbonate bedrocks4 (Turekian and Wedepohl, 1961) are shown. (-): not determined. $\mathrm{R}=$ river, $\mathrm{BR}=$ bedrock.

\begin{tabular}{|c|c|c|c|c|c|c|c|c|c|c|c|c|c|c|c|c|c|c|c|c|c|}
\hline$\mu \mathrm{g} \cdot \mathrm{g}^{-1}$ & Station & & La & $\mathrm{Ce}$ & Pr & Nd & Sm & Eu & Gd & Tb & Dy & Ho & Er & Tm & Yb & Lu & $\sum$ REE & Th & $Y$ & Sc & U \\
\hline \multirow[t]{26}{*}{ Sediment } & \multirow[t]{2}{*}{ T1 } & $\bar{x}$ & 18.76 & 37.64 & 4.71 & 17.71 & 3.54 & 0.76 & 3.30 & 0.46 & 2.56 & 0.50 & 1.46 & 0.22 & 1.48 & 0.22 & 93.32 & 5.56 & 13.73 & 17.18 & 1.44 \\
\hline & & $\sigma$ & 2.65 & 5.31 & 0.72 & 2.75 & 0.62 & 0.13 & 0.63 & 0.09 & 0.57 & 0.11 & 0.33 & 0.05 & 0.39 & 0.04 & 10.81 & 0.99 & 3.21 & 4.44 & 0.27 \\
\hline & \multirow[t]{2}{*}{ T3 } & $\overline{\bar{x}}$ & 18.28 & 36.72 & 4.53 & 16.99 & 3.37 & 0.78 & 3.18 & 0.44 & 2.40 & 0.47 & 1.36 & 0.2 & 1.35 & 0.20 & 90.27 & 5.01 & 12.69 & 15.75 & 1.40 \\
\hline & & $\sigma$ & 2.24 & 4.64 & 0.50 & 1.83 & 0.35 & 0.08 & 0.38 & 0.04 & 0.18 & 0.03 & 0.05 & 0.02 & 0.11 & 0.01 & 10.53 & 0.58 & 0.74 & 1.46 & 0.09 \\
\hline & \multirow[t]{2}{*}{ T5 } & $\bar{x}$ & 22.24 & 44.46 & 5.38 & 20.09 & 3.94 & 0.78 & 3.57 & 0.48 & 2.75 & 0.49 & 1.45 & 0.21 & 1.46 & 0.21 & 107.51 & 6.22 & 14.13 & 12.81 & 1.49 \\
\hline & & $\sigma$ & 4.77 & 9.13 & 1.14 & 3.99 & 0.87 & 0.21 & 0.91 & 0.14 & 0.83 & 0.16 & 0.50 & 0.08 & 0.62 & 0.07 & 12.77 & 1.64 & 4.97 & 3.13 & 0.52 \\
\hline & \multirow[t]{2}{*}{ MG } & $\overline{\bar{x}}$ & 20.34 & 40.67 & 4.92 & 18.56 & 3.66 & 0.78 & 3.36 & 0.47 & 2.60 & 0.48 & 1.44 & 0.21 & 1.49 & 0.22 & 99.20 & 6.23 & 13.67 & 12.65 & 1.55 \\
\hline & & $\sigma$ & 3.06 & 6.45 & 0.78 & 3.00 & 0.58 & 0.13 & 0.54 & 0.06 & 0.38 & 0.08 & 0.28 & 0.04 & 0.38 & 0.03 & 11.67 & 1.36 & 2.51 & 3.87 & 0.41 \\
\hline & \multirow[t]{2}{*}{ M2 } & $\bar{x}$ & 20.73 & 45.00 & 4.96 & 18.19 & 3.56 & 0.75 & 3.24 & 0.45 & 2.42 & 0.46 & 1.35 & 0.21 & 1.45 & 0.21 & 102.98 & 6.69 & 12.25 & \begin{tabular}{|l|l|}
14.17 \\
\end{tabular} & 1.47 \\
\hline & & $\sigma$ & 4.57 & 10.44 & 1.14 & 4.26 & 0.94 & 0.20 & 0.79 & 0.11 & 0.68 & 0.12 & 0.40 & 0.06 & 0.46 & 0.05 & 12.67 & 2.47 & 4.10 & 4.45 & 0.45 \\
\hline & \multirow[t]{2}{*}{ T6 } & $\bar{x}$ & 19.88 & 39.98 & 4.80 & 18.15 & 3.54 & 0.76 & 3.25 & 0.48 & 2.51 & 0.48 & 1.47 & 0.20 & 1.43 & 0.21 & 97.14 & 5.40 & 13.66 & 11.18 & 1.50 \\
\hline & & $\sigma$ & 1.02 & 1.71 & 0.29 & 1.21 & 0.24 & 0.11 & 0.39 & 0.09 & 0.45 & 0.10 & 0.30 & 0.05 & 0.32 & 0.05 & 11.46 & 0.62 & 2.66 & 1.80 & 0.33 \\
\hline & \multirow[t]{2}{*}{ T7 } & $\overline{\bar{x}}$ & 21.84 & 44.02 & 5.31 & 20.16 & 3.95 & 0.84 & 3.65 & 0.50 & 2.86 & 0.52 & 1.53 & 0.22 & 1.75 & 0.21 & 107.36 & 6.07 & 15.28 & 11.88 & 1.59 \\
\hline & & $\sigma$ & 4.48 & 9.72 & 0.96 & 3.48 & 0.45 & 0.07 & 0.35 & 0.04 & 0.27 & 0.05 & 0.15 & 0.03 & 0.35 & 0.03 & 12.62 & 1.13 & 1.96 & 1.66 & 0.31 \\
\hline & \multirow[t]{2}{*}{ 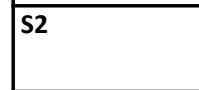 } & $\overline{\bar{x}}$ & 18.56 & 37.96 & 4.59 & 17.28 & 3.41 & 0.71 & 3.18 & 0.45 & 2.55 & 0.46 & 1.32 & 0.20 & 1.35 & 0.20 & 92.22 & 5.07 & 13.08 & 16.18 & 1.38 \\
\hline & & $\sigma$ & 2.79 & 6.32 & 0.81 & 3.28 & 0.58 & 0.12 & 0.55 & 0.08 & 0.63 & 0.10 & 0.29 & 0.05 & 0.38 & 0.05 & 10.85 & 1.01 & 3.02 & 3.75 & 0.43 \\
\hline & \multirow[t]{2}{*}{15} & $\bar{x}$ & 26.17 & 54.36 & 6.52 & 24.06 & 4.69 & 0.95 & 4.27 & 0.58 & 3.15 & 0.58 & 1.70 & 0.24 & 1.64 & 0.24 & 129.15 & 7.45 & 16.39 & 9.84 & 1.70 \\
\hline & & $\sigma$ & 5.49 & 11.71 & 1.25 & 4.68 & 0.84 & 0.14 & 0.73 & 0.10 & 0.52 & 0.09 & 0.29 & 0.03 & 0.31 & 0.03 & 15.51 & 1.37 & 2.94 & 1.14 & 0.30 \\
\hline & \multirow[t]{2}{*}{ T8 } & $\bar{x}$ & 20.23 & 41.44 & 5.10 & 19.17 & 3.86 & 0.83 & 3.61 & 0.49 & 2.71 & 0.50 & 1.43 & 0.20 & 1.30 & 0.20 & 101.07 & 5.63 & 13.95 & 10.06 & 1.32 \\
\hline & & $\sigma$ & 1.39 & 2.71 & 0.32 & 1.50 & 0.31 & 0.09 & 0.29 & 0.04 & 0.27 & 0.05 & 0.14 & 0.01 & 0.10 & 0.01 & 11.87 & 0.18 & 1.19 & 1.62 & 0.08 \\
\hline & \multirow[t]{2}{*}{\begin{tabular}{|l|} 
Mean Tafna R \\
\end{tabular}} & $\bar{x}$ & 20.70 & 42.22 & 5.08 & 19.05 & 3.75 & 0.79 & 3.46 & 0.48 & 2.65 & 0.49 & 1.45 & 0.21 & 1.47 & 0.21 & 102.01 & 5.93 & 13.88 & 13.17 & 1.48 \\
\hline & & $\sigma$ & 2.33 & 5.17 & 0.58 & 2.07 & 0.39 & 0.07 & 0.34 & 0.04 & 0.22 & 0.04 & 0.11 & 0.01 & 0.14 & 0.01 & 12.07 & 0.78 & 1.21 & 2.57 & 0.11 \\
\hline & Sebou ${ }^{1} R$ & $\bar{x}$ & 21.29 & 41.84 & 5.03 & 19.44 & 3.98 & 0.89 & 3.62 & 0.59 & 3.16 & 0.67 & 1.70 & 0.28 & 1.72 & 0.27 & 104.47 & - & - & - & - \\
\hline & \begin{tabular}{|l} 
Gascogne $^{2}$ R \\
\end{tabular} & $\bar{x}$ & 25.34 & 55.58 & 6.09 & 23.46 & 4.57 & 0.89 & 3.15 & 0.44 & 2.44 & 0.47 & 1.30 & 0.19 & 1.25 & 0.18 & 125.35 & - & & - & 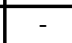 \\
\hline & Dams & & 22.65 & 45.60 & 5.63 & 21.05 & 4.23 & 0.91 & 4.02 & 0.55 & 3.03 & 0.60 & 1.62 & 0.23 & 1.56 & 0.22 & 111.90 & 5.89 & 15.81 & 12.13 & 1.72 \\
\hline & DamB & & 31.72 & 64.73 & 7.61 & 28.27 & 5.47 & 1.22 & 5.08 & 0.67 & 3.64 & 0.68 & 2.00 & 0.27 & 1.76 & 0.27 & 153.39 & 8.21 & 18.21 & 15.81 & 1.79 \\
\hline \multirow[t]{3}{*}{ Bedrock } & BR Tafna & $\bar{x}$ & 7.53 & 15.26 & 1.89 & 7.24 & 1.65 & 0.30 & 1.53 & 0.27 & 1.75 & 0.37 & 1.05 & 0.16 & 1.05 & 0.16 & 40.21 & 3.30 & 10.40 & 5.90 & 2.20 \\
\hline & PAAS ${ }^{3}$ & $\bar{x}$ & 38.20 & 79.60 & 8.83 & 33.90 & 5.55 & 1.08 & 4.66 & 0.77 & 4.68 & 0.99 & 2.85 & 0.41 & 2.82 & 0.43 & 184.77 & - & $\begin{array}{lll}- & - \\
\end{array}$ & - & - \\
\hline & Carbonate $\mathrm{BR}^{4}$ & $\bar{x}$ & - & 11.50 & 1.10 & 4.70 & 1.30 & 0.20 & 1.30 & 0.20 & 0.90 & 0.30 & 0.50 & 0.04 & 0.50 & 0.20 & 24.54 & 1.70 & 30.00 & 1.00 & 2.20 \\
\hline
\end{tabular}


Table 3: REE ratios ( $\mathrm{La} / \mathrm{Yb}, \mathrm{La} / \mathrm{Sm}, \mathrm{Sm} / \mathrm{Yb})$ and REE anomaly (Eu/Eu*) during four campaigns (in 2014 and 2015) associated with two contrasting hydrological conditions (HW: high water; LW: low water), normalised to mean local bedrock.

\begin{tabular}{|c|c|c|c|c|c|c|c|c|c|}
\hline & \multirow[t]{2}{*}{ Station } & \multicolumn{2}{|c|}{$(\mathrm{La} / \mathrm{Yb}) \mathrm{n}$} & \multicolumn{2}{|c|}{$(\mathrm{La} / \mathrm{Sm}) \mathrm{n}$} & \multicolumn{2}{|c|}{$(\mathrm{Sm} / \mathrm{Yb}) \mathrm{n}$} & \multicolumn{2}{|c|}{$\mathrm{Eu}_{\mathrm{n}} / \mathrm{Eu}_{\mathrm{n}} *$} \\
\hline & & 2014 & 2015 & 2014 & 2015 & 2014 & 2015 & 2014 & 2015 \\
\hline \multirow{10}{*}{ HW } & T1 & 2.19 & 1.99 & 1.18 & 1.24 & 1.86 & 1.61 & 1.19 & 1.29 \\
\hline & T3 & 2.29 & 1.80 & 1.21 & 1.15 & 1.89 & 1.57 & 1.23 & 1.22 \\
\hline & T5 & 2.68 & 2.21 & 1.20 & 1.28 & 2.22 & 1.73 & 1.07 & 1.22 \\
\hline & MG & 2.16 & 2.10 & 1.19 & 1.23 & 1.81 & 1.70 & 1.23 & 1.18 \\
\hline & M2 & 2.28 & 2.18 & 1.18 & 1.56 & 1.92 & 1.40 & 1.14 & 1.24 \\
\hline & T6 & 2.95 & 1.64 & 1.35 & 1.18 & 2.18 & 1.39 & 1.13 & 1.22 \\
\hline & T7 & 2.71 & 1.14 & 1.37 & 1.11 & 1.98 & 1.03 & 1.14 & 1.28 \\
\hline & S2 & 2.22 & 1.87 & 1.21 & 1.20 & 1.83 & 1.56 & 1.22 & 1.06 \\
\hline & 15 & 2.85 & 2.43 & 1.29 & 1.24 & 2.20 & 1.95 & 1.19 & 1.13 \\
\hline & T8 & 2.42 & 2.24 & 1.14 & 1.14 & 2.12 & 1.97 & 1.25 & 1.20 \\
\hline \multirow{12}{*}{ LW } & T1 & 1.42 & 1.72 & 1.08 & 1.17 & 1.31 & 1.47 & 1.27 & 1.27 \\
\hline & T3 & 1.52 & 2.02 & 1.18 & 1.19 & 1.29 & 1.69 & 1.27 & 1.28 \\
\hline & T5 & 1.63 & 2.56 & 1.21 & 1.25 & 1.35 & 2.06 & 1.21 & 1.14 \\
\hline & MG & 1.67 & 1.87 & 1.20 & 1.23 & 1.39 & 1.52 & 1.28 & 1.28 \\
\hline & M2 & 1.79 & 1.94 & 1.17 & 1.23 & 1.53 & 1.57 & 1.24 & 1.29 \\
\hline & T6 & 1.66 & 1.95 & 1.17 & 1.21 & 1.42 & 1.61 & 1.29 & 1.26 \\
\hline & T7 & 1.54 & 1.95 & 1.16 & 1.17 & 1.33 & 1.67 & 1.30 & 1.25 \\
\hline & S2 & 1.64 & 2.18 & 1.13 & 1.21 & 1.33 & 1.80 & 1.27 & 1.27 \\
\hline & 15 & 1.89 & 1.88 & 1.18 & 1.14 & 1.61 & 1.64 & 1.25 & 1.25 \\
\hline & T8 & 2.06 & 2.04 & 1.18 & 1.13 & 1.74 & 1.80 & 1.26 & 1.32 \\
\hline & DamB & & 2.52 & & 1.27 & & 1.99 & & 1.32 \\
\hline & Dams & & 2.03 & & 1.17 & & 1.74 & & 1.25 \\
\hline
\end{tabular}


Table 4: Concentrations of EDTA extractable REE (except Sm and La, Ce, and Nd in MG, which were below the detection limit) in Tafna River bed sediments (\% of total content) from the sampling stations during two contrasting hydrological conditions (high water, HW, October 2014) and (low water, LW, June 2014).

\begin{tabular}{|c|c|c|c|c|c|c|c|c|c|c|c|c|c|c|c|}
\hline \multirow[t]{2}{*}{2014} & \multirow[t]{2}{*}{ Station } & \multicolumn{14}{|c|}{ Extractable REE $\left(\mu \mathrm{g} \cdot \mathrm{g}^{-1}\right)$} \\
\hline & & La & $\mathrm{Ce}$ & $\mathrm{Pr}$ & $\mathrm{Nd}$ & $\mathrm{Sm}$ & $\mathrm{Eu}$ & $\mathrm{Gd}$ & $\mathrm{Tb}$ & Dy & Ho & $\mathrm{Er}$ & $\mathrm{Tm}$ & $\mathrm{Yb}$ & Lu \\
\hline \multirow[t]{10}{*}{ HW } & T1 & 1.40 & 3.70 & 0.46 & 1.95 & - & 0.10 & 0.46 & 0.07 & 0.33 & 0.06 & 0.15 & 0.02 & 0.11 & 0.02 \\
\hline & T3 & 1.73 & 4.50 & 0.58 & 2.42 & - & 0.13 & 0.58 & 0.08 & 0.40 & 0.07 & 0.18 & 0.02 & 0.13 & 0.02 \\
\hline & T5 & 0.80 & 1.80 & 0.25 & 1.04 & - & 0.06 & 0.24 & 0.04 & 0.17 & 0.03 & 0.08 & 0.01 & 0.05 & 0.01 \\
\hline & MG & 0.93 & 2.20 & 0.31 & 1.29 & - & 0.07 & 0.31 & 0.05 & 0.22 & 0.04 & 0.10 & 0.01 & 0.08 & 0.01 \\
\hline & M2 & 0.71 & 1.77 & 0.22 & 0.92 & - & 0.05 & 0.23 & 0.03 & 0.16 & 0.03 & 0.07 & 0.01 & 0.05 & 0.01 \\
\hline & T6 & 0.77 & 1.54 & 0.24 & 0.97 & - & 0.06 & 0.25 & 0.04 & 0.18 & 0.03 & 0.08 & 0.01 & 0.06 & 0.01 \\
\hline & T7 & 1.26 & 3.12 & 0.41 & 1.69 & - & 0.10 & 0.41 & 0.06 & 0.31 & 0.06 & 0.15 & 0.02 & 0.11 & 0.02 \\
\hline & S2 & 0.85 & 2.02 & 0.28 & 1.16 & - & 0.06 & 0.27 & 0.04 & 0.19 & 0.03 & 0.09 & 0.01 & 0.07 & 0.01 \\
\hline & 15 & 1.08 & 2.60 & 0.37 & 1.54 & - & 0.09 & 0.36 & 0.05 & 0.26 & 0.05 & 0.12 & 0.02 & 0.09 & 0.01 \\
\hline & T8 & 1.14 & 2.73 & 0.39 & 1.69 & - & 0.09 & 0.40 & 0.06 & 0.28 & 0.05 & 0.13 & 0.02 & 0.09 & 0.01 \\
\hline \multirow[t]{10}{*}{ LW } & $\mathrm{T} 1$ & 1.54 & 3.81 & 0.50 & 2.15 & - & 0.12 & 0.50 & 0.07 & 0.35 & 0.06 & 0.16 & 0.02 & 0.11 & 0.02 \\
\hline & T3 & 0.92 & 2.13 & 0.29 & 1.24 & - & 0.07 & 0.30 & 0.04 & 0.21 & 0.04 & 0.10 & 0.01 & 0.07 & 0.01 \\
\hline & T5 & 1.20 & 3.00 & 0.38 & 1.63 & - & 0.09 & 0.40 & 0.06 & 0.29 & 0.05 & 0.13 & 0.02 & 0.09 & 0.01 \\
\hline & MG & - & - & 0.26 & - & - & 0.07 & 0.31 & 0.04 & 0.22 & 0.04 & 0.10 & 0.01 & 0.07 & 0.01 \\
\hline & M2 & 0.78 & 3.64 & 0.24 & 1.00 & - & 0.06 & 0.26 & 0.04 & 0.18 & 0.03 & 0.08 & 0.01 & 0.06 & 0.01 \\
\hline & T6 & 0.84 & 1.76 & 0.26 & 1.12 & - & 0.06 & 0.28 & 0.04 & 0.20 & 0.04 & 0.09 & 0.01 & 0.07 & 0.01 \\
\hline & T7 & 1.28 & 3.16 & 0.41 & 1.73 & - & 0.10 & 0.42 & 0.06 & 0.31 & 0.06 & 0.15 & 0.02 & 0.11 & 0.02 \\
\hline & S2 & 0.93 & 2.30 & 0.31 & 1.31 & - & 0.07 & 0.31 & 0.05 & 0.23 & 0.04 & 0.10 & 0.01 & 0.08 & 0.01 \\
\hline & 15 & 1.23 & 2.96 & 0.41 & 1.74 & - & 0.10 & 0.41 & 0.06 & 0.30 & 0.05 & 0.14 & 0.02 & 0.10 & 0.01 \\
\hline & T8 & 0.93 & 2.17 & 0.31 & 1.30 & - & 0.07 & 0.30 & 0.04 & 0.22 & 0.04 & 0.10 & 0.01 & 0.07 & 0.01 \\
\hline
\end{tabular}

